Universidade de São Paulo

Instituto de Física

\title{
Caracterização estrutural e magnética de amostras de c-GaN implantadas com Fe, $\mathrm{Mn}$ e $\mathrm{Cu}$
}

\author{
Victor Augusto Nieto Righetti
}

Orientador: Prof. Dr. Valmir Antonio Chitta

Banca Examinadora:

Prof. Dr. Valmir Antonio Chitta (orientador) - IFUSP

Prof $^{\mathrm{a}}$. Dr ${ }^{\mathrm{a}}$. Euzi Conceição Fernandes da Silva - IFUSP

Prof. Dr. Américo Sheitiro Tabata - UNESP

Prof. Dr. José Antonio Huamaní Coaquira - UnB

Prof. Dr. Valdir Bindilatti - IFUSP

Tese de doutorado apresentada ao

Instituto de Física para a obtenção

do título de Doutor em Ciências 

FICHA CATALOGRÁFICA

Preparada pelo Serviço de Biblioteca e Informação do Instituto de Física da Universidade de São Paulo

Righetti, Victor Augusto Nieto

Caracterização estrutural e magnética de amostras de c-GaN implantadas com Fe, Mn e Cu. São Paulo, 2013.

Tese (Doutorado) - Universidade de São Paulo. Instituto de Física. Dept ${ }^{\circ}$. de Física dos Materiais e Mecânica.

Orientador: Profo. Dr$^{\circ}$. Valmir Antonio Chitta

Área de Concentração: Física

Unitermos: 1. Semicondutores; 2. Magnetismo; 3.

Fenômenos magnéticos 4.Espectroscopia ótica.

USP/IF/SBI-003/2014 

A man is rich in proportion to the number of things he can afford to let alone.

- Henry David Thoreau

\section{Agradecimentos}

Aos meus pais, principalmente pelo apoio incansável à minha educação sem o qual este trabalho jamais existiria, e ao meu irmão também pelo apoio e por existir.

Ao prof. Valmir Chitta, pela orientação, incentivo, paciência, e também pela introdução à esta área fascinante do conhecimento.

Aos profs. Klaus Lischka, Donat As, Detlef Schikora da U.Paderborn - Alemanha e Marcio Peron do DF-UFSCar, pelo crescimento das amostras de c-GaN/3C-SiC estudadas, e também ao prof. Marcio por tantas outras coisas: auxílio no SQUID, PL, Raman, mapas e também pelas muitas ideias e teorias discutidas e presentes neste trabalho.

Ao prof. Ariano Rodrigues pelo auxílio no equipamento e pelas discussões dos dados de Raman.

Ao prof. Eduardo Abramof e ao Dr. João Paulo Machado pelo auxílio nos difratrômetros de raios-x do INPE e também pelas discussões.

Ao chef Dr. Xavier Gratens por me ensinar quase tudo que sei sobre análise de dados magnéticos e operação de um SQUID, parte tão importante deste trabalho, e também pela realização de algumas medidas.

Ao Me. Sérgio Romero pelos tratamentos térmicos em doses homeopáticas e ao LMM pelo uso do forno.

Ao prof. Johnny Dias pela realização das implantações e pela confiança depositada no trabalho em um momento crítico.

À minha mina Dra. Paula Galgano pela alegria cotidiana, correção do texto e por me ensinar.

À todos os estudantes que eu tive o prazer de conhecer e também conviver com nestes onze anos de USP, em especial ao Dr. Giovanni Galgano pelas discussões e companhia.

Aos funcionários da USP pela solicitude; acima de tudo, em especial aos funcionários do DFMT e também da CPG pelo auxílio nos difíceis trâmites burocráticos.

Ao prof. Mario de história do Brasil no colégio Liceu Santa Cruz (será, ainda?) por despertar meu interesse na vida acadêmica.

À CAPES e CPG-IFUSP pelo apoio financeiro e à USP pelo apoio material.

À CUASO, por ser o lugar maravilhoso que é e espero que continue sendo.

Ao contribuinte paulista e brasileiro, o meu sincero muito obrigado. 



\section{Conteúdo}

1 Introdução $\quad 1$

2 Materiais e métodos $\quad 4$

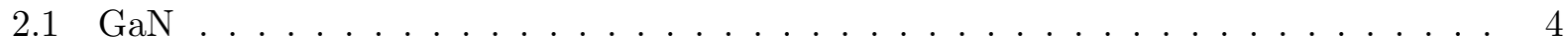

2.2 Implantação iônica . . . . . . . . . . . . . . . . . . . . . . . . . . . . . . . .

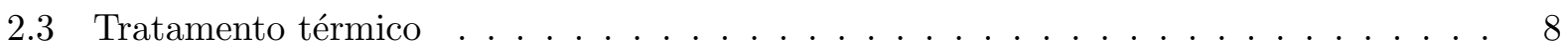

2.4 Espectroscopia de fotoluminescência . . . . . . . . . . . . . . . 10

2.5 Raman . . . . . . . . . . . . . . . . . . . . 10

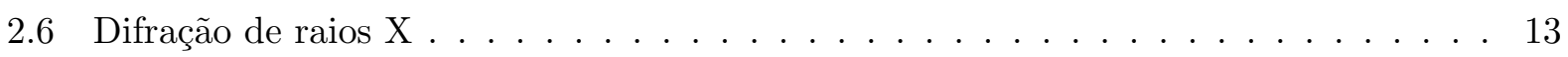

2.7 Magnetismo . . . . . . . . . . . . . . . . . . . 15

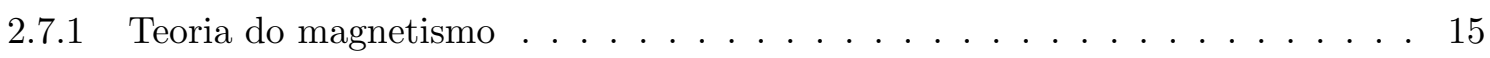

2.7.1.1 Materiais lineares . . . . . . . . . . . . . . . 16

2.7.1.2 Materiais não lineares . . . . . . . . . . . . . . . . . 17

2.7.2 SQUID (Superconducting Quantum Interference Device) . . . . . . . . . . . 19

2.7.3 Análise dos dados magnéticos . . . . . . . . . . . . . . . . . . 21

3 Simulação de implantação iônica 23

3.1 Introdução . . . . . . . . . . . . . . . . . . . . . . . . 23

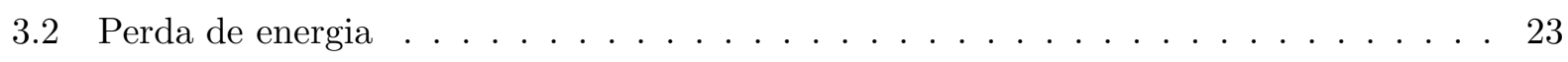

3.3 Perda de energia nuclear . . . . . . . . . . . . . . . . . . . . 24

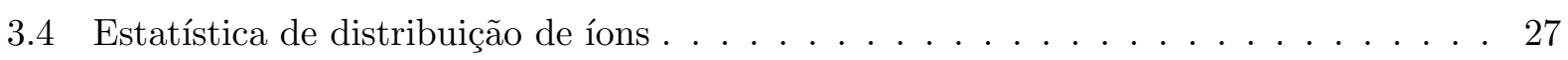

3.5 Resultados . . . . . . . . . . . . . . . . . . . . 28

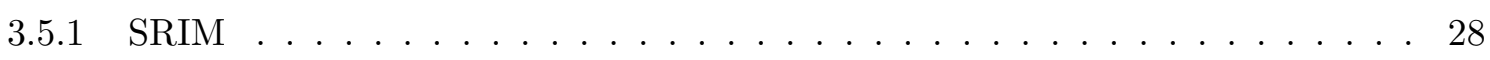

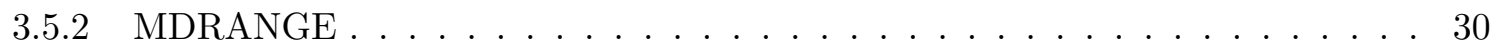

3.6 Considerações sobre os resultados de simulação $\ldots \ldots$. . . . . . . . . . . . . 33

4 Resultados experimentais $\quad 34$

4.1 Espectroscopia de $\operatorname{raios} \mathrm{X} \ldots \ldots \ldots \ldots \ldots \ldots \ldots$

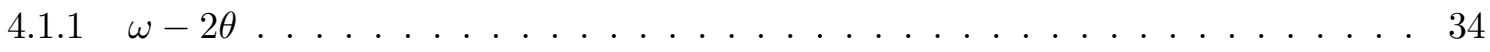

4.1.1.1 Mapas da rede recíproca . . . . . . . . . . . . . . . . . . . . . . . . . . . . . .

$4.1 .2 \quad$ Bragg-Brentano . . . . . . . . . . . . . . . . . . . . 43

4.1.3 Considerações sobre as medidas de difratometria de raios X . . . . . . . . . 45 
4.2 Espectroscopia de fotoluminescência . . . . . . . . . . . . . . . . 45

4.3 Espectroscopia Raman . . . . . . . . . . . . . . . . . . . . . 52

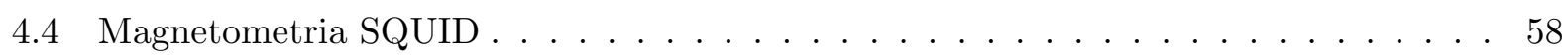

4.4 .1 Amostras de referência . . . . . . . . . . . . . . . . . . 58

4.4 .2 Amostras implantadas com $\mathrm{Fe} \ldots \ldots \ldots \ldots$. . . . . . . . . . 59

4.4.2.1 Medidas em função do campo . . . . . . . . . . . . . . 60

4.4.2.2 Medidas em função da temperatura . . . . . . . . . . . . . . 66

4.4 .3 Amostras implantadas com $\mathrm{Mn} \ldots \ldots . . \ldots$. . . . . . . . . 74

4.4.3.1 Medidas em função do campo . . . . . . . . . . . . . . . . 74

4.4.3.2 Medidas em função da temperatura . . . . . . . . . . . . . . . . 77

4.4.4 Amostras implantadas com $\mathrm{Cu}$. . . . . . . . . . . . . . . . . . . 80

5 Conclusões $\quad 84$

$\begin{array}{llr}6 & \text { Bibliografia } & 86\end{array}$ 


\section{Resumo}

Os nitretos do grupo III (AlN, GaN, InN) são semicondutores extremamente importantes na atualidade principalmente por suas aplicações em dispositivos emissores de luz de alta eficiência no visível e no ultravioleta. Neste trabalho foram estudados filmes finos de nitreto de gálio cúbico (c-GaN, zincblende) crescidos sobre substratos de carbeto de silício cúbico (3C-SiC) por epitaxia de feixe molecular assistida por plasma (PA-MBE). Inicialmente analisou-se o processo de implantação iônica através de técnicas de simulação computacional. Tendo em vista os resultados obtidos pelas simulações, as amostras foram submetidas a processo de implantação iônica com energia de feixe de $200 \mathrm{keV}$ e diferentes íons implantados (Fe, Mn e $\mathrm{Cu}$ ) nas doses de 1.2 e $2.4 \times 10^{16} \mathrm{~cm}^{-2}$. Com a implantação de íons magnéticos buscou-se a criação de um semicondutor com resposta ferromagnética acima da temperatura ambiente, enquanto que com a implantação do íons não magnéticos buscouse, principalmente, um maior entendimento sobre a influência de defeitos da rede cristalina sobre o magnetismo do material. Posteriormente às implantações e com o intuito de recuperar a rede cristalina das amostras danificada pelo processo, as amostras foram submetidas a tratamento térmico. Após cada um destes processos as amostras foram caracterizadas estruturalmente, através de medidas de difração de raios-x, espectroscopia de fotoluminescência e espectroscopia Raman e também magneticamente utilizando-se um SQUID. Conseguiu-se a caracterização quantitativa das transformações da rede cristalina pré e pós tratamento térmico com as diferentes técnicas. Foi observado comportamento ferromagnético à temperatura ambiente em amostras dopadas com os diversos íons e notou-se uma grande influência da dose implantada, tanto nas propriedades estruturais quanto magnéticas das amostras. 


\begin{abstract}
Group-III nitrides (AlN, GaN, InN) are presently very important semiconductors mainly because of applications in high-efficiency, visible and ultraviolet, light-emitting devices. In this work, thin films of cubic gallium nitride (c-GaN, zincblende), grown over cubic silicon carbide (3C-SiC) by plasmaassisted molecular beam epitaxy (PA-MBE) were studied. Initially the process of ion implantation was investigated with the aid of computer simulation software. Following the simulations results, the samples were implanted with a $200 \mathrm{keV}$ ion-beam of three different ions ( $\mathrm{Fe}, \mathrm{Mn}$ and $\mathrm{Cu}$ ) with doses of 1.2 and $2.4 \times 10^{16} \mathrm{~cm}^{-2}$. With the implantation of magnetic ions the formation of a semiconductor with room-temperature ferromagnetic response was expected, whereas the implantation of non-magnetic ions $(\mathrm{Cu})$ was performed seeking a better understanding on the influence of lattice defects on the subsequent magnetism. After the implantation the samples were annealed to recover some of the crystallinity lost due to the implantation process. After each process the samples were structurally characterized through x-ray diffraction, photoluminescence and Raman spectroscopies, and magnetically characterized through SQUID magnetometry. A quantitative measure of the transformations of the crystal lattices was obtained before and after annealing with the different techniques. Room-temperature ferromagnetic behavior was observed in the samples doped with different ions and a large influence of implanted dose was noted, in the structural properties and also in the magnetic properties.
\end{abstract}




\section{Capítulo 1}

\section{Introdução}

A spintrônica é vista como um possível caminho para o desenvolvimento de tecnologias de informação além dos limites de miniaturização fatalmente impostos aos semicondutores convencionais. No entanto, todo o conhecimento adquirido do estudo e aplicação destes materiais os tornam um ponto de partida natural para o desenvolvimento de dispositivos explorando o controle de spin. Semicondutores magnéticos como os calcógenos de európio seriam, à primeira vista, candidatos ideais à fabricação de dispositivos spintrônicos, porém, por razões de incompatibilidade de rede cristalina, filmes destes materiais não podem ser crescidos com boa qualidade sobre os semicondutores utilizados na eletrônica convencional como $\mathrm{Si}$, GaAs, GaN, SiC, etc., o que limita suas aplicações. O crescimento do semicondutor magnético "sobre" a eletrônica atual seria importante para sua integração e pleno desenvolvimento de seu potencial. Uma solução encontrada para este problema foi a utilização de semicondutores comuns dopados com íons magnéticos, chamados de semicondutores magnéticos diluídos (SMDs). Nos anos 80 o desenvolvimento destes materiais se intensificou, principalmente com o estudo de semicondutores compostos do grupo II-VI dopados com diversos íons magnéticos. No entanto, o primeiro grande avanço na área se deu através de um semicondutor composto III-V, com a observação de ferromagnetismo até a temperatura de $110 \mathrm{~K}$ em amostras de GaAs dopadas com Mn por Ohno et al. [1], com este sucesso elevou-se o interesse em SMDs baseados em semicondutores III-V.

Os nitretos do grupo III, principalmente o $\mathrm{AlN}$, GaN e InN, são materiais semicondutores importantes com os quais é possível o controle do gap em uma larga faixa de energia $(0.7$ a 6.2 $\mathrm{eV}$ ) através da formação de ligas entre os compostos [2]. Com a previsão teórica por T. Dietl et al. de ferromagnetismo acima da temperatura ambiente para o nitreto de gálio cúbico (c-GaN) e hexagonal (h-GaN), dopados com 5\% de Mn [3] aumentou consideravelmente o interesse nos nitretos cúbicos dopados com metais de transição, já que materiais semicondutores com temperaturas de Curie elevadas seriam importantes no desenvolvimento de um dispositivo spintrônico semicondutor. Além disso, devido ao seu largo gap e interação spin-órbita pouco intensa, um longo tempo de coerência de spins é esperado para o material. A dopagem em SMDs muitas vezes é realizada com metais de transição (MTs) do quarto período, que possuem uma camada $d$ incompleta e regra geral dois elétrons de valência na camada 4s. Espera-se que os íons substituam o cátion de um semicondutor composto, contribuindo os seus dois elétrons de valência e formando um estado de carga $\mathrm{MT}^{2+}$ e criando um spin localizado proveniente dos elétrons desemparelhados da camada $d$. O trabalho de Dietl considera que a interação responsável pelo ferromagnetismo neste material é do tipo RKKY (Ruderman-Kittel-Kasuya-Yosida), ou magnetismo itinerante, onde os portadores são responsáveis pelo acoplamento dos spins localizados no material. Entretanto, ainda há muita controvérsia sobre a origem do ferromagnetismo, especialmente para o GaN [4] e pode-se afirmar que ainda não foram desvendados satisfatoriamente os processos que induzem o ferromagnetismo em nitretos. Este estudo tem como objetivo aprofundar o entendimento das transformações no 
magnetismo e estrutura cristalina de amostras de nitreto de gálio cúbico dopadas por implantação iônica com íons magnéticos e não magnéticos e tratadas termicamente.

A história do nitreto de gálio (GaN) tem início com a primeira síntese em 1932 [5], realizada através da reação de amônia com gálio líquido em altas temperaturas. Este trabalho teve como objetivo a obtenção do composto, o último dos nitretos do grupo III não conhecido até então. Juza e Hahn [6] prosseguiram com o estudo, determinando a estrutura cristalina do GaN hexagonal seis anos após a primeira síntese. Trinta anos depois, com a aplicação da técnica de Deposição química em fase vapor (CVD, sigla em inglês) para o crescimento de GaN [7], Maruska e Tietjen obtiveram os primeiros filmes de alta qualidade. Mesmo sem dopagem intencional, as amostras crescidas até então sempre se mostravam condutoras tipo $n$, comportamento inicialmente atribuído a vacâncias de nitrogênio e mais recentemente à contaminação por impurezas, principalmente de $\mathrm{O}_{2}$ [8], na fase gasosa durante o crescimento. A dificuldade em encontrar um dopante tipo $p$ efetivo e a alta concentração de defeitos nos cristais crescidos em substratos pouco adequados dificultaram o desenvolvimento de dispositivos à base de GaN. O primeiro LED reportado, utilizando Mg como dopante tipo $p$, possuía eficiência ordens de grandeza menor que de LEDs existentes [9]. Com o avanço das pesquisas nas três décadas seguintes os entraves no desenvolvimento de dispositivos baseados em GaN foram aos poucos removidos. Nakamura et al. [10] desenvolvem em 1994 o primeiro LED de alta intensidade luminosa no azul utilizando heteroestruturas de InGaN/AlGaN e em 1996 é lançado no mercado o primeiro laser diodo de GaN [11]. Estes avanços foram cruciais, pois dispositivos emitindo a última cor primária faltante foram obtidos, o que possibilitou uma revolução no desenvolvimento de telas, iluminação e laseres.

Atualmente, quase a totalidade de LEDs na cor branca é fabricada utilizando-se InGaN recoberto por uma camada de material fosforescente que proporciona um alargamento para o vermelho em seu espectro de emissão. A eficiência destes dispositivos aumenta ano a ano. Em 2013 existem LEDs de InGaN/SiC disponíveis comercialmente com eficiência luminosa de $160 \mathrm{~lm} / \mathrm{W}$ apenas $20 \%$ menos eficientes do que uma lâmpada de vapor metálico típica. É de se esperar que essa tendência continue, o que tornará o LED a fonte de iluminação mais eficiente existente. Laseres baseados em GaN emitindo no ultravioleta e violeta, anteriormente só possíveis com técnicas de ótica não linear, estão amplamente disponíveis e encontram aplicações em diversas áreas como laboratórios de pesquisa, mídias óticas de alta capacidade, etc. Não só a opto-eletrônica se beneficiou do avanço nas técnicas de crescimento de GaN. Suas elevadas mobilidade, tensão de ruptura e velocidade de saturação, tornam o material propício para aplicações em dispositivos de alta potência e alta frequência. Desde 2006 estão disponíveis comercialmente transistores de alta mobilidade eletrônica (HEMT, sigla em inglês) de alta eficiência. Em 2010 transistores de mobilidade eletrônica aumentada (EEMT, sigla em inglês) baseados em AlGaN/GaN tornaram-se disponíveis comercialmente, proporcionando maior eficiência e menor tempo de chaveamento em relação a MOSFETs de alta potência convencionais [12].

O primeiro crescimento da fase cúbica foi reportado por Mizuta et al. [13] em 1986, realizado através de CVD em baixa temperatura. Com a aplicação da técnica de epitaxia por feixe molecular (MBE, sigla em inglês) ao crescimento de nitretos, tornou-se possível o crescimento de filmes de alta qualidade de c-GaN [14]. No entanto por serem metaestáveis, os cristais possuem elevada densidade de defeitos em comparação a outros materiais crescidos por MBE. A utilização de substratos de carbeto de silício (3C-SiC) para o crescimento, iniciado por Kim et al. [15] foi um avanço importante para a melhora progressiva da qualidade obtida em amostras cúbicas. Em comparação com o GaN hexagonal, o GaN cúbico possui menores campos de polarização por possuir maior simetria em sua estrutura cristalina. A polarização em poços quânticos leva à diminuição da eficiência de dispositivos opto-eletrônicos, portanto, há interesse no estudo do c-GaN com vistas em aplicações onde o h-GaN já é utilizado hoje nesta área. Já como material semicondutor, a dificuldade no controle da dopagem foi superada. Amostras tipo $n$ e tipo $p$ com ampla gama de concentração de 
portadores foram demonstradas na literatura [16]. Transistores de pesquisa do tipo HEMT já foram desenvolvidos com base no material cúbico [17]. Tendo em vista também a sua elevada mobilidade é provável que dispositivos de alto desempenho [18] baseados em c-GaN sejam desenvolvidos e comercializados no futuro.

O início da implantação iônica como método de tratamento de semicondutores se dá com a patente de Shockley em 1957 [19]. Coincidentemente nesta mesma patente Shockley propõe a utilização do tratamento térmico como técnica para a recuperação da rede cristalina de um material implantado. A indústria de semicondutores foi a principal força que moveu o desenvolvimento da técnica. O estudo detalhado do processo financiado em grande parte pela indústria do silício levou a várias aplicações da implantação iônica na fabricação de dispositivos, como exemplos: dopagem e ativação elétrica, ótica e magnética de dopantes, produção e remoção de defeitos e formação de camadas com propriedades elétricas e/ou magnéticas desejadas. Devido ao dano inerente à penetração de partículas carregadas na matéria o tratamento térmico é frequentemente associado ao processo de implantação iônica, já que é o meio mais difundido na recuperação da rede em materiais cristalinos. Além da aplicação em pesquisa na área de física dos materiais, estas técnicas foram fundamentais no desenvolvimento de dispositivos eletrônicos já que permitiram maior controle na dopagem e propriedades elétricas de diversos semicondutores. A indústria também beneficiou-se pelo fato de serem técnicas escaláveis, possibilitando produção em massa. Pode-se argumentar que é um contrassenso buscar o desenvolvimento de dispositivos de spin através de implantação iônica, tendo em vista os efeitos de perda de coerência de spin causados por defeitos e impurezas, no entanto, a técnica tem vantagens importantes sobre outros métodos de dopagem como disponibilidade e geração de alta concentração de dopantes que a tornam muito atrativa, sendo utilizada em um grande número de estudos sobre diversos semicondutores magnéticos.

Esta tese está organizada da seguinte forma: no segundo capítulo é feita a apresentação das amostras estudadas e do processo de crescimento das mesmas por MBE juntamente com os métodos utilizados para a caracterização e modificação das amostras, descrevem-se os processos de implantação iônica e tratamento térmico e em seguida as técnicas estruturais de difração de raios-x, espectroscopia Raman e de fotoluminescência; a segunda parte do capítulo é dedicada à descrição dos fenômenos magnéticos observados e também do magnetômetro SQUID utilizado para a caracterização magnética neste trabalho. No capítulo três são apresentados os resultados obtidos por simulação de implantação iônica nos softwares SRIM e MDRANGE, discutem-se nesta parte as limitações das técnicas de simulação e também o efeito de canalização de íons. O capítulo quatro é dedicado a apresentação dos resultados experimentais obtidos através das diferentes técnicas estruturais e magnéticas utilizadas. Inicialmente são mostrados os resultados obtidos por difração de raios-x em diferentes configurações feixe-amostra, em seguida os resultados de caracterização ótica por fotoluminescência e Raman são discutidos, por fim os dados de magnetometria SQUID em função do campo aplicado e da temperatura e suas relações com os resultados de caracterização estrutural são desenvolvidos. Na parte final da tese um resumo dos resultados é apresentado juntamente com as conclusões gerais do trabalho. 


\section{Capítulo 2}

\section{Materiais e métodos}

Neste capítulo são apresentados os materiais e o processo de crescimento das amostras utilizadas neste trabalho, com enfase no material de interesse principal, o nitreto de gálio. Serão discutidos também os diversos processos aos quais as amostras crescidas foram submetidas, seja com intuito de sua modificação física ou buscando sua caracterização.

\section{$2.1 \mathrm{GaN}$}

Em condições usuais de crescimento o nitreto de gálio (GaN) cristaliza-se em uma estrutura cristalina hexagonal do tipo wurtzita, composta por duas sub-redes hexagonais compactas (HC) com razão $\mathrm{c} / \mathrm{a}=\sqrt{8 / 3}$ deslocadas entre si de $3 \mathrm{c} / 8$ na direção de c. Cada átomo da sub-rede tem como primeiros vizinhos quatro átomos de outro tipo, formando um tetraedro regular com os átomos da segunda sub-rede nos vértices e o átomo ligante no centro. Na figura 2.1 vemos que dois tipos de empilhamento destas estruturas tetraédricas são possíveis: empilhando os tetraedros com as bases coincidentes quando projetadas no plano basal obtemos a estrutura hexagonal da wurtzita (2.1b), já empilhando os átomos de maneira que a projeção dos planos formem um ângulo de $60^{\circ}$ entre si obtemos a estrutura cúbica da blenda de zinco, mais conhecida pelo nome em inglês zincblende (2.1a).

a)

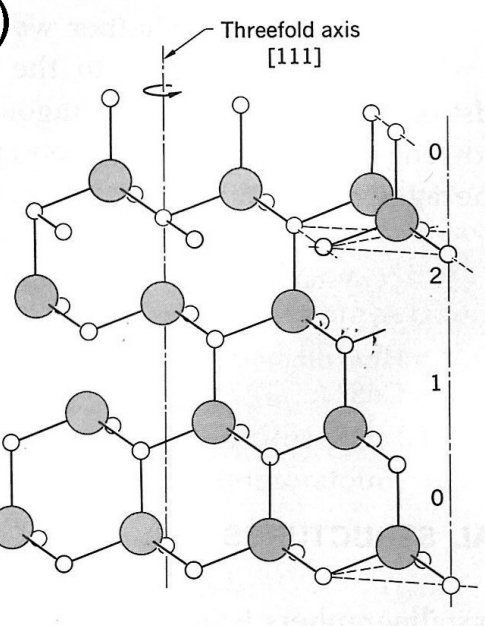

Cubic

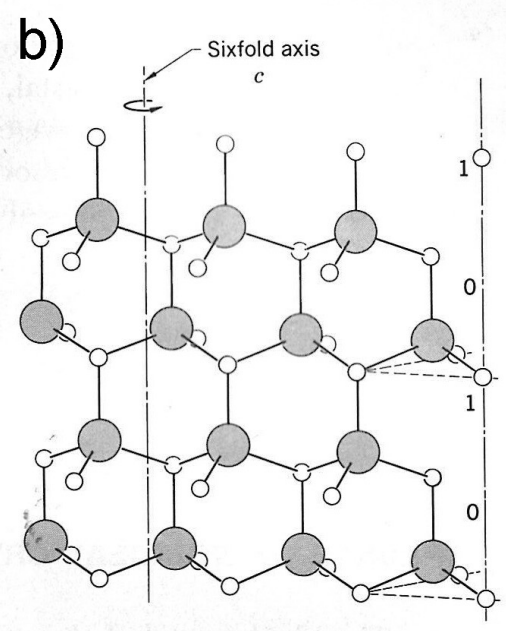

Hexagonal

Figura 2.1: Esquema com as estruturas da blenda de zinco (a) e da wurtzita (b), com os respectivos eixos de simetria. Figura retirada de Kittel [20]. 
O GaN possui algumas propriedades que o tornam interessante para diversas aplicações. É um material transparente na região do visível e extremamente duro (índice Mohs 9), com alta capacidade e condutividade térmica $(2.3 \mathrm{~W} /(\mathrm{cm} . \mathrm{K})$ a $300 \mathrm{~K})$ [21]. Sua baixa sensibilidade à radiação ionizante o tornam um semicondutor propício para aplicações em tecnologia astronáutica. O material também possui características elétricas interessantes como alta mobilidade de buracos $\left(440 \mathrm{~cm}^{2} /\right.$ V.s a $\left.300 \mathrm{~K}\right)[21]$, elevadas figuras de mérito de Johnson e temperaturas de operação tipicamente acima de $200{ }^{\circ} \mathrm{C}$, que indicam sua aptidão para aplicações de alta potência. Devido ao seu largo gap direto e alta transparência, o material mostrou-se adequado para a aplicação em LEDs emitindo no violeta / ultravioleta, sendo o primeiro material semicondutor empregado com sucesso nestes dispositivos. Embora o GaN já seja um material difundido como emissor de luz, sua aplicação à eletrônica de alta potência ainda é tímida, no entanto, tendo em vista suas características físicas, é esperado que ele seja um material chave para o desenvolvimento de novos dispositivos nesta área. Como principal empecilho a esse desenvolvimento o GaN possui uma elevada densidade de defeitos, em torno de $10^{8} \mathrm{~cm}^{-3}$, mesmo com as melhores técnicas de crescimento disponíveis atualmente.

As camadas de c-GaN estudadas neste trabalho foram crescidas sobre substratos de carbeto de silício de politipo 3C (3C-SiC). O SiC é um material que apresenta elevado grau de polimorfismo com mais de 250 estruturas cristalinas identificadas [22]. O politipo $3 \mathrm{C}$ possui, assim como o c-GaN, estrutura cristalina da blenda de zinco.

Vemos na tabela 2.1 um resumo de algumas propriedades físicas de alguns semicondutores relevantes.

\begin{tabular}{|c|c|c|c|c|c|}
\hline Material & Estrutura & Parâmetros de rede $(\AA)$ & $\mathrm{E}_{\text {gap }}(\mathrm{eV})(2 \mathrm{~K})$ & $\omega_{T O}\left(\mathrm{~cm}^{-1}\right)$ & $\omega_{L O}\left(\mathrm{~cm}^{-1}\right)$ \\
\hline $\mathrm{c}-\mathrm{GaN}$ & Zincblende & 4.52 & 3.30 & 555 & 740 \\
$\mathrm{~h}-\mathrm{GaN}$ & Wurtzita & $\mathrm{a}=3.16, \mathrm{c}=5.125$ & 3.47 & $535 \& 563$ & $735 \& 742$ \\
$3 \mathrm{C}-\mathrm{SiC}$ & Zincblende & 4.36 & 2.36 & 796 & 965 \\
$\mathrm{GaAs}$ & Zincblende & 5.65 & 1.42 & 272 & 301 \\
\hline
\end{tabular}

Tabela 2.1: Constantes físicas dos materiais estudados. Dados de Levinshtein [21] e NSM Archive [23].

Técnicas de crescimento epitaxial de cristais desenvolveram-se com intensidade nas décadas de 70 e 80 e permitiram o crescimento controlado de heteroestruturas de semicondutores com precisão de monocamadas. Os procedimentos mais comuns são: $(i)$ epitaxia por feixe molecular (Molecular Beam Epitaxy - MBE, em inglês), com fontes sólidas e gasosas dos elementos e crescimento em câmara de alto vácuo, método mais utilizado em meios acadêmicos e (ii) epitaxia por fase de vapor (VPE), com fontes gasosas em vácuo moderado; o método mais utilizado na indústria por facilitar o crescimento de amostras em grande escala, possuindo custos de implantação e produção reduzidos em relação ao MBE.

No crescimento heteroepitaxial de amostras, a escolha do substrato para o crescimento dos filmes é fundamental. Primeiramente, o substrato deve possuir a mesma estrutura cristalina do filme a ser crescido, além disso os parâmetros de rede de ambos devem ser próximos. Incompatibilidade (ou descasamento) entre os materiais acarreta, no crescimento de amostras, em propriedades usualmente tidas como indesejáveis como: elevada tensão interfacial, elevada densidade de defeitos e formação de fases secundárias. Sendo o c-GaN um material metaestável, a formação do composto em equilíbrio termoquímico só pode ocorrer em condições extremas de temperatura e pressão e ainda não existem técnicas difundidas para o crescimento de amostras bulk de boa qualidade cristalina, assim, outro material deve ser utilizado como substrato. O 3C-SiC, substrato utilizado neste estudo, possui como principal qualidade um descasamento no parâmetro de rede de apenas $3.5 \%$ em relação ao c-GaN, valor baixo em comparação a outro substrato usualmente utilizado, GaAs, 
que possui incompatibilidade de aproximadamente 20\%. Em compensação, a alta condutividade do substrato impede o estudo dos filmes através de medidas elétricas.

A técnica de crescimento utilizada foi epitaxia de feixe molecular assistida por plasma (PAMBE), realizada no laboratório do Grupo de Optoeletrônica da Universidade de Paderborn - Alemanha, em colaboração com os professores Klaus Lischka, Donat As, Detlef Schikora e Marcio Peron. O aparato experimental para crescimento de amostras está esquematizado na figura 2.2.

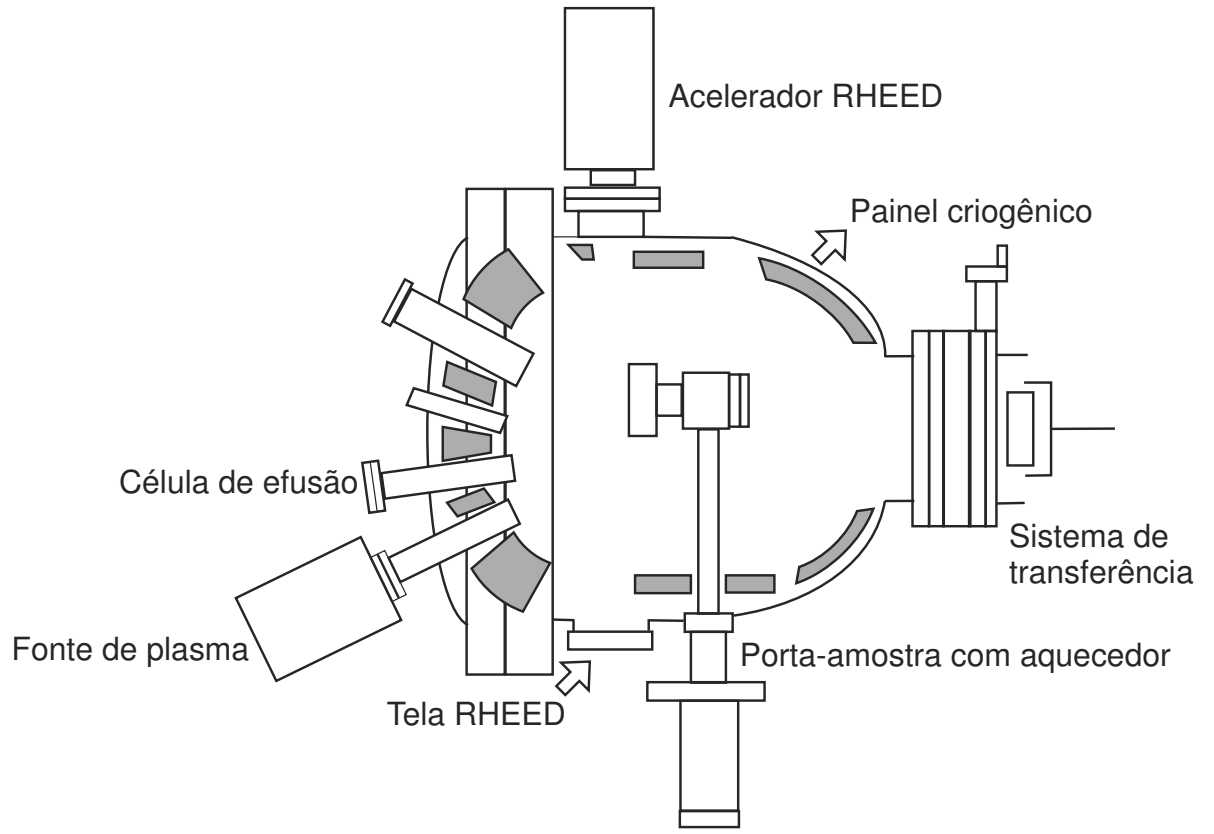

Figura 2.2: Arranjo esquemático de uma câmara de crescimento PA-MBE.

O equipamento consiste de uma evaporadora em ultra-alto vácuo com baixa taxa de deposição. Os átomos de Ga são sublimados em células de efusão enquanto o $\mathrm{N}$ é introduzido através de um plasma. O vácuo além de evitar que substâncias espúrias contaminem o cristal, aumenta o livre caminho médio dos átomos evaporados no percurso entre as células de efusão e o substrato. Esse é um fator importante pois é desejável que a reação química que leva a formação do cristal ocorra apenas no substrato. A estequiometria na superfície e a taxa de deposição são controladas, primeiramente pelo fluxo de íons proveniente das fontes. Para os átomos de Ga o controle é feito por um obturador e também pela temperatura da célula de efusão. Fluxos típicos de Ga durante o crescimento foram de $5 \times 10^{14} \mathrm{~cm}^{-2} \mathrm{~s}^{-1}$ obtidos com a temperatura da célula em $850{ }^{\circ} \mathrm{C}$. O nitrogênio foi introduzido por uma fonte plasma de rádio-frequência (Oxford Applied Research CARS 25 RF) operando com potência de $260 \mathrm{~W}$. O outro parâmetro importante de controle é a temperatura do substrato que influencia diretamente a estequiometria na superfície. Nos crescimentos a mesma foi mantida em torno de $720{ }^{\circ} \mathrm{C}$.

O crescimento é acompanhado por difração de elétrons de alta energia por reflexão (RHEED). A técnica consiste em um feixe de elétrons de alta energia (da ordem de dezenas de $\mathrm{keV}$ ), incidindo na amostra em um ângulo rasante $\left(\right.$ da ordem de $1^{\circ}$ ) durante todo o processo. $O$ feixe difratado incide em uma tela fosforescente criando um padrão visível. Do padrão e sua intensidade podese obter em tempo real informações como velocidade e modo de crescimento das amostras. Com posse destas informações realiza-se o ajuste fino dos parâmetros de crescimento, fundamental para a obtenção do cristal metaestável. Em condições típicas, o feixe de elétrons penetra apenas algumas monocamadas do material, dessa forma os padrões de difração gerados são altamente sensíveis a estruturas superficiais e tem boa resolução temporal. 
Vemos na figura 2.3 padrões RHEED obtidos durante o crescimento do filme de c-GaN da amostra do conjunto 2a. Na figura 2.3a o padrão obtido após a nucleação do c-GaN, a figura 2.3b mostra o padrão durante o crescimento e por último em $2.3 \mathrm{c}$ vemos o padrão referente à etapa final do processo. Nota-se que o padrão passa de um pico central puntiforme intenso para o padrão usual de uma amostra lisa caracterizado por picos de difração em formato de bastão, resultado das condições de difração de Laue aplicadas ao sistema bidimensional.

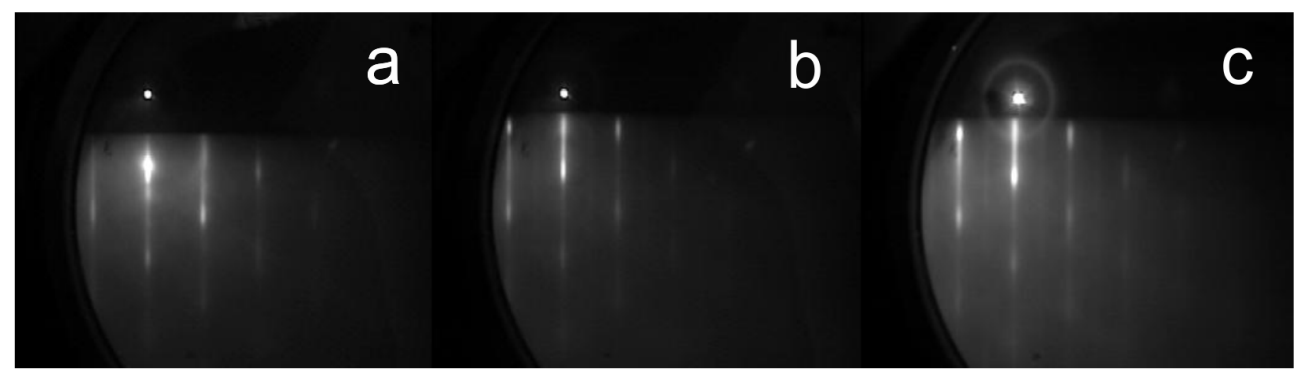

Figura 2.3: Evolução do padrão RHEED durante o crescimento do filme de c-GaN da amostra 2a.

Com o aquecimento da amostra é gerada radiação no infravermelho que interfere com o espectro RHEED, dificultando sua observação. Esse problema não ocorre durante o crescimento de semicondutores de gap estreito como o Si, devido a absorção da radiação pelo próprio substrato. Tanto o filme como o substrato das amostras estudadas não absorvem eficientemente essa radiação possuindo gap de 3.30 e $2.36 \mathrm{eV}$, respectivamente. Uma maneira encontrada para sanar esse problema foi o crescimento de uma fina camada de Si na face do substrato oposta a face de crescimento do c-GaN, com intuito de absorver parte da radiação térmica. Maiores detalhes sobre os crescimentos podem ser encontrados na referência [24].

Um diagrama da seção transversal das amostras virgens pode ser visto na figura 2.4.

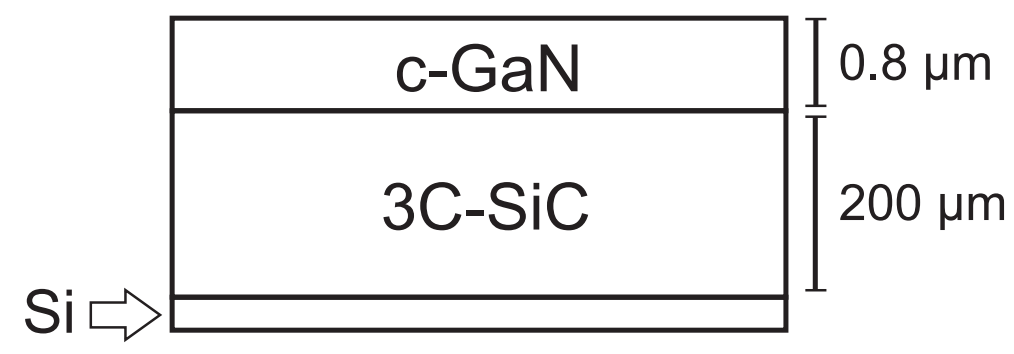

Figura 2.4: Diagrama esquemático com a seção transversal das amostras estudadas.

\subsection{Implantação iônica}

O processo de implantação iônica consiste na ionização de átomos, que pela ação de um campo elétrico são acelerados na direção e colidem com um material a ser tratado. Os íons incidentes interagem com os átomos do alvo perdendo energia até serem absorvidos, alterando as propriedades do material na região afetada. As mudanças nas características do material, resultantes do processo de implantação, dependem de certos parâmetros como: energia inicial dos íons, dose implantada (número de íons implantados por unidade de área), ângulo de incidência do feixe iônico e temperatura do material durante a implantação.

Nas últimas décadas a técnica de implantação iônica apresentou um grande avanço, principalmente devido à sua aplicação na dopagem de silício em larga escala, sendo hoje a técnica mais 
utilizada para esta finalidade. Duas vantagens da técnica são um excepcional controle na dose implantada e o baixo número de impurezas introduzidas no processo. Através de implantação iônica é possível a obtenção de uma densidade de dopantes maior do que em técnicas onde o crescimento e a dopagem das amostras ocorrem concomitantemente já que não são impostos limites de solubilidade a priori. A principal desvantagem da técnica é o dano à rede cristalina inerentemente associado à penetração de partículas carregadas na matéria. Na implantação iônica em GaN, esse problema é especialmente sério devido ao alto ponto de fusão e à baixa temperatura de dissociação do material, sendo esta menor do que a temperatura tida como ideal para a recuperação da rede durante o tratamento térmico [25].

As implantações foram realizadas no implantador HVEE $500 \mathrm{kV}$ do Laboratório de Implantação Iônica do Instituto de Física da Universidade Federal do Rio Grande do Sul pelo professor Johnny Dias. O implantador consiste em uma fonte de íons do tipo "catodo oco" que alimenta um acelerador eletrostático gerando um feixe iônico, o feixe tem sua energia selecionada e é direcionado à amostra através de um magneto de separação, a energia do feixe de íons utilizado foi de $200 \mathrm{keV}$ em todas as implantações. Sabendo o fluxo de íons incidente, obtém-se a dose desejada através do tempo de irradiação da amostra. Foram implantadas amostras em duas doses diferentes: $1.2 \mathrm{e}$ $2.4 \times 10^{16} \mathrm{~cm}^{-2}$. Cada amostra crescida por MBE foi clivada em quatro, três dos pedaços foram irradiados com um íon diferente entre $\mathrm{Fe}, \mathrm{Mn}$ e $\mathrm{Cu}$ e um foi preservado como referência, esses quatro pedaços provenientes de uma mesma amostra chamamos de conjunto. Das amostras estudadas um conjunto (conjunto 1) foi implantado com dose $1.2 \times 10^{16} \mathrm{~cm}^{-2}$ outros dois (conjuntos 2a e 2b) com dose $2.4 \times 10^{16} \mathrm{~cm}^{-2}$, as amostras são identificadas na tese combinando-se o nome de seu conjunto com o símbolo do íon implantado, por exemplo, a amostra do grupo 1 implantada com manganês é denominada amostra Mn1. É apresentado um diagrama exemplificando o processo na figura 2.5. Dentro de um conjunto é possível a comparação direta de resultados, o que é mais difícil entre amostras de conjuntos diferentes já que as amostras inicialmente não eram idênticas entre si, fato evidenciado pelas técnicas de caracterização estrutural. Todas as implantações foram realizadas à temperatura ambiente com incidência normal (100) do feixe iônico nas amostras.

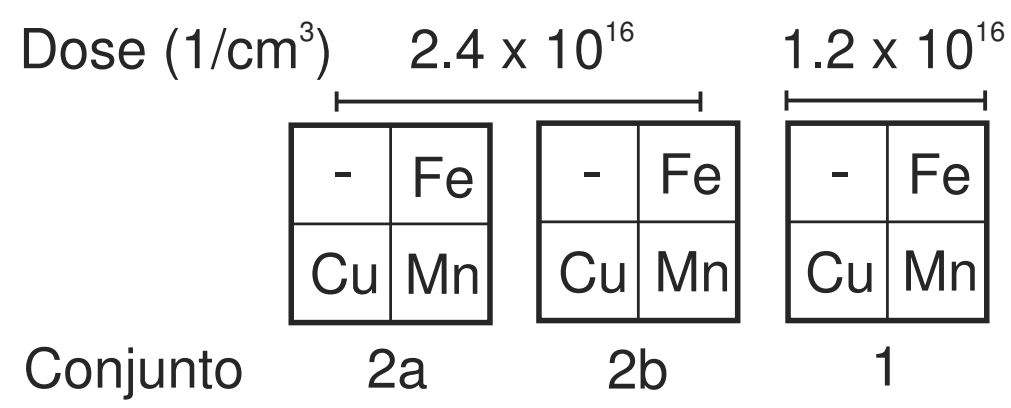

Figura 2.5: Esquema da clivagem e implantação das amostras de c-GaN com diferentes íons.

\subsection{Tratamento térmico}

O processo de tratamento térmico originou-se por volta de 5000 A.C. e teve como sua primeira aplicação a recuperação da ductilidade de peças de cobre forjadas, sendo ainda hoje o método mais difundido para esta finalidade. De uma maneira simples, o processo consiste no aquecimento do material à temperatura desejada na qual é mantido por um intervalo de tempo e seu posterior resfriamento cuja velocidade é também um fator potencialmente importante. A dinâmica do processo ocorre com a difusão de átomos dentro do material facilitada pela energia térmica introduzida no sistema. 
Neste trabalho o tratamento térmico teve como principal objetivo a recuperação da rede cristalina do filme de c-GaN danificada pela implantação iônica. De uma maneira geral a temperatura necessária para um tratamento térmico efetivo é de dois terços do ponto de fusão do material [26] o que para o GaN significaria uma temperatura de tratamento em torno de $1800{ }^{\circ} \mathrm{C}$. Estudos em h-GaN mostram que a recuperação da rede não é completa mesmo em temperaturas de até 1500 ${ }^{\circ} \mathrm{C}$ [27]. Entretanto, em temperaturas a partir de $720{ }^{\circ} \mathrm{C}$ o material se decompõe termicamente com liberação de gás nitrogênio o que torna proibitivo o tratamento em condições ideais. Dois procedimentos são usualmente utilizados para dificultar a decomposição dos filmes: pode-se efetuar o procedimento sob pressão de $\mathrm{N}_{2}$, porém são necessárias atmosferas de até 15 kbar para a efetiva supressão da decomposição [28] o que torna pouco prático este procedimento. Pode-se também isolar o material através da cobertura dos filmes. Geralmente são utilizados filmes do próprio GaN com as camadas posicionadas face a face, esta escolha é vantajosa pois evita a contaminação das amostras por outros materiais.

O tratamento térmico das amostras de c-GaN foi realizado em um forno tubular Lindberg do Laboratório de Materiais Magnéticos do IFUSP, com auxílio do Me. Sérgio Romero. O sistema é acoplado a trilhos que permitem o aquecimento do forno antes do contato com a amostra, com isso busca-se reduzir ao mínimo o tempo gasto para a amostra atingir a temperatura de tratamento. Monitorando a temperatura na região da amostra com um termopar desloca-se o forno para a posição de aquecimento, removendo-o ao final do tempo de tratamento desejado. Foram realizados tratamentos térmicos em dois conjuntos de amostras (1 e 2a, implantados com dose 1.2 e $2.4 \times$ $10^{16}$ íns $/ \mathrm{cm}^{2}$ respectivamente) além de uma amostra do conjunto $2 \mathrm{~b}$ implantada com $2.4 \times 10^{16}$ íons $/ \mathrm{cm}^{2}$ de Fe. As oito amostras dos conjuntos 1 e 2a foram submetidas a uma temperatura de 900 ${ }^{\circ} \mathrm{C}$ por 5 minutos, enquanto a amostra Fe2b foi tratada em duas etapas: $800{ }^{\circ} \mathrm{C}$ e posteriormente 900 ${ }^{\circ} \mathrm{C}$ ambas também por 5 minutos. Com intuito de dificultar a dissociação do GaN, os tratamentos foram realizados sob atmosfera de $\mathrm{N}_{2}(1 \mathrm{~atm})$ e as amostras foram empilhadas aos pares com filmes não implantados de GaN cobrindo as amostras face a face.

Vemos na tabela 2.2 um resumo das amostras estudadas.

\begin{tabular}{|c|c|c|c|c|c|c|}
\hline Amostra & Dose $\left(10^{16} \mathrm{~cm}^{-2}\right)$ & Íon Impl. & $C_{\text {pico }}(\%)$ & $C_{\mathrm{m}}(\%)$ & Massa $(\mathrm{mg})$ & Trat. Térmico \\
\hline $\mathrm{Fe} 2 \mathrm{a}$ & 2.4 & $\mathrm{Fe}$ & 2.6 & 1.7 & 24.87 & $900{ }^{\circ} \mathrm{C}$ \\
$\mathrm{Mn} 2 \mathrm{a}$ & 2.4 & $\mathrm{Mn}$ & 2.5 & 1.7 & 12.75 & $900{ }^{\circ} \mathrm{C}$ \\
$\mathrm{Cu} 2 \mathrm{a}$ & 2.4 & $\mathrm{Cu}$ & 2.7 & 1.8 & 15.74 & $900{ }^{\circ} \mathrm{C}$ \\
$\mathrm{Fe} 2 \mathrm{~b}$ & 2.4 & $\mathrm{Fe}$ & 2.6 & 1.7 & 18.65 & 800 e $900{ }^{\circ} \mathrm{C}$ \\
$\mathrm{Mn} 2 \mathrm{~b}$ & 2.4 & $\mathrm{Mn}$ & 2.5 & 1.7 & 16.89 & Não \\
$\mathrm{Cu} 2 \mathrm{~b}$ & 2.4 & $\mathrm{Cu}$ & 2.7 & 1.8 & 19.80 & Não \\
$\mathrm{Fe} 1$ & 1.2 & $\mathrm{Fe}$ & 1.3 & 0.8 & 19.86 & $900^{\circ} \mathrm{C}$ \\
$\mathrm{Mn} 1$ & 1.2 & $\mathrm{Mn}$ & 1.3 & 0.8 & 13.96 & $900{ }^{\circ} \mathrm{C}$ \\
$\mathrm{Cu} 1$ & 1.2 & $\mathrm{Cu}$ & 1.4 & 0.9 & 9.84 & $900^{\circ} \mathrm{C}$ \\
Ref2a & - & - & - & - & 14.78 & $900{ }^{\circ} \mathrm{C}$ \\
Ref2b & - & - & - & - & 15.34 & Não \\
Ref1 & - & - & - & - & 16.59 & $900{ }^{\circ} \mathrm{C}$ \\
\hline
\end{tabular}

Tabela 2.2: Tabela das amostras estudadas com as respectivas concentrações de íons implantados, média $\left(C_{\mathrm{m}}\right)$ e de pico $\left(C_{\text {pico }}\right)$, obtidas através de simulação pelo software SRIM, massa e temperatura de tratamento térmico. 


\subsection{Espectroscopia de fotoluminescência}

O efeito de fotoluminescência (PL - photoluminescence em inglês) consiste inicialmente na absorção de um fóton por um elétron da banda de valência, com o aumento em sua energia o elétron é promovido para a banda de condução e nesse processo cria-se um par elétron-buraco denominado éxciton. O processo de recombinação excitônica ocorre com a emissão de um fóton de energia $h \nu=E_{\text {gap }}-E_{\text {lig }}$, sendo $\nu$ a frequência do fóton emitido, $E_{\text {gap }}$ a diferença de energia entre o topo

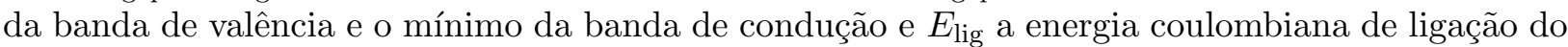
éxciton. Medindo-se a intensidade da emissão proveniente do material em função da energia dos fótons emitidos obtém-se o espectro de fotoluminescência do mesmo. Esse espectro portanto, nos fornece dados sobre a energia dos elétrons de condução e valência e sobre a interação entre elétrons e buracos.

Um efeito decorrente dos defeitos e impurezas presentes nos materiais é a criação de estados dentro do gap. Existindo estes estados, tornam-se possíveis transições entre a banda de condução e a banda de valência através de estados intermediários doador $(D)$ e aceitador $(A)$, como esquematizado na figura 2.6, sendo $E_{D A}$ a energia da transição Doador-Aceitador e $E_{X}$ a energia da transição excitônica. Transições diretas entre os estados doador ou aceitador e a banda de valência também são possíveis. A posição em energia de um estado dentro do gap é peculiar a cada dopante ou tipo de defeito, que poderá ser associado a um pico de luminescência novo ou um deslocamento de um já existente no espectro.

\section{Banda de condução}

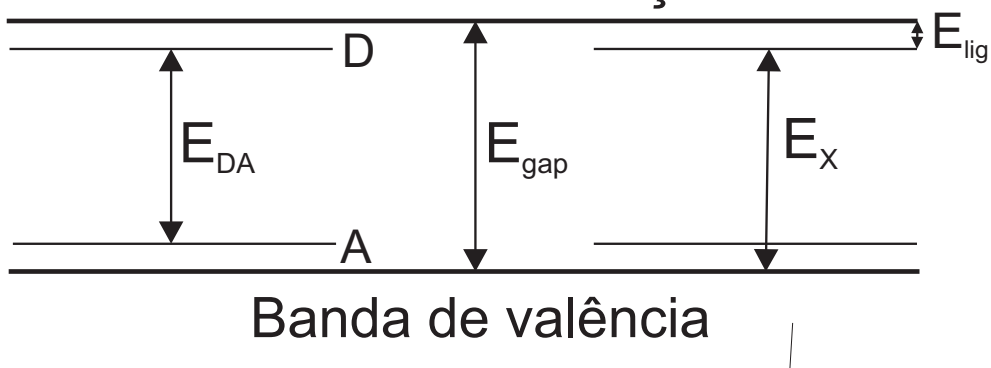

Figura 2.6: Diagrama representando os níveis de energia dos elétrons em um semicondutor, com as transições de fotoluminescência estudadas.

Um espectro típico a baixa temperatura de uma amostra de c-GaN com os picos referentes com as transições doador-aceitador (DA) e excitônica (X) assinalados pode ser observado na figura 2.7.

Os espectros de fotoluminescência foram obtidos no Departamento de Física da UFSCar com auxílio do Prof. Marcio Peron. As medidas foram realizadas em modo contínuo através de janela ótica em temperaturas de 10 a $300 \mathrm{~K}$ com resfriamento realizado por compressor em circuito fechado de He CTI Cryogenics. A fonte utilizada foi um Laser de HeCd Kimmon emitindo na linha $\lambda=$ $325 \mathrm{~nm}$ com potência nominal de $5 \mathrm{~mW}$ e a deteção feita por uma CCD Andor Shamrock acoplada a uma rede de difração monocromadora de 600 ou 1200 linhas $/ \mathrm{mm}$.

\subsection{Raman}

A técnica de espectroscopia Raman, assim como a espectroscopia de fotoluminescência, utiliza um feixe de luz incidente num material como fonte de energia, mas ao invés de transições eletrônicas mede-se o espalhamento inelástico de um fóton ou espalhamento Raman. Esse método fornece informação sobre os estados vibracionais do sólido estudado. Como esses estados são sensíveis à desordem microscópica, a qualidade cristalina do material pode ser estimada através da intensidade, 


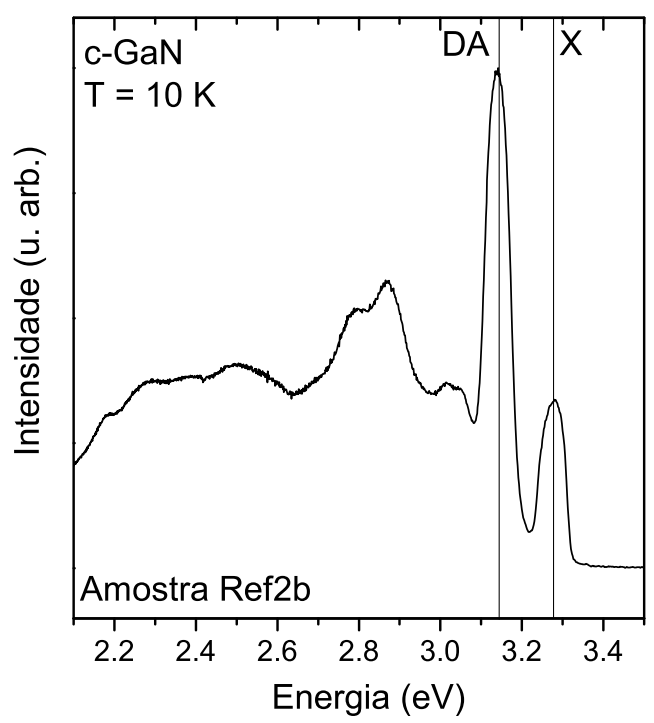

Figura 2.7: Espectro de fotoluminescência de uma amostra virgem (referência 2b) de c-GaN a 10 $\mathrm{K}$, com picos doador-aceitador e excitônico assinalados.

energia e forma dos picos do espectro. A figura 2.8 mostra possíveis transições entre níveis de energia vibracionais, na interação dos fônons com um fóton de frequência $\omega$. O espalhamento elástico ou Rayleigh é o que ocorre com maior probabilidade, o fóton interage com as vibrações coletivas do material de forma que seu vetor de onda $\vec{k}$ tem a direção alterada mas seu módulo permanece constante. No espalhamento Raman do tipo Stokes, o fóton incidente emerge da interação com os fônons com frequência $\omega_{f}<\omega$, o contrário ocorre no espalhamento anti-Stokes onde a frequência do fóton re-emitido $\omega_{f}$ é maior que $\omega$. Tipicamente, um em $10^{7}$ fótons espalhados sofre espalhamento Raman [29].

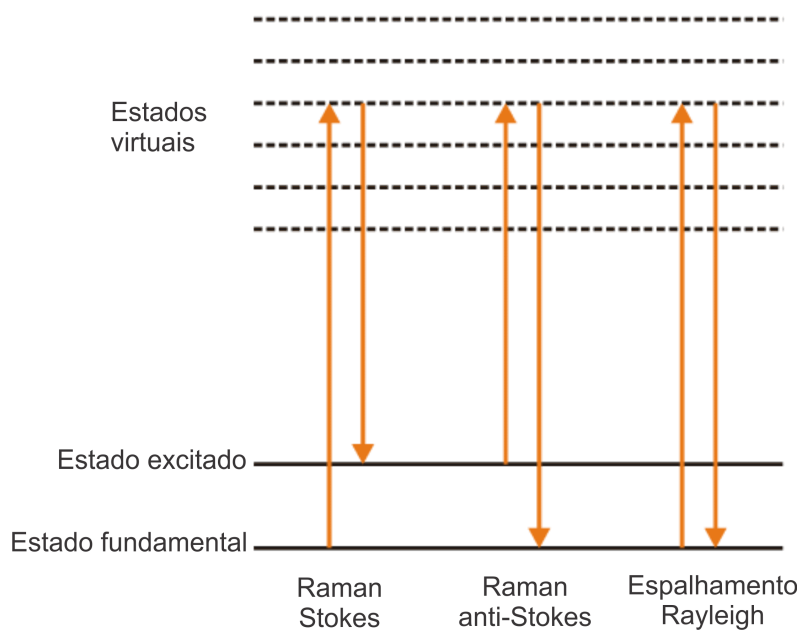

Figura 2.8: Esquema simplificado dos níveis de energia vibracionais em um sólido, mostrando os diferentes tipos de espalhamento.

Em um cristal composto como o GaN, ocorre uma quebra de simetria que separa os fônons do 
material em dois tipos: óticos e acústicos. Os fônons acústicos são correspondentes às vibrações onde os dois átomos da base oscilam aproximadamente em fase. Os fônons óticos correspondem às vibrações coletivas da rede, tanto longitudinais (LO) como transversais (TO), onde a distância entre os átomos positivo e negativo oscila mais fortemente, criando um momento de dipolo elétrico variável. Esse dipolo elétrico oscilante leva a uma forte interação dos fônons óticos com fótons de frequência na região do infravermelho. Tanto fônons óticos quanto acústicos interagem com fótons através de espalhamento Raman.

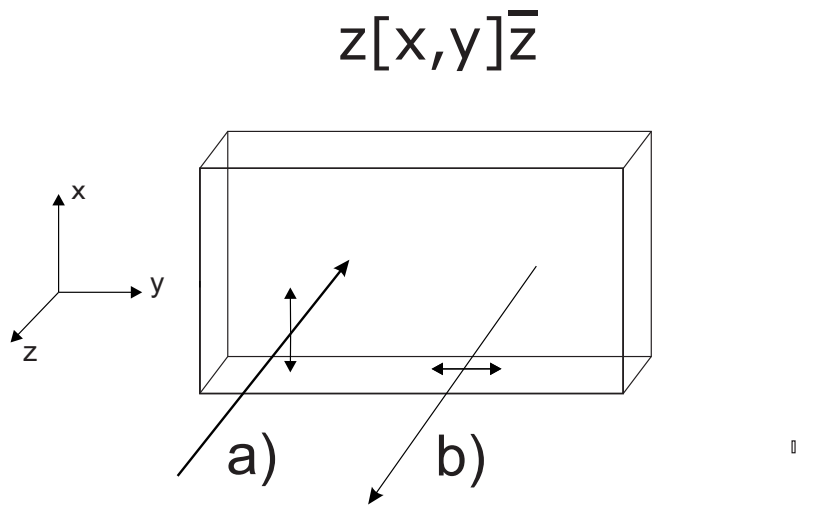

Figura 2.9: Arranjo esquemático de um experimento de Raman realizado na configuração $z[x, y] \bar{z}$. a) feixe incidente com sua direção de polarização, b) feixe medido polarizado no eixo y.

Para a descrição da configuração geométrica utilizada na medição de espectros Raman é amplamente utilizada a notação de Porto, onde são condensadas as direções dos vetores de onda dos fótons incidente e espalhado $\left(\overrightarrow{k_{i}}\right.$ e $\left.\overrightarrow{k_{e}}\right)$ e dos vetores campo elétrico dos mesmos fótons $\left(\vec{E}_{i}\right.$ e $\left.\vec{E}_{e}\right)$ na seguinte notação: $\overrightarrow{k_{i}}\left[\vec{E}_{i}, \vec{E}_{e}\right] \overrightarrow{k_{e}}$. Definindo a direção z[001] como perpendicular a superfície da amostra temos por exemplo a configuração $z[x, y] \bar{z}$ representada na figura 2.9 .

Existem regras de seleção para os modos de vibração. Dependendo da estrutura cristalina da amostra e da configuração de espalhamento utilizada, certos modos são suprimidos e tornam-se inativos. Para o caso do c-GaN (estrutura cristalina do tipo Zincblende) crescido na direção [001] as regras de seleção para os modos LO e TO estão resumidas na tabela 2.3.

\begin{tabular}{|c|c|c|}
\hline Configuração & modo LO & modo TO \\
\hline$z[x, y] \bar{z}$ & permitido & proibido \\
$z[x, x] \bar{z}$ & proibido & proibido \\
\hline
\end{tabular}

Tabela 2.3: Resumo das regras de seleção para os modos Raman LO e TO em cristais com estrutura da blenda de zinco, referentes às duas polarizações de vetor campo elétrico espalhado na configuração de retroespalhamento. Retirada de Olego [30]

Vemos que o modo TO é proibido nas duas polarizações e portanto não deveria estar presente em espectros Raman de c-GaN na configuração de retroespalhamento, no entanto, essa proibição depende da simetria do cristal. Na prática, defeitos no cristal levam a uma quebra de simetria e o pico TO é frequentemente encontrado nos espectros. Em geral, uma perturbação local pode levar ao aparecimento do pico TO [31], no entanto a dependência de uma perturbação para a ativação deste modo leva a uma diminuição de sua intensidade.

Na figura 2.10 é apresentado como exemplo um espectro Raman não polarizado de uma das amostras estudadas realizado em temperatura ambiente, observa-se no espectro picos Raman provenientes das diferentes camadas constituintes das amostras e presença de fase secundária de h-GaN 
no filme.

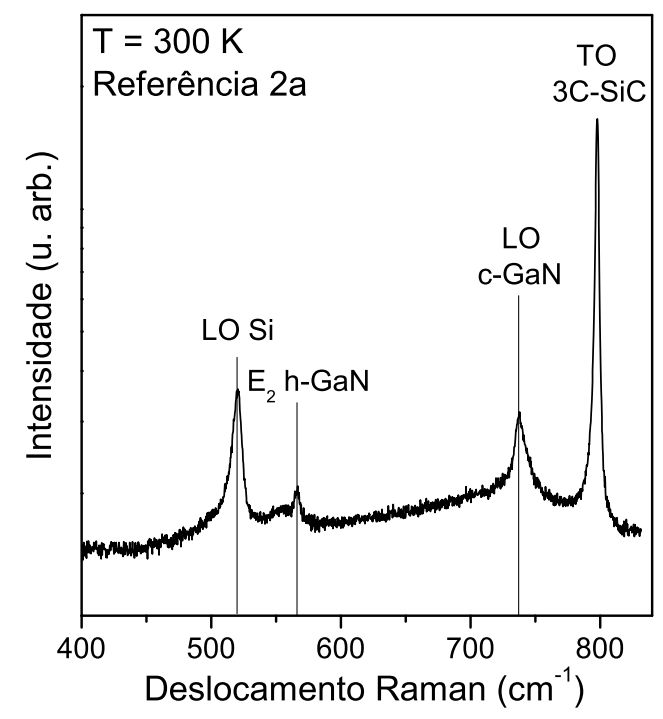

Figura 2.10: Espectro Raman não polarizado de uma amostra virgem de c-GaN (Referência 2a) realizado em temperatura ambiente, com os picos Raman referentes às diferentes camadas das amostras assinalados.

As amostras de c-GaN foram caracterizadas por espectroscopia Raman no Departamento de Física da UFSCar com auxílio do Prof. Ariano Rodrigues. As medições foram realizadas à temperatura ambiente na configuração de retroespalhamento com o feixe incidindo perpendicularmente à amostra. O experimento teve como fonte um laser de $\mathrm{Ar}^{+}$modelo Coherent Innova emitindo nas linhas $\lambda=514$ e $568 \mathrm{~nm}$. As medidas realizadas na linha 514 apresentam mais ruido já que a luminescência do substrato também é captada e deve ser removida dos espectros, este problema foi resolvido medindo-se na linha 568 já que os fótons desta linha provocam uma intensidade de luminescência muito menor no $3 \mathrm{C}-\mathrm{SiC}$, por possuírem menor energia. O feixe incidente não foi polarizado assim como o feixe espalhado não sofreu polarização na coleta, portanto o espectro obtido reflete uma superposição das configurações $z[x, y] \bar{z}$ e $z[x, x] \bar{z}$. A aquisição do sinal ocorreu por CCD Refrigerada por $\mathrm{N}_{2}$ e o tempo de aquisição para cada espectro ficou entre 10 e 40 minutos medindo-se o espalhamento Stokes. A referência para a calibração do deslocamento Raman foi o pico do Si cristalino em $520.91 \pm 0.01 \mathrm{~cm}^{-1}$.

\subsection{Difração de raios $\mathrm{X}$}

O fenômeno de difração consiste na variação da direção de propagação de uma onda devida à interação com centros espalhadores e ocorre quando a distância entre os centros é da mesma ordem do comprimento da onda incidente. Os planos cristalográficos de um material cristalino funcionam de fato como centros espalhadores para a radiação com comprimento de onda da ordem da distância interplanar $d_{h k l}$. Para cristais reais, esta distância, da ordem de $1-10 \mathrm{~nm}$, é coincidente com a região do espectro dos raios X. Através da diferença de caminho ótico entre as reflexões de diferentes planos do mesmo conjunto pode-se determinar a relação entre o ângulo de incidência $(\omega)$, distância interplanar e comprimento de onda $(\lambda)$ para que haja interferência construtiva no feixe difratado com mesmo ângulo (espalhamento elástico). Esta relação, apresentada na equação 2.1, é conhecida 
como lei de Bragg.

$$
2 d_{h k l} \operatorname{sen} \omega=\lambda
$$

Sabendo-se um dos parâmetros da lei de Bragg, pode-se obter uma relação entre os dois restantes na presença de picos de difração. Usualmente utiliza-se uma radiação de comprimento de onda conhecido e variando-se o ângulo de incidência (e do detetor, correspondentemente) obtém-se um espectro, com picos de difração referentes a cada conjunto de planos no material, determinado pelos índices de Miller $(h k l)$, que satisfaz a eq. 2.1. Finalmente obtém-se a distância interplanar do conjunto referente a cada pico através da medida do ângulo de incidência correspondente. Medindo a intensidade difratada em função do ângulo do feixe difratado obtemos o espectro de raios X de um material contendo informação sobre seu espaço recíproco.

Para cristais cúbicos, a distância interplanar está relacionada com os índices de Miller $h k l$ e o parâmetro de rede $a$ através da equação 2.2 .

$$
d_{h k l}=\frac{a}{\sqrt{h^{2}+k^{2}+l^{2}}}
$$

O desenvolvimento da técnica de espectroscopia de raios $\mathrm{X}$ foi instrumental para a determinação da estrutura cristalina de muitos compostos no início do século XX e ainda é muito utilizada na caracterização de diversos materiais cristalinos e até mesmo de moléculas, sendo difundida em especial no estudo de semicondutores. Com ela vários parâmetros podem ser obtidos de maneira não destrutiva incluindo: parâmetros e estrutura da rede cristalina, deteção e quantificação de fases, espessura e tensionamento de camadas.

Um diagrama com a notação de ângulos utilizada é mostrado na figura 2.11:

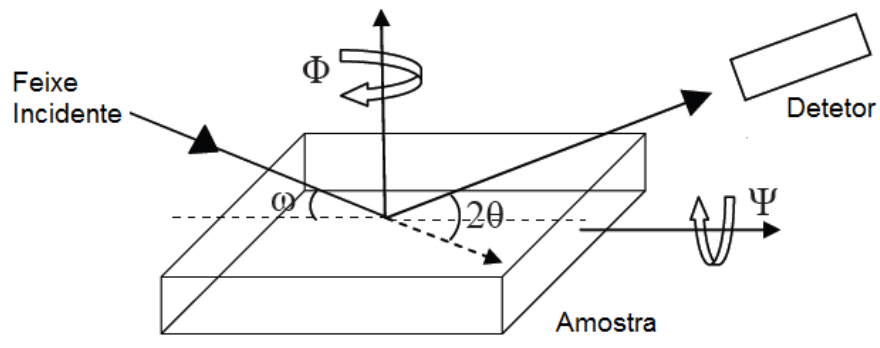

Figura 2.11: Notação para ângulos usualmente utilizada em cristalografia.

onde $\omega$ é o ângulo de incidência, $2 \theta$ o ângulo de difração com relação ao feixe incidente, $\Phi$ o ângulo referente ao eixo de rotação normal à amostra e $\Psi$ o ângulo referente ao eixo de rotação paralelo à amostra.

Vemos na figura 2.12 um exemplo típico de espectro de difração de raios $\mathrm{X}$ de uma das amostras estudadas na configuração $\omega-2 \theta$. Estão presentes neste espectro os picos referentes aos conjuntos de planos (002) tanto do filme de c-GaN como do substrato de 3C-SiC.

As medidas de difratometria de raios $\mathrm{X}$ das amostras de c-GaN foram realizadas no LAS-INPE com auxílio do Prof. Eduardo Abramof e do Dr. João Paulo Machado. Para as medidas $\omega-2 \theta$ foi utilizado um difratômetro de alta resolução Philips X'Pert PRO em duas configurações: detetor aberto para medições $\omega-2 \theta$ simples e triplo eixo (adição de monocromador no feixe difratado) para os mapas da rede recíproca. O difratômetro X'Pert PRO é equipado com tubo de $\mathrm{Cu}\left(K_{\alpha}\right)$ utilizado com os parâmetros: $V_{\text {tubo }}=40 \mathrm{kV}$ e $i_{\text {tubo }}=50 \mathrm{~mA}$ e a deteção foi realizada com um detetor proporcional de Xe. Os mapas da rede recíproca das amostras referência foram obtidos pelo Prof. Marcio Peron logo após o crescimento das amostras na Universidade de Paderborn também com um Philips X'Pert PRO. Já para as medidas Bragg-Brentano foi utilizado um difratômetro 


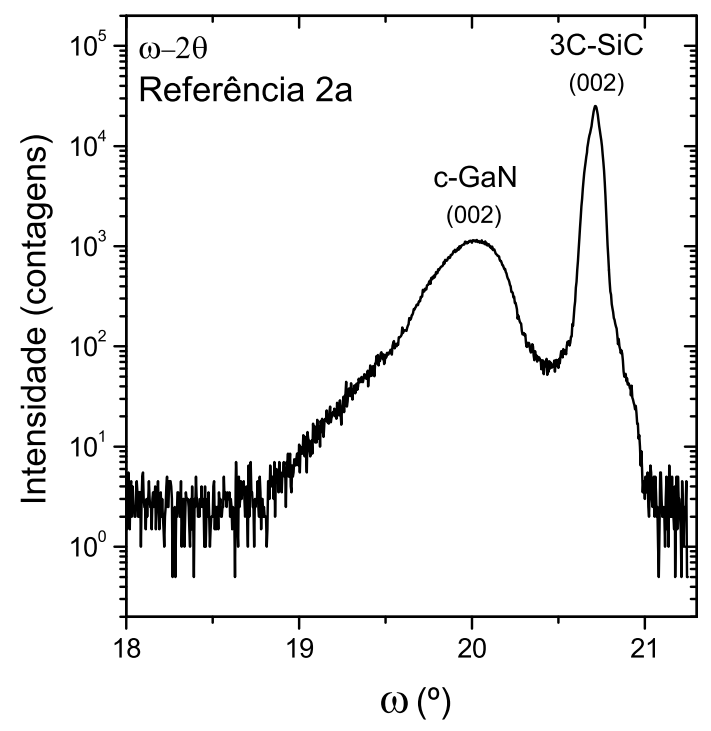

Figura 2.12: Espectro de difração de raios X de uma amostra (Referência 2a) de c-GaN realizado na configuração $\omega-2 \theta$, com os picos referentes ao filme de nitreto e ao substrato de carbeto assinalados.

PANalytical X'Pert Powder equipado com tubo de $\mathrm{Cu}(40 \mathrm{kV}, 45 \mathrm{~mA}$ max.) e detetor linha modelo X'Celerator de 128 canais, o diferencial deste sistema é a alta intensidade do sinal medido, propiciado principalmente pela largura do feixe e eficiência de coleta do detetor múltiplo, estas características, no entanto, implicam necessariamente em uma redução na resolução angular dos espectros.

\subsection{Magnetismo}

\subsubsection{Teoria do magnetismo}

Uma corrente elétrica $I$ percorrendo uma espira de área infinitesimal $\overrightarrow{d A}$ gera um dito momento magnético $\overrightarrow{d \mu}$ de acordo com a equação:

$$
\overrightarrow{d \mu}=I \overrightarrow{d A}
$$

no CGS o momento magnético possui como unidade o emu. Macroscopicamente, a soma dos momentos infinitesimais dentro de uma área se cancela no interior sobrando apenas a corrente perimetral. Desta maneira:

$$
\vec{\mu}=I \int \overrightarrow{d S}
$$

Sendo m a massa de um material e $\rho$ a sua densidade podemos definir magnetização $(\vec{M})$ como $\vec{\mu} / \mathrm{m}$. Em um material magnético $\vec{B}, \vec{H}$ e $\vec{M}$ estão relacionados pela seguinte equação:

$$
\vec{B}=\vec{H}+4 \pi \rho \vec{M} \quad(\mathrm{CGS})
$$

Um material magnético é dito linear se a razão $\mathrm{M} / \mathrm{H}$ é constante, esta razão recebe o nome de susceptibilidade magnética (por massa) ( $\chi$ ) cuja unidade no sistema CGS é o emu/(Oe.g). 
O Hamiltoniano de um átomo livre pode ser descrito pela soma da energia cinética e potencial dos elétrons do átomo:

$$
\mathcal{H}_{0}=\sum_{i=1}^{Z} \frac{\left(\overrightarrow{p_{i}}\right)^{2}}{2 m_{e}}+V_{i}
$$

sendo a somatória sobre os $i$ elétrons.

Podemos introduzir um campo magnético em $\mathcal{H}_{0}$ associando o momento linear $\overrightarrow{p_{i}}$ com o momento canônico $\vec{p}=m \vec{v}+q \vec{A}$, onde $\vec{v}$ é a velocidade do elétron e $\vec{A}$ o potencial vetor magnético. Fazendo uma escolha de calibre tal que $\vec{A}(\vec{r})=(\vec{B} \times \vec{r}) / 2$ e associando $\overrightarrow{p_{i}} \rightarrow \vec{p}$ obtemos o Hamiltoniano $(H)$ de um átomo em um campo magnético (detalhes deste cálculo podem ser encontrados em Blundell [32]):

$$
\mathcal{H}=\mathcal{H}_{0}+\frac{e}{2 m_{e} c}(\vec{L}+2 \vec{S}) \cdot \vec{B}+\frac{e^{2}}{8 m_{e} c^{2}} \sum_{i}\left(\vec{B} \times \overrightarrow{r_{i}}\right)^{2} \quad(\mathrm{CGS})
$$

Onde $\vec{B}$ é o campo magnético aplicado, $c$ a velocidade da luz no vácuo, $S$ o spin total do átomo, $L$ o momento angular orbital total, $e$ a carga do elétron e $m_{e}$ sua massa.

\subsubsection{Materiais lineares}

Os materiais lineares podem ser separados pelo sinal de sua susceptibilidade magnética. Os materiais com $\chi$ negativo são chamados de diamagnéticos. O diamagnetismo é uma propriedade presente em todos os materiais, onde um campo magnético aplicado induz no material um momento magnético oposto a este campo. Na ausência de elétrons desemparelhados em um átomo, o segundo termo da equação 2.7 se anula, sobrando apenas o chamado termo diamagnético, considerando sem perda de generalidade $\mathbf{B}=\mathrm{B} \hat{k}$ :

$$
\mathcal{H}=\mathcal{H}_{0}+\frac{e^{2}}{8 m_{e} c^{2}} \sum_{i} B^{2}\left(x_{i}^{2}+y_{i}^{2}\right)
$$

Assumindo que a correção diamagnética é pequena em relação a $H_{0}$ e o átomo possui simetria esférica de modo que $\left\langle x_{i}^{2}\right\rangle=\left\langle y_{i}^{2}\right\rangle=1 / 3\left\langle r_{i}^{2}\right\rangle$ temos que a variação de energia devido ao termo diamagnético em primeira ordem é:

$$
\Delta E=\frac{B^{2} e^{2}}{12 m_{e} c^{2}} \sum_{i}\left\langle 0\left|r_{i}^{2}\right| 0\right\rangle
$$

A magnetização para um número $N$ de momentos magnéticos em um volume $V$ é dada por:

$$
M=-\frac{N}{V} \frac{\delta \Delta E}{\delta B}=-\frac{N}{V} \frac{e^{2} B}{6 m_{e} c^{2}} \sum_{i=1}^{Z}\left\langle r_{i}^{2}\right\rangle
$$

Assumindo $B=\mu_{0} H$, a susceptibilidade magnética é dada por:

$$
\chi_{\text {Dia }}=-\frac{N}{V} \frac{e^{2}}{6 m_{e} c^{2}} \sum_{i=1}^{Z}\left\langle r_{i}^{2}\right\rangle
$$

Vemos que em primeira ordem a susceptibilidade diamagnética de um material é negativa, independente da temperatura e proporcional ao raio atômico e número atômico efetivo dos átomos constituintes. 
Se um átomo possui momento angular total diferente de zero o segundo termo do seu Hamiltoniano como visto na equação 2.7 é não nulo. Como a magnitude deste termo é ordens de grandeza maior que o termo diamagnético estes materiais possuem susceptibilidade magnética positiva e são chamados de paramagnéticos.

A energia de um momento magnético $\vec{\mu}$ imerso em um campo $\vec{B}$ é dada por: $E=-\vec{\mu} \cdot \vec{B}$. Considerando um modelo mais simplificado, onde são permitidas apenas duas energias $(\mu B$ e $-\mu B)$ temos que o valor médio do momento magnético é:

$$
\langle\mu\rangle=\mu P(\mu)+(-\mu) P(-\mu)=1 / Z\left(\mu e^{\mu B / k T}-\mu e^{-\mu B / k T}\right)=\frac{2 \mu}{Z} \operatorname{senh}(\mu B / k T)
$$

Onde a probabilidade $P$ de um estado é dada pelo fator de Boltzmann $Z^{-1} e^{-E / k T}, k$ a denominada constante de Boltzmann. Sendo $Z$ a função de partição do sistema dada por:

$$
Z=e^{\mu B / k T}+e^{-\mu B / k T}=2 \cosh (\mu B / k T)
$$

Portanto a magnetização é dada pela chamada equação de Langevin:

$$
M=N\langle\mu\rangle=N \mu \tanh \left(\frac{\mu B}{k T}\right)
$$

Se $\mu B \ll k T$ temos que $\tanh x \sim x$, portanto:

$$
\vec{M}=\frac{N \mu^{2}}{k} \frac{\vec{B}}{T}
$$

A equação 2.15 é chamada de lei de Curie. $N \frac{\mu^{2}}{k}$, a constante de proporcionalidade entre $\vec{M}$ e $\vec{B} / T$ é chamada de constante de Curie. Esta equação expressa o paramagnetismo como a competição entre o campo e a temperatura no alinhamento de momentos magnéticos, sendo uma boa aproximação em regiões de alta temperatura ou baixo campo.

Um átomo com momento angular total $J$ possui $2 J+1$ níveis de energia possíveis em relação a um campo magnético aplicado o que torna o cálculo acima mais complicado, no entanto a lei de Curie ainda é válida com a constante de Curie $(C)$ dada por:

$$
C=\frac{\mu_{B}^{2}}{3 k} N g^{2} J(J+1) \quad(\mathrm{CGS})
$$

onde $\mu_{B}$ é o magneton de Bohr, $g$ o fator giromagnético do elétron e $J$ o momento angular total.

\subsubsection{Materiais não lineares}

Até agora consideramos apenas a interação de momentos magnéticos isolados com um campo magnético. Pode-se representar a interação entre os momentos em um material através de um campo molecular $\left(B_{M}\right)$. Na teoria introduzida por Weiss, temos que o campo molecular é proporcional à magnetização no material, sendo $\lambda$ a constante de proporcionalidade.

$$
\overrightarrow{B_{M}}=\lambda \vec{M}
$$

de maneira que o campo magnético total é dado por $\vec{B}+\lambda \vec{M}$. A lei de Curie (eq 2.15) com o termo do campo molecular se torna:

$$
\chi=\frac{C}{T}=\frac{M}{B+\lambda M}
$$

que pode ser reescrita como: 


$$
\chi=\frac{C}{T-C \lambda}=\frac{C}{T-T_{c}}
$$

sendo $T_{c}=\mathrm{C} \lambda$ a temperatura crítica do sistema chamada de temperatura de Curie, acima da qual o material se torna paramagnético. A equação 2.19 é conhecida como lei de Curie-Weiss, válida para temperaturas acima de $T_{c}$, assim como na lei de Curie sistemas reais se aproximam da lei de Curie-Weiss em condições de alta temperatura ou baixo campo magnético.

Alguns materiais apresentam alinhamento espontâneo de seus momentos magnéticos, os três tipos básicos de ordenamento espontâneo são o ferromagnetismo, antiferromagnetismo e ferrimagnetismo. A interação que media este ordenamento é conhecida como interação de troca ou exchange em inglês e tem como origem a interação eletrostática entre os elétrons, sujeitos ao princípio de exclusão de Pauli. A energia associada com esta interação é descrita pelo Hamiltoniano de Heisenberg $(H)$ :

$$
H=-2 \sum_{i<j} J_{i j} \overrightarrow{S_{i}} \cdot \overrightarrow{S_{j}}
$$

onde $\vec{S}_{i}$ e $\overrightarrow{S_{j}}$ são os spins totais dos átomos $i$ e $j$ e $J$ uma constante característica da interação.

Se $J>0$ o ordenamento é ferromagnético já que o sistema possui energia mínima para $\overrightarrow{S_{i}}$ e $\overrightarrow{S_{j}}$ com mesmo sentido, o contrário ocorre se $J<0$ e os spins tendem a se alinhar com sentido oposto caracterizando um ordenamento antiferromagnético se $S_{i}=S_{j}$ ou ferrimagnético se $S_{i} \neq S_{j}$.

Ao contrário dos outros tipos de magnetismo, a magnetização dos materiais ferri- e ferromagnéticos não é função de estado em relação ao campo aplicado, dependendo não apenas do estado atual do material mas também de seus estados passados. Portanto a magnetização de um material ferromagnético não pode ser representada como uma função $M(B)$, e deve ser descrita por uma curva de histerese, representada na figura 2.13.

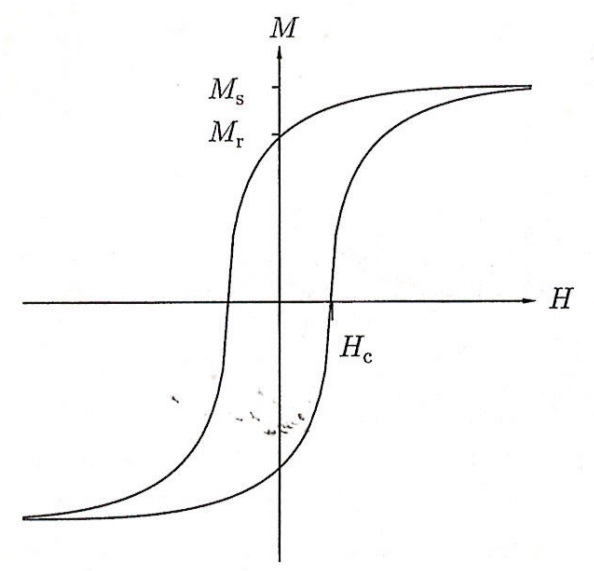

Figura 2.13: Curva de magnetização em função do campo aplicado de um material apresentando histerese. Retirado de Blundell [32].

Submetendo um material ferromagnético desmagnetizado à um campo magnético crescente observa-se um aumento da magnetização proporcional ao campo, atingindo-se uma magnetização máxima chamada de magnetização de saturação $M_{s}$, com a remoção progressiva do campo aplicado, a redução da magnetização não acompanha a redução do campo e quando o campo se anula ainda resta uma dita magnetização remanente $\left(M_{r}\right)$, para que $\mathrm{M}$ se anule é necessária a aplicação de um campo $H_{c}$, conhecido como campo coercivo, estes são os três parâmetros principais característicos de um material ferromagnético. Seguindo-se com o campo no sentido negativo até a saturação e 
removendo-o progressivamente o mesmo comportamento de atraso entre a magnetização e o campo aplicado ocorre, formando assim um ciclo de histerese. $\chi_{T}$ então é definida como a soma das susceptibilidades de todas as contribuições magnéticas presentes em uma amostra.

\subsubsection{SQUID (Superconducting Quantum Interference Device)}

O SQUID é um magnetômetro sensível, capaz de medir momentos magnéticos tão baixos quanto $10^{-7}$ emu. Ele se baseia em um fenômeno quântico conhecido como efeito Josephson que consiste em uma supercorrente $(I)$ percorrendo em dois materiais supercondutores acoplados fracamente através de um isolante fino, conjunto conhecido como junção Josephson. Esta seção expõe parte da teoria desenvolvida na Ref. [33].

Os pares de Cooper responsáveis pelo comportamento supercondutor tem comportamento de bósons, em temperaturas próximas da temperatura absoluta a maioria dos pares se encontram no estado fundamental e podem ser descritos pela mesma função de onda. Aplicando a equação de Schroedinger em cada parte da junção temos:

$$
\begin{aligned}
i \hbar \frac{\delta \psi_{1}}{\delta t} & =H \psi_{1}+K \psi_{2} \\
i \hbar \frac{\delta \psi_{2}}{\delta t} & =H \psi_{2}+K \psi_{1}
\end{aligned}
$$

Onde $\mathrm{H}$ é o operador Hamiltoniano, $\psi_{1}$ e $\psi_{2}$ as funções de onda dos pares de Cooper em cada lado da junção e K uma constante proporcional à corrente. Assumindo que $\psi_{1}$ é auto-função de $H$ temos para uma diferença de potencial $\mathrm{V}$ aplicada:

$$
\begin{aligned}
i \hbar \frac{\delta \psi_{1}}{\delta t} & =(q V / 2) \psi_{1}+K \psi_{2} \\
i \hbar \frac{\delta \psi_{2}}{\delta t} & =(-q V / 2) \psi_{2}+K \psi_{1}
\end{aligned}
$$

Reescrevendo $\psi_{i}=\sqrt{r_{i}} e^{i \phi_{i}}$ e substituindo em 2.22 temos:

$$
\begin{aligned}
\frac{\delta r_{1}}{\delta t} & =\frac{-2 K}{h} \sqrt{r_{1} r_{2}} \operatorname{sen} \phi \\
\frac{\delta r_{2}}{\delta t} & =\frac{2 K}{h} \sqrt{r_{1} r_{2}} \operatorname{sen} \phi
\end{aligned}
$$

Onde q é a carga do elétron, $h$ a constante de Planck, $\phi=\phi_{2}-\phi_{1}$ as fases das funções de onda em cada lado da junção, $r_{i}$ é a densidade de pares de Cooper e $\frac{\delta r_{1}}{\delta t}$ a corrente que atravessa a junção.

Derivando as fases $\phi_{1}$ e $\phi_{2}$ temos:

$$
\begin{aligned}
\frac{\delta \phi_{1}}{\delta t} & =\frac{K}{h} \sqrt{\frac{r_{2}}{r_{1}}} \cos \phi+\frac{q V}{2 h} \\
\frac{\delta \phi_{2}}{\delta t} & =\frac{K}{h} \sqrt{\frac{r_{1}}{r_{2}}} \cos \phi-\frac{q V}{2 h}
\end{aligned}
$$


De 2.24 obtemos $\phi(t)$, somando e integrando ambos os lados:

$$
\phi(t)=\phi_{0}+\frac{q}{h} \int V(t) d t
$$

Um sensor SQUID DC consiste de duas junções Josephson ligadas em paralelo como esquematizado na figura 2.14 .

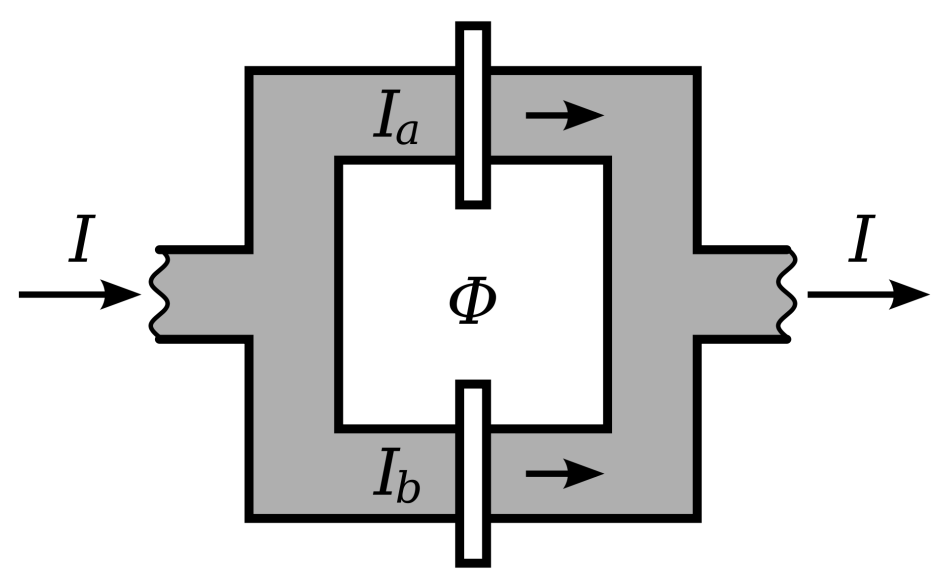

Figura 2.14: Diagrama esquemático do sensor de um SQUID DC.

A diferença de fase entre os dois polos deve ser independente do caminho, portanto aplicando 2.25 para as duas junções e igualando temos que:

$$
\phi=\phi_{b}-\phi_{a}=\frac{2 q}{h} \Phi
$$

Onde $\Phi$ é o fluxo magnético que atravessa o dispositivo.

Definindo $\phi_{0}$ como $\phi_{a}=\phi_{0}+\frac{q}{h} \Phi$ e $\phi_{b}=\phi_{0}-\frac{q}{h} \Phi$ temos de 2.23 que:

$$
I=\operatorname{sen}\left(\phi_{0}\right) \cos \left(\frac{q \Phi}{h}\right)
$$

Assim vemos que a corrente de tunelamento oscila em função do fluxo magnético com período $h / q$, sendo esse o princípio básico que permite a medição de fluxo magnético através de um sensor SQUID DC.

Um magnetômetro SQUID modelo Cryogenics S600 foi utilizado na caracterização magnética das amostras deste estudo. Este sistema incorpora um sensor SQUID DC e uma bobina supercondutora fornecendo campos de até $6.5 \mathrm{~T}$ dentro de um criostato à He líquido que possibilita a realização de medidas em temperaturas de 2 a $300 \mathrm{~K}$. Um esquema do magnetômetro é apresentado na figura 2.15 .

A cada mudança no campo ou temperatura da amostra o sistema necessita de um tempo, maior ou menor, para atingir condições de medida no novo estado. O tempo de estabilização da temperatura é basicamente fixo e depende apenas da temperatura inicial e final do sistema. 


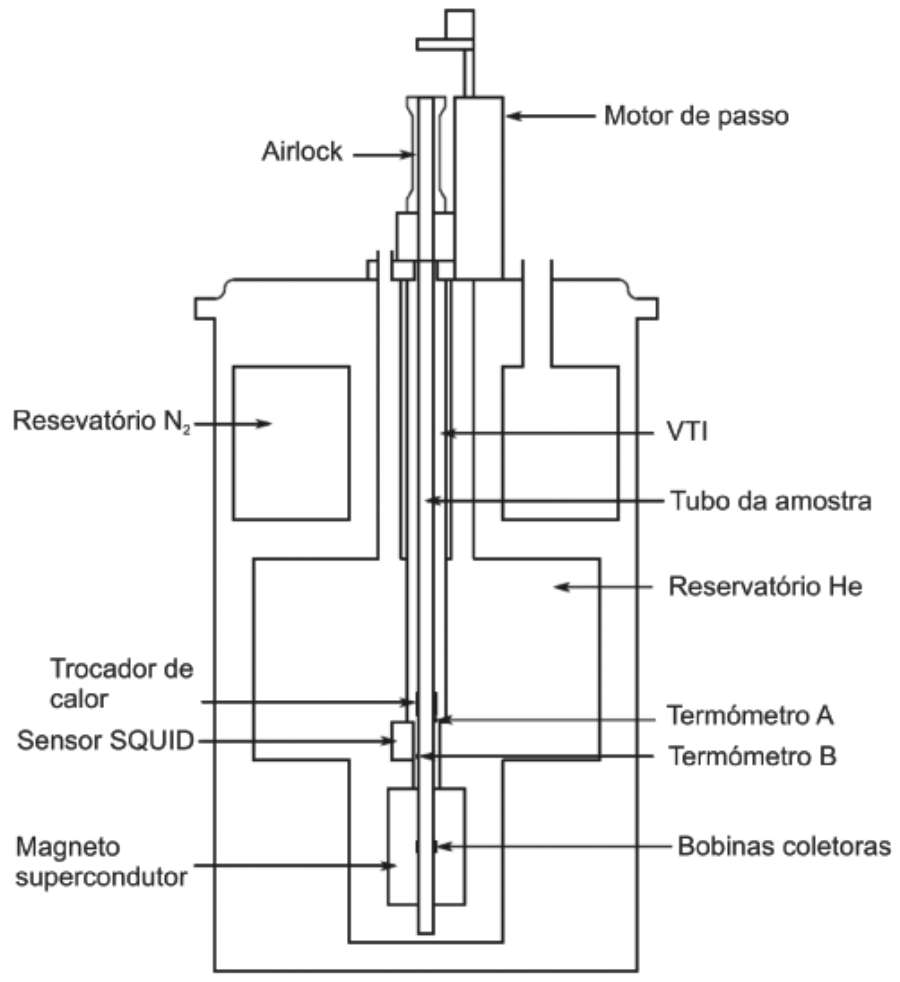

Figura 2.15: Esquema do sistema SQUID Cryogenics S600.

Já a estabilização do campo depende fortemente do sinal magnético da amostra. Em regiões de campo com momentos magnéticos próximos ao zero o sistema pode levar horas para alcançar as condições de estabilidade usualmente estabelecidas. Este problema afeta especialmente as amostras analisadas já que o momento magnético das mesmas é baixo, tipicamente da ordem de $10^{-5}$ emu. Para manter um tempo aceitável de medida é introduzida uma nova restrição que força a medição do ponto após um determinado tempo de espera, usualmente 30 minutos. Em todas as medidas o campo magnético foi aplicado em direção paralela ao plano das amostras.

\subsubsection{Análise dos dados magnéticos}

Da medição de uma amostra no SQUID em um determinado campo e temperatura obtém-se como resultado o momento magnético total: a soma das contribuições de cada forma de magnetismo presente na amostra. No caso geral observamos as respostas dia-, para- e ferromagnéticas. Dois tipos básicos de medidas foram realizados para a caracterização magnética das amostras: magnetização em função do campo com temperatura fixa e em função da temperatura com campo fixo. A medida em função do campo é geralmente a primeira a ser realizada, ela é útil pois apresenta um panorama geral da amostra, evidenciando cada tipo de magnetismo. As medidas em função da temperatura são importantes principalmente por serem descritas pela equação de Curie-Weiss e portanto são úteis para um estudo mais detalhado do paramagnetismo, outro tipo de medida em função da temperatura utilizada foi a zero-field-cooled - field-cooled (ZFC-FC), usada para a deteção de fenômenos magnéticos irreversíveis.

Geralmente é possível a extração do sinal referente a cada forma de magnetismo. A saturação do ferromagnetismo das amostras estudadas ocorre sempre abaixo de $10 \mathrm{kOe}$, desta maneira apenas dia- e paramagnetismo, ambos efeitos lineares, influenciam a variação do momento magnético em altos campos. Assim, de uma medida em função do campo, extrai-se o sinal referente ao ferro- 
magnetismo através da subtração da contribuição linear, obtida através de ajuste linear acima do campo de saturação. Optou-se por não realizar esta subtração para a apresentação nos dados do presente trabalho já que a mesma não é necessária e introduz ruido nas medidas. Sendo o diamagnetismo independente da temperatura, o paramagnetismo é extraído da parte linear através de medidas em diferentes temperaturas. O restante não é necessariamente diamagnetismo, Bonanni et al. [34] mostraram a existência de paramagnetismo de Van-Vleck, independente da temperatura, em amostras de h-GaN dopadas com Fe. O ferromagnetismo também pode ser extraído das medidas em função da temperatura, para isso realizam-se medidas em dois ou mais campos nos quais o ferromagnetismo da amostra tenha atingido a saturação. Para cada temperatura a magnetização de saturação $\left(\mathrm{M}_{s}\right)$ é obtida pelo cruzamento do ajuste linear dos dados em função do campo com o eixo da magnetização, o mesmo procedimento utilizado para obtenção de $\mathrm{M}_{s}$ nas medidas em função do campo, porém com número reduzido de pontos (2-3 tipicamente) sendo assim pouco preciso. A diferença entre as medidas nos dois campos dividida pela diferença entre os campos nos fornece a susceptibilidade magnética corrigida para o ferromagnetismo $\left(\chi_{\text {corr }}\right)$. Nas análises das medidas em função da temperatura foram ajustadas equações de Curie-Weiss para a obtenção da constante de Curie, no entanto informação sobre a temperatura crítica $\left(T_{c}\right)$ é perdida devido a incerteza na obtenção de $\chi_{\text {Dia para remoção. }}$

A determinação da incerteza nos ajustes das magnetizações de saturação se tornou complicada pelo fato de os erros padrão obtidos pelo ajuste linear serem fortemente subestimados. O limite de magnetização para deteção de ferromagnetismo foi estabelecido em $2 \times 10^{-4} \mathrm{emu} / \mathrm{g}$, com o critério de que esse foi o maior valor de magnetização encontrado em uma amostra referência. A natureza ferromagnética de uma amostra pode ser demonstrada com maior precisão através do sinal da magnetização obtidas em medidas em baixo campo aplicado (100 Oe tipicamente) altamente estabilizado. O sistema CGS foi utilizado na análise dos dados magnéticos. Essa escolha foi feita tendo em vista que este é o sistema utilizado por quase toda a literatura da área e portanto facilita a comparação de dados. A tabela 2.4 apresenta os fatores de conversão das unidades mais utilizadas para o SI.

\begin{tabular}{|c|c|}
\hline Grandeza & Fator de conversão \\
\hline Campo magnético & $1 \mathrm{~A} / \mathrm{m}=4 \pi / 10^{3} \mathrm{Oe}$ \\
Momento magnético & $1 \mathrm{Am}^{2}=10^{3} \mathrm{emu}$ \\
Magnetização por massa & $1 \mathrm{Am}^{2} / \mathrm{kg}=1 \mathrm{emu} / \mathrm{g}$ \\
Susceptibilidade por massa & $1 \mathrm{~m}^{3} / \mathrm{kg}=10^{3} / 4 \pi \mathrm{emu} /$ Oe.g \\
\hline
\end{tabular}

Tabela 2.4: Fatores de conversão do CGS para o SI de algumas grandezas magnéticas. 


\section{Capítulo 3}

\section{Simulação de implantação iônica}

\subsection{Introdução}

Com o aumento da capacidade de processamento dos computadores no final do século 20 tornouse possível a simulação computacional de processos de implantação iônica em um intervalo cada vez maior de energia. Além da capacidade computacional os modelos utilizados nos cálculos evoluíram, melhorando de maneira geral a precisão dos resultados obtidos.

As duas técnicas mais utilizadas atualmente são a aproximação de colisão binária $(B C A$, em inglês) [35] e métodos de dinâmica molecular [36], utilizadas pelos programas SRIM (Stopping and Range of Ions in Matter) e MDRANGE respectivamente. Esses softwares fornecem informações importantes sobre o processo: profundidade final dos íons implantados (perfil de implantação), energia depositada em função da profundidade e nos programas que levam em conta a rede cristalina, a influência no processo do ângulo de incidência do feixe em relação a rede cristalina. Usamos a palavra íons no texto referindo-se aos projéteis incidentes, os átomos do material a ser implantado designamos átomos-alvo ou simplesmente átomos.

Várias teorias físicas foram desenvolvidas para descrever o processo de interação de íons com a matéria. A descrição dos processos de perda de energia dos íons na matéria é útil para uma maior compreensão do processo de implantação.

\subsection{Perda de energia}

Com intuito de facilitar o estudo do processo de implantação iônica foi inicialmente proposta por Bohr [37] a separação entre a perda de energia nuclear e eletrônica. A parte nuclear diz respeito à transferência de energia entre o íon e átomo e se dá predominantemente por colisões elásticas, já a parte eletrônica diz respeito às colisões predominantemente inelásticas entre os íons e os elétrons dos átomos. Esta é uma aproximação razoável pois a interação do íon com os elétrons, ocorre quase que instantemente em comparação à interação com os núcleos, o que nos permite analisar os dois fenômenos separadamente.

Podemos expressar essa separação através do poder de freamento (ou stopping power, em inglês) do material, definido como a variação da energia do íon por unidade de comprimento e portanto possuindo unidade de força. Separando os termos nuclear e eletrônico do poder de freamento total temos:

$$
-\frac{d E}{d x}=-\left(\left.\frac{d E}{d x}\right|_{\text {nuclear }}+\left.\frac{d E}{d x}\right|_{\text {eletrônico }}\right)
$$

$-\frac{d E}{d x}$ é o poder de freamento total, sendo o sinal menos convencional para que a variação seja positiva. 
Vemos na figura 3.1 os poderes de freamento eletrônico e nuclear em função da energia do feixe para implantação de Fe em GaN, calculados pelo software SRIM. Devido à proximidade das massas atômicas, resultados semelhantes são obtidos para implantação de $\mathrm{Mn}$ e Cu.

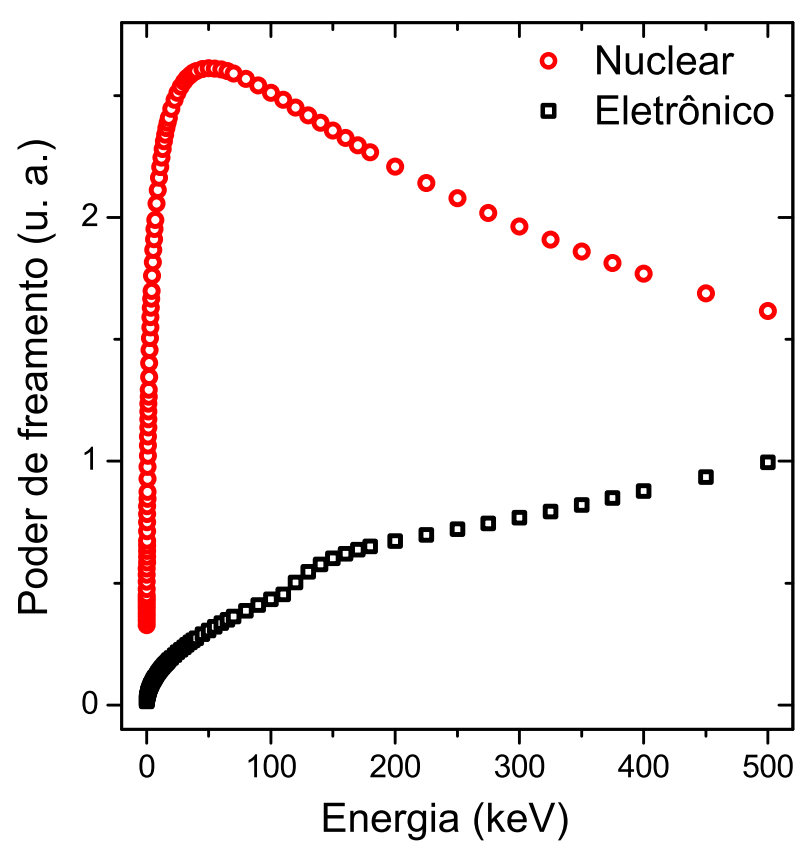

Figura 3.1: Poder de freamento eletrônico e nuclear em função da energia do feixe de íons para o GaN implantado com Fe. Calculados pelo software SRIM.

A perda de energia eletrônica é igual à transferência de energia para a nuvem eletrônica do material devida à interação coulombiana com o íon incidente. A derivação do poder de freamento eletrônico teve início com a teoria de Bohr que considera a colisão de um projétil carregado com um elétron ligado. Bethe posteriormente adicionou correções relativísticas ao modelo que contou também com contribuição de Bloch. Na década de 70 e 80 modelos ditos semi-empíricos foram criados, conectando dados experimentais disponíveis à teoria. O principal deles é o modelo ZBL (Ziegler, Biersack, Littmark) que se baseia na extrapolação para qualquer íon em meio sólido ou gasoso de dados precisos obtidos no freamento de prótons e átomos de $\mathrm{He}$ em alvos leves, este é o modelo utilizado para o cálculo do poder de freamento eletrônico pelos softwares SRIM e MDRANGE.

Sendo a perda de energia nuclear o mecanismo de freamento principal na energia de $200 \mathrm{keV}$ utilizada nas implantações deste trabalho, convém uma descrição mais detalhada da física do processo.

\subsection{Perda de energia nuclear}

Sabemos que nas energias em questão colisões inelásticas entre os íons incidentes e os núcleos do material são pouco prováveis. Desprezando as colisões dissipativas podemos descrever esse processo através de uma teoria clássica de espalhamento por forças centrais. Utilizando as coordenadas em relação ao centro de massa do sistema, podemos escrever as equações do movimento de uma forma 
mais concisa. Temos da literatura [35] que a energia transferida para o átomo-alvo durante a colisão é dada por:

$$
T=\frac{4 M_{1} M_{2}}{\left(M_{1}+M_{2}\right)^{2}} E_{0} \operatorname{sen}^{2}\left(\frac{\Theta}{2}\right)
$$

onde $M_{1}$ e $M_{2}$ são as massas dos átomos interagentes, $E_{0}$ a energia inicial do íon, e $\Theta$ o ângulo de espalhamento no referencial do centro de massa.

Sendo o processo conservativo, temos pela conservação da energia no referencial do centro de massa:

$$
E=\frac{\mu}{2}\left(\dot{r}^{2}+r^{2} \dot{\Theta}^{2}\right)+V(r)
$$

$\mu=\frac{M_{1} M_{2}}{M_{1}+M_{2}}$ é a massa reduzida do sistema e $V(r)$ o potencial de interação entre os átomos, dependente apenas da distância entre eles.

Pela conservação do momento angular temos, em função da velocidade inicial do íon $v_{0}$ e do parâmetro de impacto $b$ :

$$
\begin{aligned}
& L=\mu r^{2} \dot{\Theta} \\
& L=\mu v_{0} b
\end{aligned}
$$

De (3.4) e (3.5) temos que:

$$
\dot{\Theta}=\frac{v_{0} b}{r^{2}}
$$

substituindo $\dot{\Theta}$ em (3.3) e resolvendo para $\dot{r}$ obtemos a equação do movimento radial:

$$
\dot{r}=v_{0} \sqrt{1-\frac{V(r)}{E}-\left(\frac{b}{r}\right)^{2}}
$$

Pela regra da cadeia $\frac{d \Theta}{d r}=\frac{d \Theta}{d t} \frac{d t}{d r}=\frac{\dot{\Theta}}{\dot{r}}$, portanto:

$$
\frac{d \Theta}{d r}=\frac{b}{r^{2} \sqrt{1-\frac{V(r)}{E}-\left(\frac{b}{r}\right)^{2}}}
$$

Integrando em $r$ obtemos a equação para o ângulo final de espalhamento $\Theta$ em função do parâmetro de impacto $b$, da energia inicial do íon $E$ e do potencial $V(r)$ :

$$
\Theta=\pi-2 \int_{r_{\min }}^{\infty} \frac{b}{r^{2} \sqrt{1-\frac{V(r)}{E}-\left(\frac{b}{r}\right)^{2}}} d r
$$

Podemos relacionar essas expressões com o poder de freamento nuclear através da relação:

$$
-\frac{d E}{d x}=\rho_{a t} S_{n u c}(E)
$$

onde $\rho_{a t}$ é a densidade atômica do material e $S_{n u c}$ a seção de choque diferencial devido a interação com os núcleos:

$$
S_{n u c}=2 \pi \int T(b) b d b
$$


Sendo assim $S_{n u c}$ a energia média transferida para o átomo-alvo sobre todos os parâmetros de impacto.

Temos então as equações necessárias para o cálculo da energia transferida pelos íons para os núcleos dos átomos-alvo, do ângulo de deflexão e do poder de freamento nuclear, mas ainda precisamos de um potencial de interação interatômico $V(r)$.

Uma primeira aproximação para o potencial seria o de Coulomb $V_{c}=\frac{Z_{1} Z_{2} e^{2}}{r}$, sendo $Z_{1}$ e $Z_{2}$ o número atômico dos átomos envolvidos e $e$ a carga do elétron. Esse modelo não seria válido para átomos multieletrônicos pois os elétrons das camadas externas são tanto atraídos pelas cargas do núcleo positivo, quanto repelidos pelos elétrons internos com efeito de atenuação do potencial, processo conhecido como blindagem. O potencial externo seria então, não o potencial coulombiano mas um potencial reduzido, dito blindado.

Um modelo utilizado por programas de implantação iônica consiste em definir o potencial interatômico como o coulombiano multiplicado por uma função de blindagem $\phi$, assumindo simetria esférica para o potencial.

$$
V(r)=V_{c} \phi(r)
$$

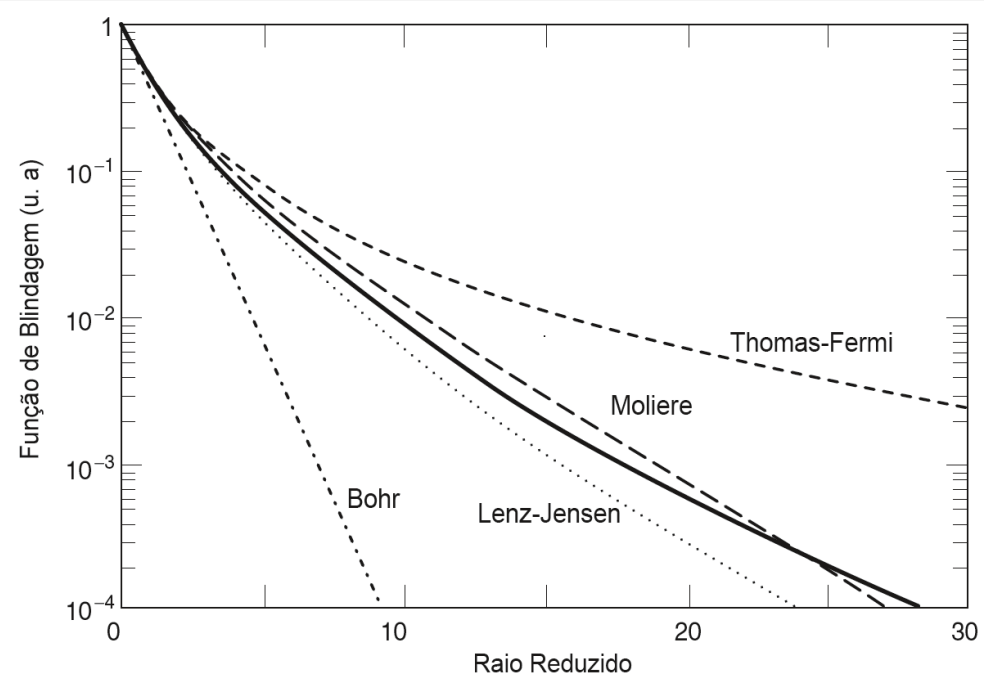

Figura 3.2: Função de blindagem universal (linha sólida) em função do raio reduzido comparada com outras funções de blindagem históricas. Adaptado de [38].

Historicamente várias fórmulas foram propostas para a função de blindagem, começando pelo potencial do átomo de Bohr onde $\phi$ é simplesmente $e^{-\frac{r}{a_{0}}}$, sendo $a_{0}$ o raio de Bohr. Atualmente é utilizada uma função analítica conhecida como universal. Essa função foi obtida calculando-se por métodos numéricos potenciais para diversos pares de átomos e posteriormente ajustando uma curva aos dados obtidos. Comparando-se os resultados previstos pela função universal com potenciais determinados experimentalmente, pôde-se concluir que o desvio padrão teórico-experimental médio é de aproximadamente $5 \%$ [35], inferior a modelos anteriores.

A função universal, plotada na figura 3.2, utilizada para o cálculo do poder de freamento nos softwares SRIM e MDRANGE, é dada por:

$$
\phi(x)=0.1818 e^{-3.2 x}+0.5099 e^{-0.9432 x}+0.2802 e^{-0.4028 x}+0.02817 e^{-0.2016 x}
$$

onde x é uma variável adimensional conhecida como raio reduzido. 


$$
x=\frac{r}{a_{U}} \quad a_{U}=0.8854 \frac{a_{0}}{Z_{1}^{0.23}+Z_{2}^{0.23}}
$$

Sendo $Z_{i}$ o número atômico dos átomos e $a_{0}$ o raio de Bohr. A escala da função de blindagem depende das cargas dos átomos envolvidos.

Vemos que o nome perda de energia nuclear é enganoso pois, de fato, a interação do íon se dá com o núcleo através do seu potencial blindado, ou seja com o átomo como um todo.

\subsection{Estatística de distribuição de íons}

Um esquema simplificado em duas dimensões da implantação de um íon é mostrado na figura 3.3. O processo de implantação é estocástico, sendo que íons incidentes com os mesmos parâmetros de implantação se depositam, em geral, em regiões diferentes. Na interação com cada átomo-alvo, a direção de movimento do íon é geralmente alterada, criando uma trajetória irregular. O alcance $(R)$ de um íon, dado pelo comprimento da sua trajetória geralmente não é relevante, já que íons com mesmo alcance podem ser depositados em profundidades muito distintas. Utiliza-se ao invés de $R$ o alcance projetado $(x)$ definido como a projeção do vetor deslocamento do íon no eixo de incidência do feixe.

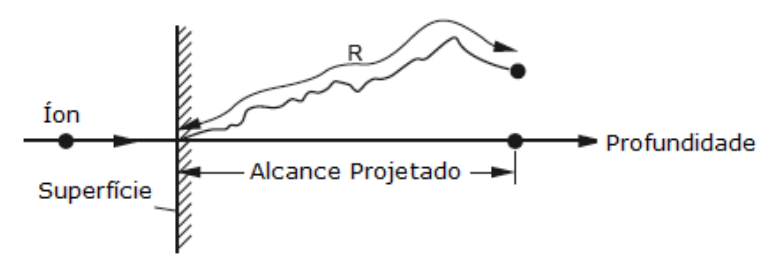

Figura 3.3: Esquema simplificado da implantação de um íon em duas dimensões.

Implantando-se $\mathrm{N}$ íons o alcance médio é dado por:

$$
R_{p}=\left(\sum_{i=0}^{N} x_{i}\right) / N
$$

Pode-se também definir um alcance radial, que indica o desvio médio dos íons nas componentes perpendiculares à do feixe $(y$ e $z)$.

$$
R_{\text {rad }}=\sum_{i=0}^{N} \sqrt{y_{i}{ }^{2}+z_{i}^{2}} / N
$$

Em um modelo simplificado pode-se descrever o perfil de implantação através de uma gaussiana:

$$
N(x)=\frac{D_{i m p}}{\Delta R_{p} \sqrt{2 \pi}} \exp \left[-\frac{1}{2}\left(\frac{x-R_{p}}{\Delta R_{p}}\right)^{2}\right]
$$

onde $D_{i m p}$ é a dose implantada e $\Delta R_{p}$ é o desvio padrão do alcance médio ou straggling, definido como:

$$
\Delta R_{p}=\sqrt{\sum_{i=0}^{N}\left(x_{i}-R_{p}\right)^{2} / N}
$$


Praticamente, o perfil não é uma gaussiana, sendo a cauda do interior do material, menos alongada que a da superfície. A assimetria do perfil de implantação é dada por:

$$
\gamma=\sum_{i=0}^{N}\left(x_{i}-R_{p}\right)^{3} / N \Delta R_{p}{ }^{3}
$$

esse parâmetro $\gamma$ é conhecido como skewness em inglês e numa gaussiana vale zero, aumentando proporcionalmente com a assimetria da curva.

\subsection{Resultados}

Foram realizadas simulações de implantação iônica pelos softwares SRIM e MDRANGE. No software SRIM foram simuladas implantações com Fe, $\mathrm{Mn}$ e $\mathrm{Cu}$ em GaN. Já nas simulações no MDRANGE apenas o íon Mn foi estudado mas espera-se que os resultados sejam semelhantes para os íons $\mathrm{Fe}$ e $\mathrm{Cu}$ já que os três íons possuem massa atômica semelhante. Assim como na implantação real a energia inicial dos íons a serem implantados foi de $200 \mathrm{keV}$. No MDRANGE a estrutura cristalina utilizada para o GaN foi a cúbica (zincblende), já para o SRIM não há diferença entre as duas formas alotrópicas já que as suas densidades são iguais.

\subsubsection{SRIM}

O SRIM é software padrão para simulação de implantação iônica. Ele utiliza métodos de Monte Carlo e diversas aproximações para resolver numericamente as equações de movimento descritas na seção 3.3, em cada colisão do íon com os átomos-alvo, obtendo a sua trajetória e energia depositada dentro do material. A simulação é realizada íon a íon para um determinado número de íons $\left(10^{5}\right.$ tipicamente), de modo que os dados sejam estatisticamente relevantes. A versão SRIM2008.4 foi utilizada para os cálculos.

O SRIM não leva em conta a estrutura cristalina do sólido implantado, apenas a sua densidade ${ }^{1}$, os átomos constituintes e a sua estequiometria são utilizados nos cálculos. Assim, não é possível o estudo da influência do ângulo de incidência do feixe no material, já que o sólido é considerado amorfo.

Vários resultados sobre a física do processo de implantação podem ser obtidos, mas para a interpretação dos dados gerados pelo programa é necessário ter em mente as suas limitações. Primeiramente colisões provenientes de íons distintos são tratadas como independentes, ou seja, eventos causados por íons anteriores não influenciam a medida para íons posteriores. Essa aproximação é chamada implantação a dose zero. A outra limitação importante é que os cálculos são realizados a $T=0$, os efeitos térmicos como difusão e reordenamento da rede durante a implantação, que podem ser muito relevantes, são ignorados. Todos os perfis foram obtidos com $10^{5}$ íons simulados.

A figura 3.4 mostra perfis de implantação (íons depositados em função da profundidade) de Fe, $\mathrm{Mn}$ e $\mathrm{Cu}$ em nitreto de gálio a $200 \mathrm{keV}$.

A unidade do eixo y do perfil gerado pelo SRIM $(1 / \mathrm{cm})$ se mostra conveniente pois é independente da dose implantada. A concentração real de íons na amostra $\frac{i o n s}{\mathrm{~cm}^{3}}$ é obtida multiplicando-se os valores pela dose implantada na unidade $\frac{1}{\mathrm{~cm}^{2}}$. Essa separação só é possível devido à aproximação de dose zero, assim os valores de densidade e concentração do eixo y variam linearmente com a dose, por exemplo: para obter a concentração das amostras implantadas com dose $1.2 \times 10^{16} \mathrm{~cm}^{-2}$ dividiríamos por dois o valor do eixo y esquerdo na figura 3.4. Sabendo a dose e a densidade atômica do material implantado, podemos determinar a porcentagem atômica de íons implantados em função da profundidade.

\footnotetext{
${ }^{1} \mathrm{~A}$ densidade para o GaN utilizada em todos os cálculos foi de $6.15 \frac{\mathrm{g}}{\mathrm{cm}^{3}}$
} 


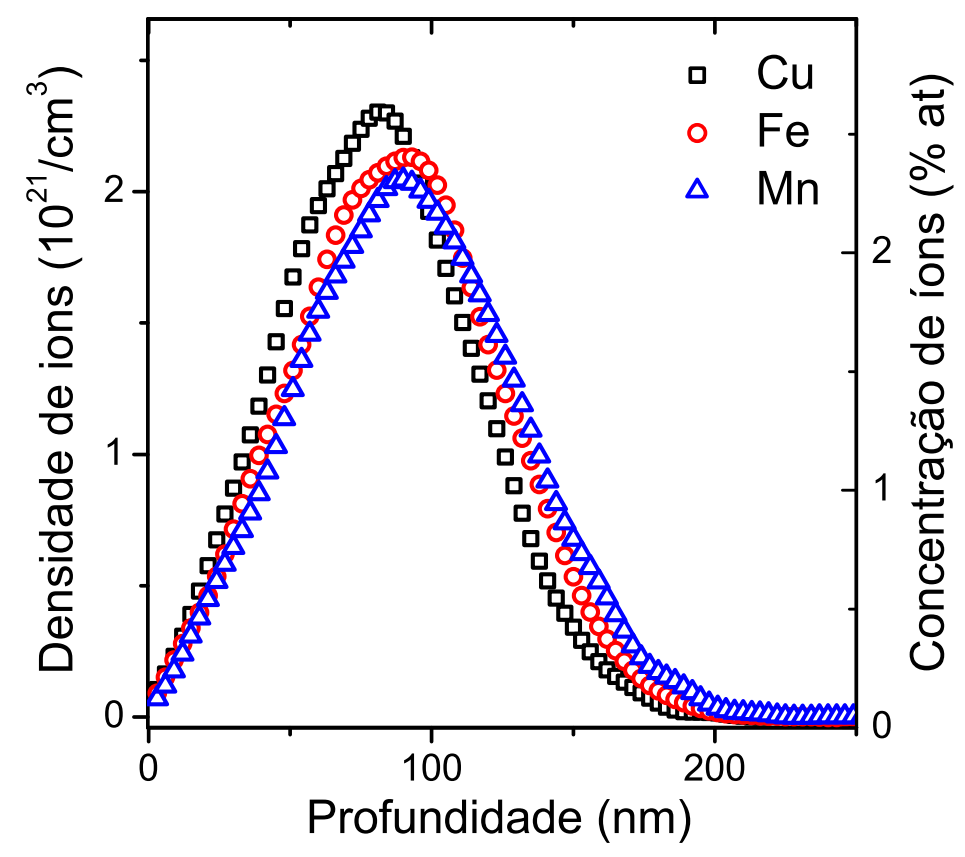

Figura 3.4: Perfis de implantação de Fe, Mn e Cu em GaN para energia de feixe de $200 \mathrm{keV}$ e dose implantada $2.4 \times 10^{16} \mathrm{~cm}^{-2}$ em função da densidade e concentração atômica de íons. Obtido com $10^{5}$ íons simulados pelo SRIM.

A simulação pelo SRIM também fornece a energia depositada no material pelos íons em função da profundidade, esses dados podem ser utilizados para uma estimativa das mudanças causadas pela implantação. A deposição de energia é dividida em três partes: perda de energia para a ionização dos elétrons do material, para formação de vacâncias e para excitação de fônons.

A maior parte da energia inicial dos íons é absorvida pelo material na forma de fônons. Para os íons estudados na implantação à $200 \mathrm{keV}$ aproximadamente $60 \%$ da energia inicial dos íons é convertida em fônons.

O programa também fornece dados sobre a criação de vacâncias durante a implantação. Cada átomo-alvo deslocado com energia superior à energia de deslocamento limiar (da ordem de $10 \mathrm{eV}$ ) pode por sua vez deslocar outros íons criando-se um efeito em cascata. Como um íon incidente provoca da ordem de centena de deslocamentos, são os átomos-alvo deslocados que depositam a maior parte da energia no material. A simulação não leva em conta diversos processos de annealing dinâmico como aniquilação de defeitos e formação de aglomerados. Caracterizações de amostras de GaN implantadas baseadas em técnicas de quantificação de defeitos RBS/C e XTEM indicam um forte grau de annealing dinâmico em diversas condições de implantação [39], assim espera-se que a densidade de defeitos obtida por simulação seja superestimada, embora a forma da curva seja aproximadamente correta [40], falhando principalmente na previsão de defeitos conhecidos em inglês como end of range ou EOR, uma camada de alta concentração de defeitos que se forma próxima ao alcance máximo.

Por último, a energia depositada pelos íons em processos de ionização dos átomos-alvo é proporcional ao poder de freamento eletrônico, assim como as energias depositadas para a formação de vacâncias e fônons estão associadas ao poder de freamento nuclear. De acordo com as simulações cerca de $20 \%$ da energia dos íons é depositada em processos de ionização, resultado coerente com os 
valores (em $200 \mathrm{keV}$ ) encontrados na figura 3.1, referente à variação dos poderes de freamento em função da energia do feixe incidente, que por sua vez estão em acordo com experimentos realizados em uma ampla gama de energias [35]. Vemos na figura 3.5 os perfis de energia total depositada e energia depositada na produção de vacâncias, simulados pelo software SRIM para implantação de Fe em GaN na energia de $200 \mathrm{keV}$.

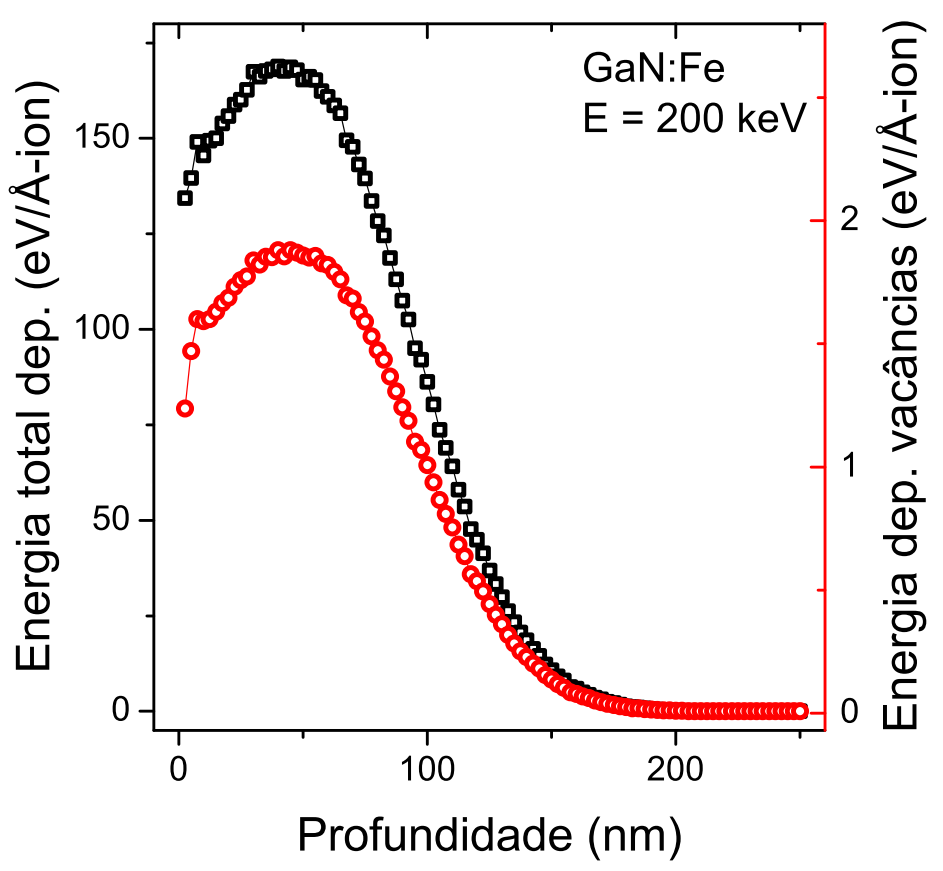

Figura 3.5: Perfis de deposição de energia total e de energia para criação de vacâncias para simulação de implantação de Fe em GaN na energia de $200 \mathrm{keV}$. Obtido com $10^{5}$ íons simulados pelo SRIM.

Um resumo dos resultados obtidos nas simulações realizadas pelo software SRIM encontra-se na tabela 3.1.

\begin{tabular}{|c|c|c|c|c|}
\hline Íon & Alc. Proj. Médio $(\mathrm{nm})$ & Straggling $(\mathrm{nm})$ & Alc. Radial Médio $(\mathrm{nm})$ & $\gamma$ \\
\hline $\mathrm{Fe}$ & 87 & 35 & 39 & 0.15 \\
$\mathrm{Mn}$ & 91 & 38 & 42 & 0.15 \\
$\mathrm{Cu}$ & 80 & 34 & 36 & 0.25 \\
\hline
\end{tabular}

Tabela 3.1: Estatística da distribuição de íons ( $\mathrm{Fe}, \mathrm{Mn}$ e $\mathrm{Cu}$ ) obtidos por simulação de implantação em GaN pelo software SRIM na energia de $200 \mathrm{keV}$.

\subsubsection{MDRANGE}

O MDRANGE é um software que utiliza métodos de dinâmica molecular (MD), para simular a implantação de íons em materiais. Uma das vantagens do programa é que a estrutura cristalina do material é fornecida ao programa átomo por átomo, e o ângulo de incidência do feixe iônico pode ser alterado, tornando possível o estudo do efeito de canalização de íons ou ion channeling em 
inglês. O MDRANGE também realiza a simulação íon a íon usando a aproximação de implantação a dose zero, a precisão nos dados gerados é proporcional ao número de íons simulados.

A figura 3.6 mostra uma estrutura cristalina do tipo Zincblende, vista por três direções: a) "randômica", ângulo onde não se formam canais; b) planar, onde planos da rede se alinham gerando canais planos; e c) axial, onde faces das células unitárias se alinham formando canais aproximadamente cilíndricos.
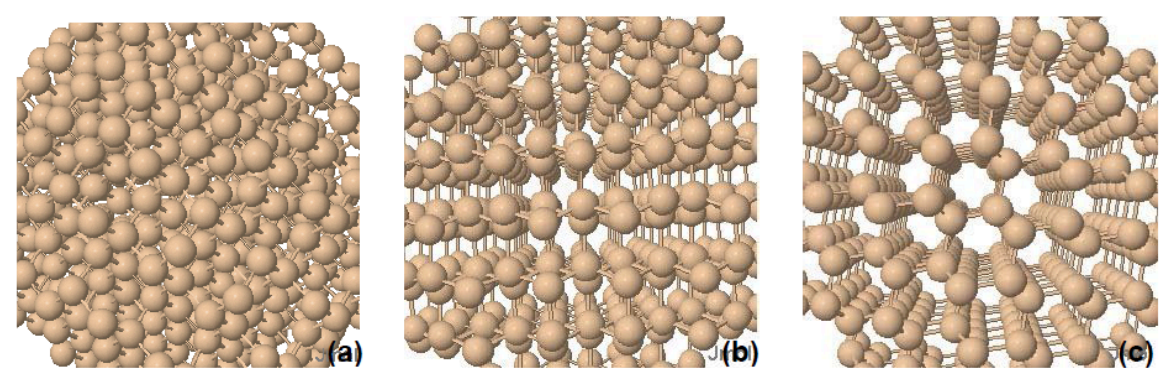

Figura 3.6: Rede direta da blenda de zinco vista de três direções diferentes: a) direção randômica, b) $\perp(112)$, c) $\perp$ (110). Figura renderizada com o software JMol, com os átomos de Ga e N igualmente representados para maior clareza.

A implantação pode ser realizada com o feixe de íons em direções nas quais existam canais, como por exemplo a direção [112] do c-GaN forma canais planos (como os da figura 3.6b) e a direção [110] forma canais aproximadamente cilíndricos (figura 3.6c). Quando um íon incide frontalmente em um canal a interação com os átomos se dá de forma rasante. Nesse tipo de interação, o campo de Coulomb blindado geralmente é suficiente para mudar a trajetória do íon de modo que ele permaneça dentro do canal [38], com isso as colisões de alta transferência de energia com os núcleos é desfavorecida, aumentando o alcance médio dos íons que participam desse processo.

Mesmo incidindo em ângulos oblíquos, os íons ainda podem entrar em canais como esquematizado na figura 3.7 .

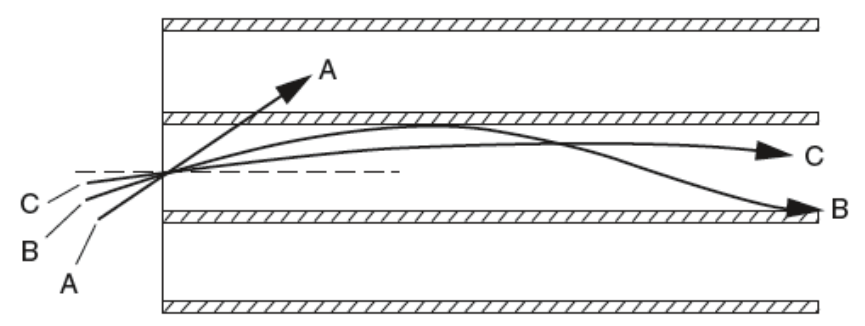

Figura 3.7: Esquema de trajetória com incidência oblíqua em canais. Retirado de [38].

Esse fenômeno diminui com o aumento do ângulo até um valor crítico $\left(\theta_{c}\right)$ onde o perfil corresponde aproximadamente a implantação em um sólido amorfo. Na figura 3.7 o ângulo de implantação do íon $\mathrm{A}$ é maior que $\theta_{c}$ enquanto os ângulos de $\mathrm{B}$ e $\mathrm{C}$ são menores. Encontramos na literatura um valor de $\theta_{c}=7^{\circ}$ para a implantação de $\mathrm{Mn}$ em GaN [41]. Espera-se que nessa condição, os canais perpendiculares aos planos (100) não sejam utilizados, e que o material possa ser considerado como amorfo durante a implantação.

A figura 3.8 mostra os perfis de implantação de Mn em c-GaN para uma incidência de feixe perpendicular aos planos (110), que formam canais cilíndricos, aos planos (112) que formam canais planos e a um ângulo randômico $\left(\theta=7^{\circ}\right)$. A energia dos íons implantados foi de $200 \mathrm{keV}$.

Os valores médios de alcance estão na tabela 3.2 . 


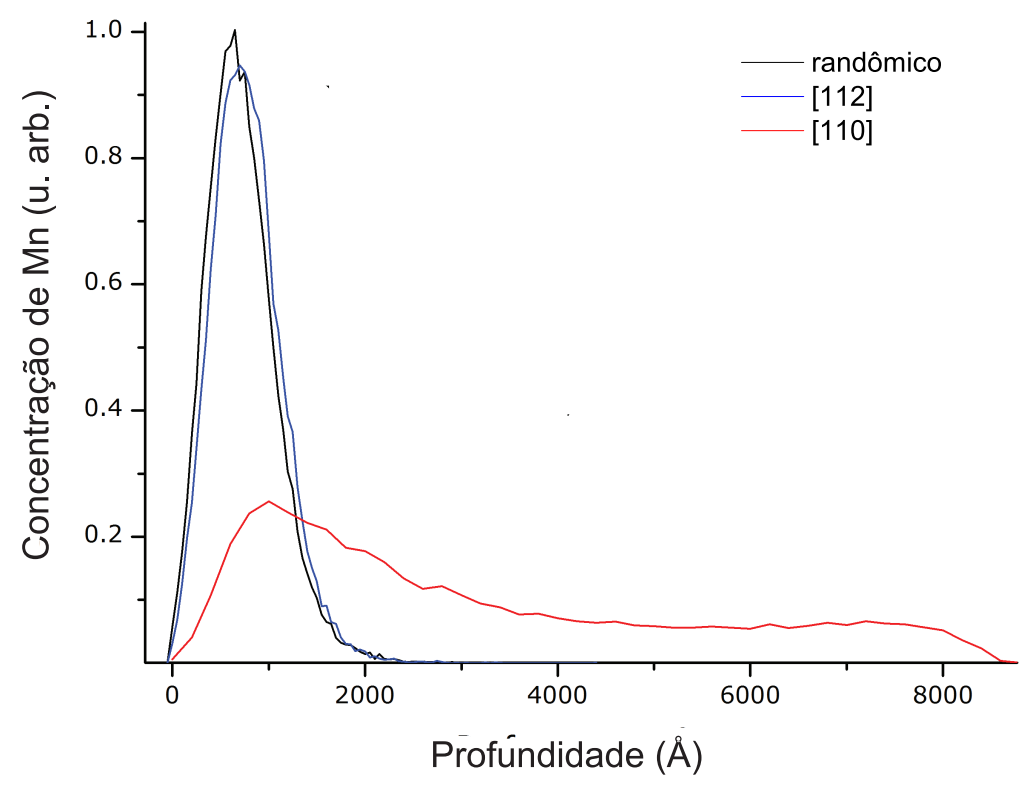

Figura 3.8: Perfis de implantação de Mn em c-GaN com feixes incidentes em uma direção randômica, perpendicular aos planos (112) e aos (110) com energia de $200 \mathrm{keV}$, calculados pelo MDRANGE.

\begin{tabular}{|c|c|c|}
\hline Ângulo & Alc. Proj. Médio $(\mathrm{nm})$ & Straggling $(\mathrm{nm})$ \\
\hline randômico & 84 & 33 \\
$\perp(112)$ & 89 & 36 \\
$\perp(110)$ & 318 & 227 \\
\hline
\end{tabular}

Tabela 3.2: Alcances médios e straggling obtidos em simulações de implantação de Mn em c-GaN pelo software MDRANGE, para alguns ângulos de incidência e energia do feixe de $200 \mathrm{keV}$.

Observou-se que na implantação em ângulo randômico os resultados obtidos com o MDRANGE foram compatíveis com a simulação do SRIM. Já na simulação de implantação com feixe perpendicular aos planos (110), situação mostrada na figura 3.6c observou-se que uma grande parte dos íons utiliza canais. O alcance médio é mais de quatro vezes maior do que a implantação em um ângulo randômico. Porém, o algoritmo do MDRANGE também utiliza a aproximação de implantação a dose zero, essa aproximação leva a valores de alcance médio superestimados, em configurações de implantação com alta probabilidade de canalização. Uma explicação para esse fenômeno é que o dano causado por íons anteriores, muitas vezes leva ao deslocamento de um átomo-alvo para dentro de um canal gerando uma obstrução. Com o aumento da dose implantada a probabilidade de um íon se depositar a uma profundidade maior diminui, já que parte dos canais encontram-se bloqueados, levando a um estreitamento crescente com a dose dos perfis de implantação, nas configurações que favorecem a canalização [38].

A implantação perpendicular aos planos (112), configuração vista na figura 3.6b, levou a um aumento de $8 \%$ no alcance médio e um alargamento perceptível do perfil a profundidades maiores, em relação ao perfil randômico, indicativos do fenômeno de canalização, porém com probabilidade muito menor do que a implantação perpendicular aos planos (110), evidenciando uma menor eficiência na utilização de canais planos, em relação a canais cilíndricos. Como sabe-se que o pro- 
grama superestima em grande medida os efeitos de canalização, é possível que a diferença entre uma implantação real efetuada em uma direção que forma canais planos (como a (100)) e em uma direção randômica seja muito pequena.

\subsection{Considerações sobre os resultados de simulação}

Técnicas de simulação de implantação iônica são ferramentas importantes para a descrição do processo físico, fornecendo informações fundamentais sobre a transformação imposta às amostras durante a implantação, como perfis de implantação e de energia depositada. Com os parâmetros de implantação entre certos limites, os dados obtidos pelas simulações nos software SRIM e MDRANGE estão em bom acordo com dados experimentais [35] [36], podendo ser utilizados para o estudo de amostras implantadas. Em comparação com o SRIM, o software MDRANGE, mais computacionalmente intensivo, aparenta obter uma precisão maior nos perfis de implantação para um certo número de íons simulados. Infelizmente a superestimação dos efeitos de canalização de íons pelo software torna imprecisa a simulação na configuração feixe-amostra utilizada nas implantações reais. Em vista destes resultados, julgamos o SRIM como o programa mais apropriado para a descrição das implantações realizadas e utilizamos os dados obtidos pelo mesmo em todas as análises posteriores. Na literatura [39] [42] encontramos a comparação entre dados obtidos por simulação e por técnicas experimentais como ToF-ERDA e RBS/C que atestam a precisão do software SRIM no cálculo em diversas condições de implantação em GaN. 


\section{Capítulo 4}

\section{Resultados experimentais}

Neste capítulo são apresentados os resultados experimentais obtidos através do estudo, pelas diversas técnicas, das amostras de c-GaN implantadas com $\mathrm{Mn}, \mathrm{Fe}$ e $\mathrm{Cu}$ e tratadas termicamente. Um objetivo desta seção é a investigação das características estruturais e suas transformações devidas aos processos de implantação e tratamento térmico e a relação destas transformações com o magnetismo observado nas amostras.

\subsection{Espectroscopia de raios $\mathrm{X}$}

Com a exceção de um mapa da rede recíproca, todas as medidas de espectroscopia de raios $\mathrm{X}$ foram realizadas observando-se os picos de difração referentes aos conjuntos de planos (002) do 3C-SiC e c-GaN. Isso deve-se ao fato destes conjuntos possuírem maior fator de estrutura, o que torna mais rápida a obtenção dos espectros.

\subsection{1 $\omega-2 \theta$}

A configuração $\omega-2 \theta$ é a mais utilizada para medidas de difração de raios X. Os espectros são obtidos varrendo-se o ângulo de incidência $\omega$ do feixe e medindo o feixe difratado com o detector posicionado com o dobro deste ângulo em relação ao feixe incidente.

Na figura 4.1 são apresentadas as medidas de difração das amostras referência dos três grupos, não tratadas termicamente.

Observou-se nos espectros das três referências um pico largo em torno de $\omega=20^{\circ}$ associado com o conjunto de planos (002) c-GaN e também um pico mais estreito em torno de $\omega=20.7^{\circ}$ associado com o conjunto de planos (002) 3C-SiC. A qualidade cristalina dos filmes de c-GaN podem ser avaliadas pelas respectivas larguras a meia-altura de cada pico, sendo a largura do pico proporcional à densidade de defeitos presente nas amostras. Obtemos para as amostras referência 1, 2a e $2 \mathrm{~b}$ larguras a meia altura de $0.411,0.395$ e $0.403^{\circ}$ respectivamente, indicando que a amostra Ref2a apresenta qualidade cristalina superior, seguida pelas amostras Ref2b e por último Ref1. Utilizou-se distribuições de Voigt nos ajustes para extração das larguras. A Voigtiana é obtida através da convolução de uma Gaussiana com uma Lorentziana e é uma função muito utilizada para descrição de diversos espectros de difração. O ajuste fornece as larguras das partes Gaussiana e Lorentziana separadamente, a largura combinada $\sigma_{V}$ foi obtida através do procedimento descrito em Olivero et al. [43].

Com a produção de defeitos decorrente da implantação iônica é esperado que as larguras das amostras aumente, já o efeito inverso nas amostras é esperado do tratamento térmico devido à redução da densidade de defeitos. Apresenta-se na tabela 4.1 o resumo das larguras à meia altura 


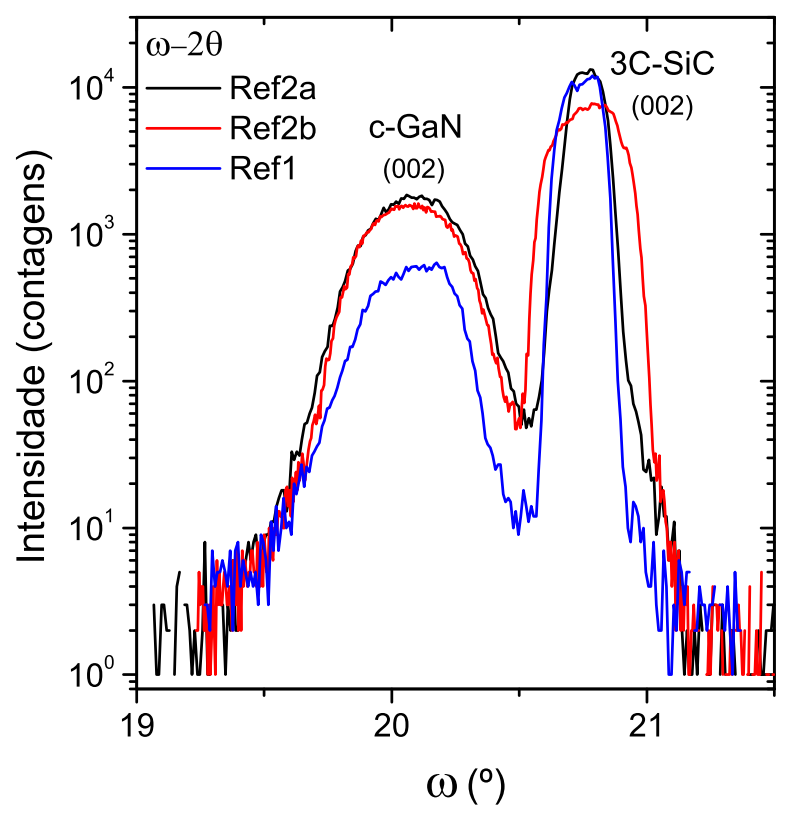

Figura 4.1: Medidas de difração de raios X na configuração $\omega-2 \theta$ das amostras referência não tratadas.

$\left(\sigma_{V}\right)$ extraídas dos espectros de difração de raios X na configuração $\omega-2 \theta$ das amostras virgens, após implantação e após implantação e tratamento térmico.

\begin{tabular}{|c|c|c|c|c|c|}
\hline Amostra & $\sigma_{V}\left(^{\circ}\right)$ virgem & $\sigma_{V}\left(^{\circ}\right)$ implantada & $\Delta \sigma_{\text {VImp }}\left(^{\circ}\right)$ & $\sigma_{V}\left(^{\circ}\right)$ tratada & $\Delta \sigma_{\text {VTrat }}\left(^{\circ}\right)$ \\
\hline Fe1 & 0.411 & 0.429 & 0.018 & 0.361 & $-0.068\left(^{*}\right)$ \\
Fe2a & 0.395 & 0.421 & 0.026 & 0.406 & -0.015 \\
Fe2b & 0.403 & 0.454 & 0.051 & - & - \\
$\mathrm{Mn} 1$ & 0.411 & 0.420 & 0.009 & 0.478 & 0.067 \\
$\mathrm{Mn} 2 \mathrm{a}$ & 0.395 & 0.412 & 0.017 & 0.402 & -0.010 \\
$\mathrm{Mn} 2 \mathrm{~b}$ & 0.403 & 0.433 & 0.030 & - & - \\
$\mathrm{Cu} 1$ & 0.411 & 0.435 & 0.024 & 0.420 & $-0.015\left(^{*}\right)$ \\
$\mathrm{Cu} 2 \mathrm{a}$ & 0.395 & 0.425 & 0.030 & 0.391 & -0.034 \\
$\mathrm{Cu} 2 \mathrm{~b}$ & 0.403 & 0.413 & 0.010 & - & - \\
Ref1 & 0.411 & - & - & 0.396 & -0.015 \\
Ref2a & 0.395 & - & - & 0.393 & -0.002 \\
Ref2b & 0.403 & - & - & - & - \\
\hline
\end{tabular}

Tabela 4.1: Larguras à meia altura $\left(\sigma_{V}\right)$ dos picos referentes ao c-GaN (002), obtidos dos espectros das amostras de c-GaN/3C-SiC virgens, recém implantadas e tratadas e variações de largura após implantação $\left(\Delta \sigma_{\text {VImp }}\right)$ e tratamento térmico $\left(\Delta \sigma_{\text {VTrat }}\right)$. Medidas realizadas em configuração $\omega-2 \theta$. Os valores de $\Delta \sigma_{V T r a t}$ marcados com asterisco $(*)$ indicam as amostras que sofreram degradação elevada com o tratamento térmico.

As medidas de alta resolução das amostras virgens, implantadas e tratadas ocorreram em datas diferentes e a intensidade máxima no contador obtida durante a calibração do instrumento não 
permaneceu constante, assim para comparação de espectros medidos em datas diferentes as contagens foram normalizadas pela intensidade máxima de calibração, medida com o detetor aberto e parâmetros do tubo em $40 \mathrm{kV}$ e $10 \mathrm{~mA}$. Para a calibração em $\omega$ utilizamos como referência o pico do substrato de 3C-SiC (002) pois não se espera que o tratamento térmico cause expansão ou contração apreciável da rede de uma camada não implantada.

Com a implantação todas as amostras apresentaram um alargamento da largura do pico referente ao c-GaN (002), no entanto a sensibilidade da técnica foi abaixo da esperada, é possível que o sinal devido à região do filme não afetada pela implantação, correspondente a $75 \%$ do volume do filme de acordo com as simulações realizadas, tenha atenuado a variação na largura dos picos. Notase que este alargamento dos picos ocorreu preferencialmente à esquerda, indicando uma expansão da rede cristalina da amostra implantada e tratada termicamente. Sendo os raios atômicos dos três íons implantados maiores que o do gálio, os íons tanto substitucionais quanto intersticiais são, em parte, responsáveis por este efeito [44] que também pode ser notado nos espectros de algumas amostras tratadas termicamente.

Na figura 4.2 pode-se observar as medidas de difração na configuração $\omega-2 \theta$ das amostras do conjunto 2a implantadas, não tratadas termicamente. Foi constatado um alargamento de $0.026^{\circ}$ e $0.030^{\circ}$ no espectro das amostras Fe2a e Cu2a respectivamente, enquanto que a amostra Mn2a apresentou um alargamento menor de $0.017^{\circ}$.
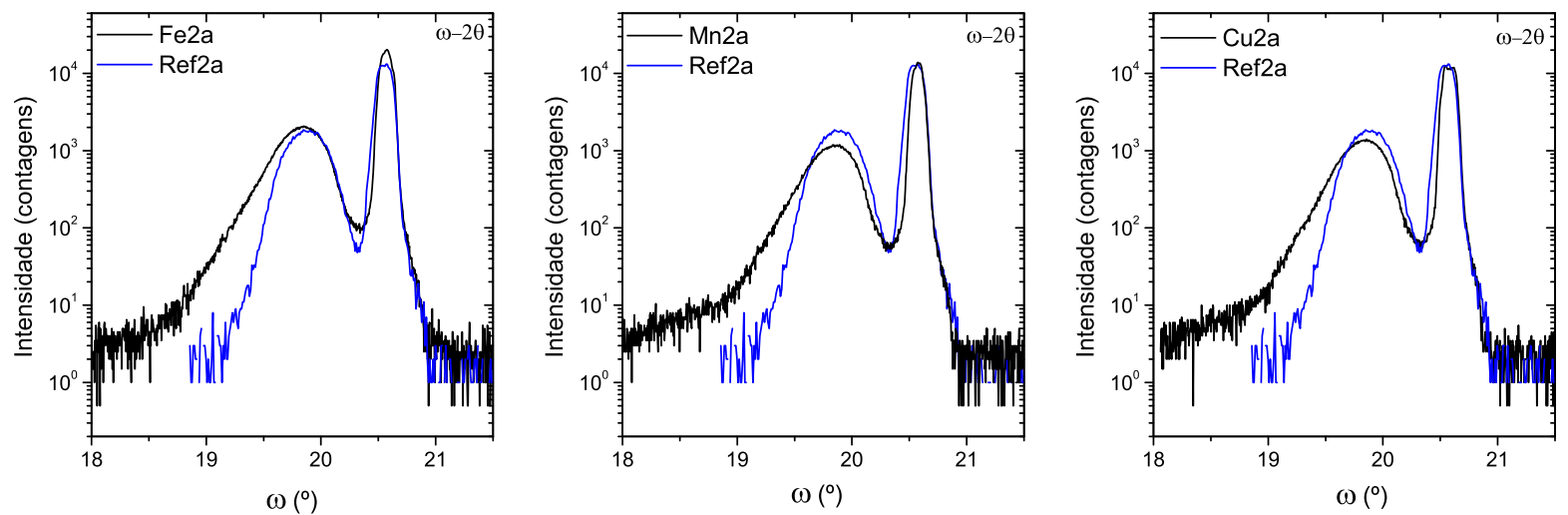

Figura 4.2: Medidas de difração de raios $\mathrm{X}$ das amostras implantadas e não tratadas do conjunto $2 \mathrm{a}$ e da amostra referência $2 \mathrm{a}$ também não tratada. Medidas realizadas em configuração $\omega-2 \theta$.

Nos espectros das amostras do conjunto $2 \mathrm{~b}$ não tratadas termicamente (figura 4.3), implantadas nas mesmas condições que as do conjunto 2a, a amostra implantada com $\mathrm{Fe}(\mathrm{Fe} 2 \mathrm{~b})$ apresentou o maior aumento na largura, de $0.051^{\circ}$. A amostra implantada com Mn (Mn2b) apresentou alargamento de $0.030^{\circ}$ enquanto a amostra implantada com $\mathrm{Cu}(\mathrm{Cu} 2 \mathrm{~b})$ apresentou alargamento de apenas $0.010^{\circ}$, de maneira que, para o conjunto $2 \mathrm{~b}$, a implantação com Mn foi mais danosa à rede cristalina do que à implantação com $\mathrm{Cu}$, o inverso do que foi observado nos espectros do conjunto 2a. O alinhamento em $\omega$ para as amostras $\mathrm{Mn} 2 \mathrm{~b}$ e $\mathrm{Cu} 2 \mathrm{~b}$ foi realizada em relação ao pico do c-GaN pois estes espectros apresentaram picos do 3C-SiC atípicos, possivelmente por falha do sistema de aquisição já que o substrato não deve ter sido afetado pela implantação.

Vemos na figura 4.4 as medidas de difração na configuração $\omega-2 \theta$ das amostras do conjunto 1 implantadas e não tratadas termicamente. As amostras Fe1 e $\mathrm{Cu} 1$ apresentaram os maiores aumentos de largura com a implantação neste conjunto, $0.018^{\circ}$ para a $\mathrm{Fe} 1$ e $0.024^{\circ}$ para a $\mathrm{Cu} 1$. A amostra Mn1 mostrou alargamento de apenas $0.009^{\circ}$. Devido a alta flutuação na variação das larguras nas amostras implantadas com diferentes íons, não foi possível distingui-los através desta 

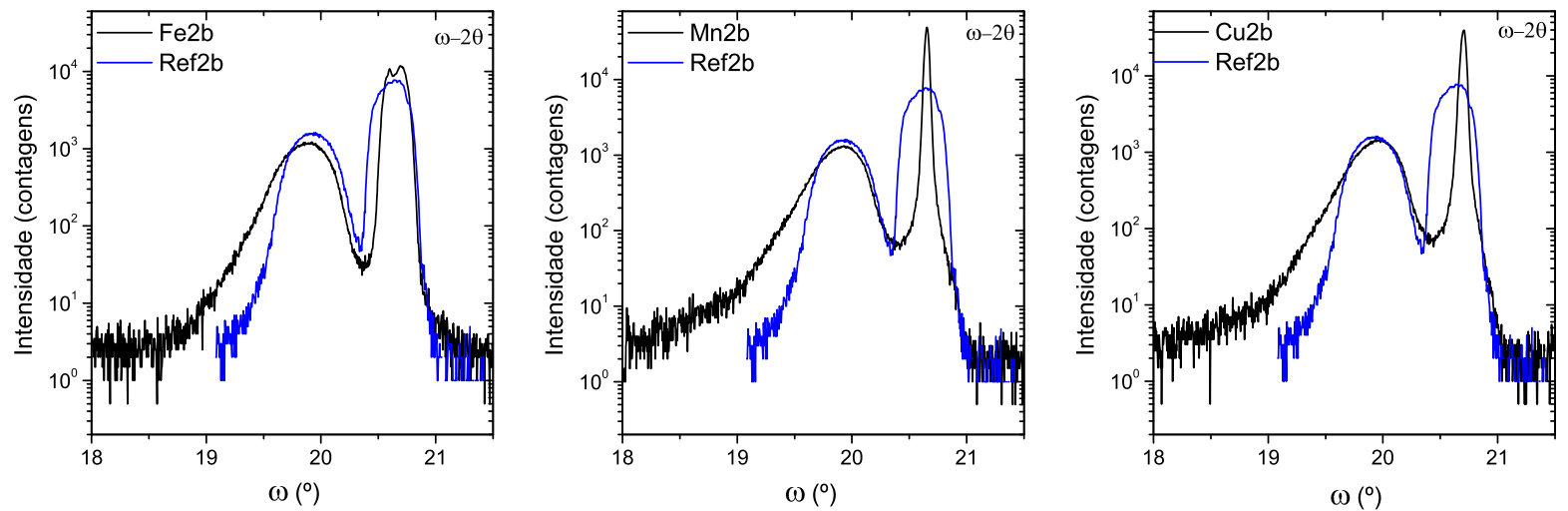

Figura 4.3: Medidas de difração de raios $\mathrm{X}$ das amostras implantadas e não tratadas do conjunto $2 \mathrm{~b}$ e da amostra referência $2 \mathrm{~b}$ também não tratada. Medidas realizadas em configuração $\omega-2 \theta$.

análise. Como esperado, as amostras implantadas com dose maior apresentaram na média um maior aumento da largura do pico do c-GaN, devido ao maior dano causado à rede pelos íons.
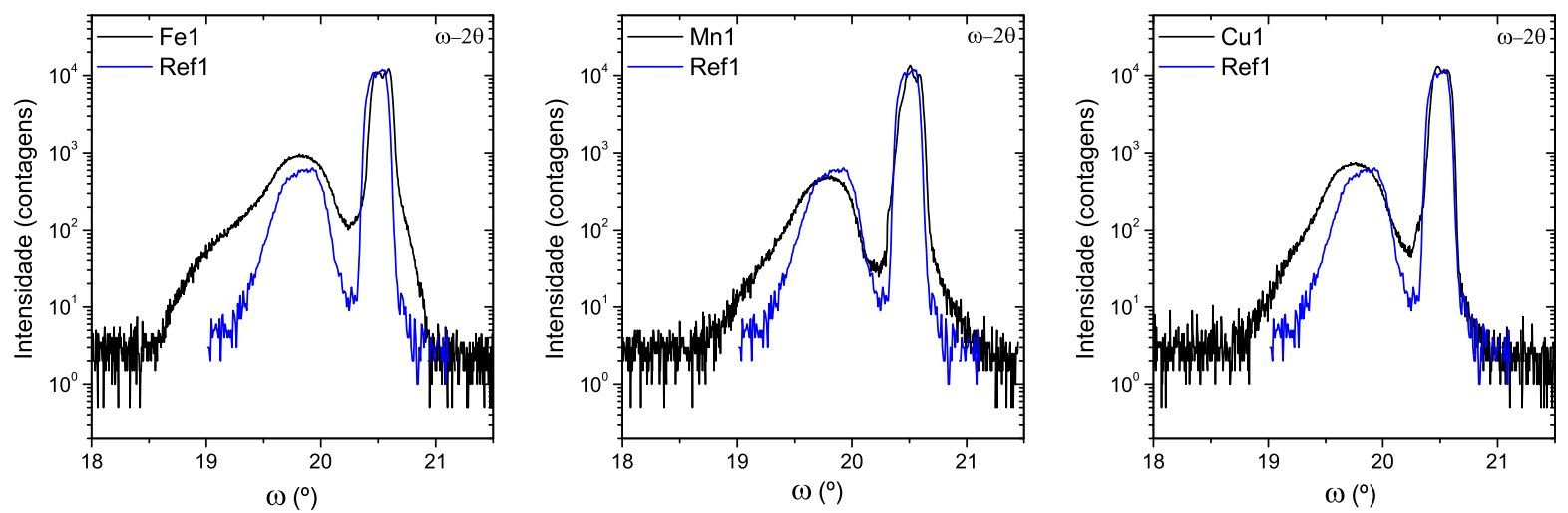

Figura 4.4: Medidas de difração de raios X das amostras implantadas e não tratadas do conjunto 1 e da amostra referência 1 também não tratada. Medidas realizadas em configuração $\omega-2 \theta$.

Após tratamento térmico realizado a $900{ }^{\circ} \mathrm{C}$ por 5 minutos as amostras implantadas do conjunto 2a apresentaram redução da largura à meia altura do pico referente ao c-GaN (002), indicando recuperação da rede cristalina com o processo. A redução foi maior para a amostra implantada com $\mathrm{Cu}(\mathrm{Cu} 2 \mathrm{a}): 0.034^{\circ}$, para as amostras Fe2a e Mn2a a redução foi de $0.015^{\circ}$ e $0.010^{\circ}$ respectivamente. Vemos os espectros de raios $\mathrm{X}$ do conjunto 2a pós-tratamento na figura 4.5.

Os espectros de difração de raios $\mathrm{X}$ realizado nas amostras do conjunto 1 tratadas (figura 4.6) também a $900{ }^{\circ} \mathrm{C}$ por 5 minutos evidenciaram que as amostras deste conjunto não recuperaram qualidade cristalina com o processo. As amostras do conjunto implantadas com $\mathrm{Fe}$ e $\mathrm{Cu}$ (Fe1, $\mathrm{Cu} 1)$ apresentaram significativa perda de intensidade no pico do c-GaN (002) após tratamento indicando degradação da rede cristalina nestas amostras, possivelmente dissociação por perda de $\mathrm{N}_{2}$ pela superfície, sendo este o mecanismo principal de degradação de amostras de GaN submetidas a altas temperaturas [45]. Como as amostras foram tratadas termicamente com a mesma amostra virgem de cobertura, é plausível que a cobertura de alguma maneira não tenha sido eficiente em impedir a 

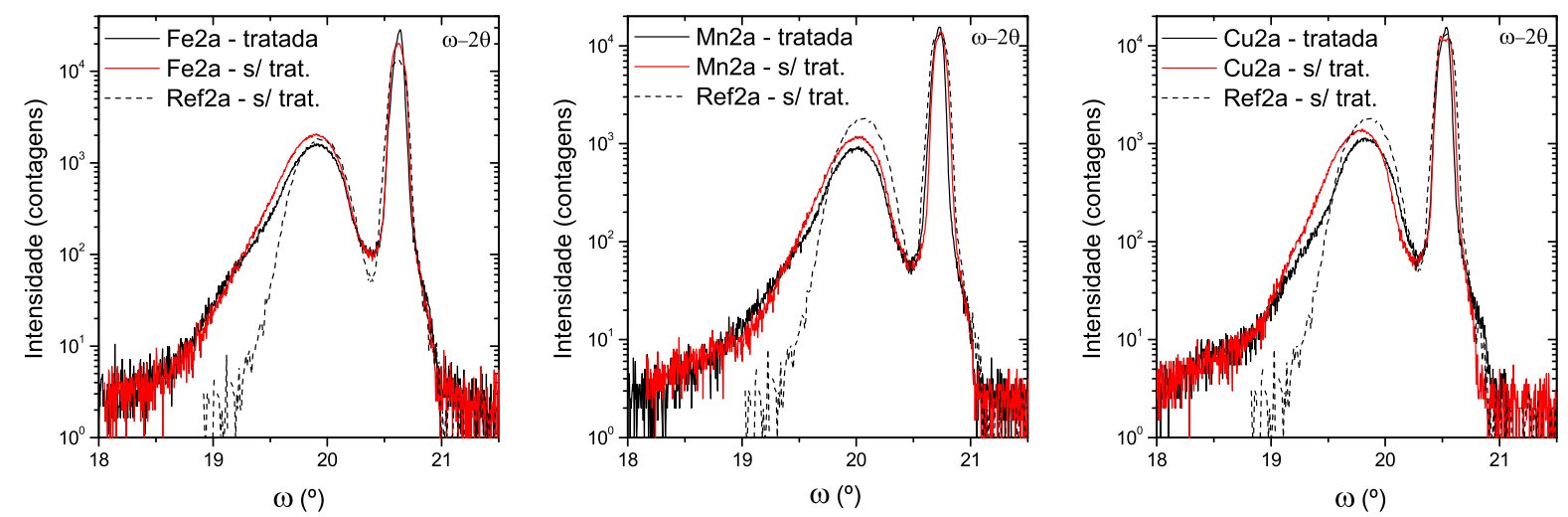

Figura 4.5: Medidas de difração de raios X das amostras implantadas do conjunto 2a pré e pós tratamento térmico. Medidas realizadas em configuração $\omega-2 \theta$.

degradação neste caso. A amostra Mn1 não apresentou redução na intensidade difratada pelo filme de c-GaN, porém foi observado um alargamento expressivo no pico correspondente, de $0.058^{\circ}$.
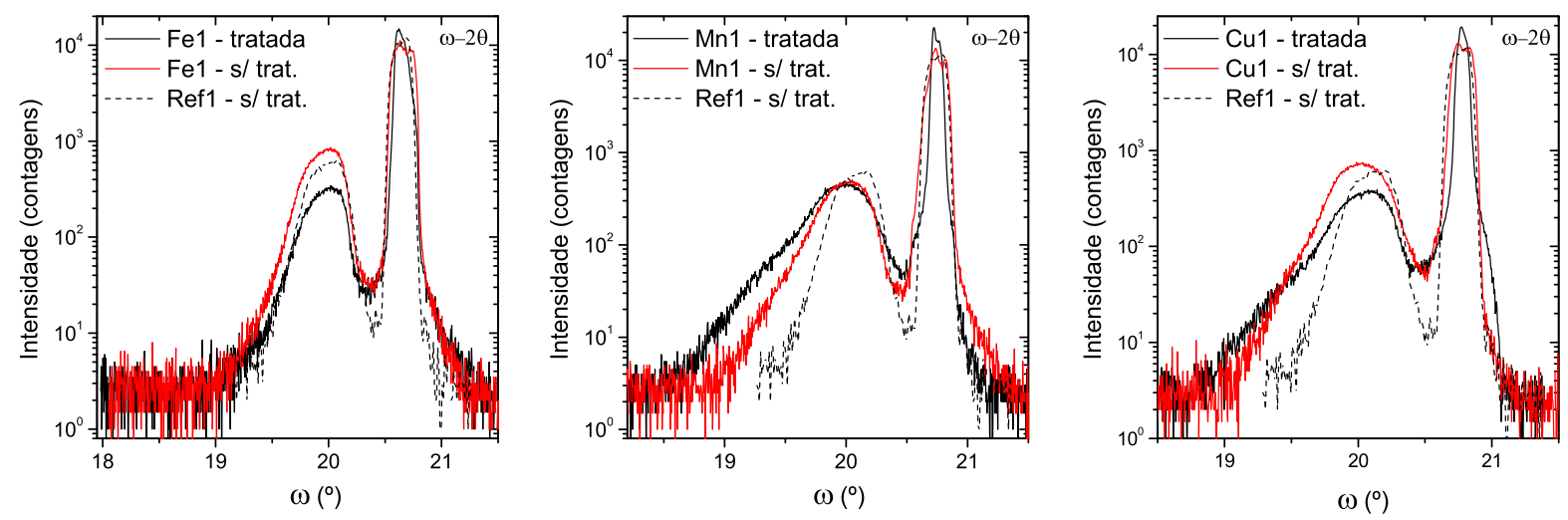

Figura 4.6: Medidas de difração de raios $\mathrm{X}$ das amostras implantadas do conjunto 1 pré e pós tratamento térmico. Medidas realizadas em configuração $\omega-2 \theta$.

Não foi observada também correlação entre o íon implantado e a variação de larguras, tanto a causada pela implantação quanto pelo posterior tratamento térmico. Esta correlação não foi observada possivelmente pela proximidade da massa atômica dos íons implantados gerando condições de implantação semelhantes e também pela flutuação da variação da largura à meia altura entre as amostras implantadas e não tratadas, com o mesmo íon nas mesmas condições (conjuntos 2a e 2b, vide tabela 4.1), não foram obtidos os espectros de raios $\mathrm{X}$ das amostras do conjunto $2 \mathrm{~b}$ tratadas o que é parcialmente justificado por esta flutuação.

\subsubsection{Mapas da rede recíproca}

Através de técnicas de difração de raios X pode-se mapear a rede recíproca de uma amostra. $\mathrm{O}$ método consiste em obter espectros $\omega-2 \theta$ variando $\omega$ e consequentemente o offset (definido como a diferença entre $\theta$ e $\omega$ ) de maneira a varrer uma área de interesse do espaço recíproco. Podemos arranjar os espectros lado a lado, em ordem crescente de offset, criando assim um mapa 2-D de 
intensidades, geralmente plotado como um gráfico de curvas de nível. Um mapa da rede recíproca consiste então de uma série de espectros $\omega-2 \theta$ arranjados de maneira que em cada um deles $\omega$ e $2 \theta$ estejam progressivamente defasados entre si. Convertendo $\theta$ e $\omega$ em vetores do espaço recíproco através das equações 4.1 obtemos um mapa da rede recíproca como o da figura 4.7.

$$
Q_{x}=\frac{\cos (\theta)-\cos (\omega-\theta)}{\lambda} \quad Q_{y}=\frac{\operatorname{sen}(\theta)+\operatorname{sen}(\omega-\theta)}{\lambda}
$$

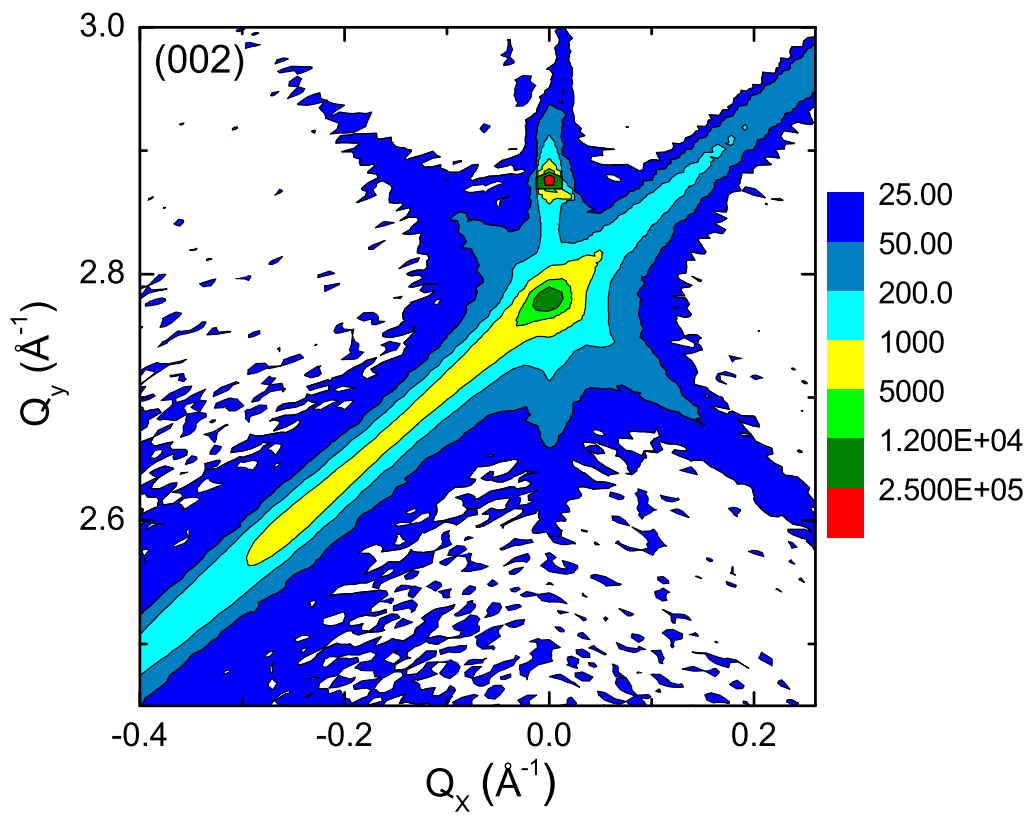

Figura 4.7: Mapa da rede recíproca (002) da referência 1 não tratada, em função dos vetores $Q_{x}$ e $Q_{y}$.

Informações sobre o material, invisíveis em espectros nas configurações $\omega-2 \theta$ ou $\omega$-scan individualmente, são evidenciadas em um mapa da rede recíproca. É apresentado na figura 4.7 o mapa da rede recíproca da amostra referência do conjunto 1. Observa-se nos mapas a presença de dois picos principais, uma versão em duas dimensões dos picos observados nos espectros de raios X convencionais, o pico do $3 \mathrm{C}-\mathrm{SiC}(002)$ acima $\left(Q_{y}\right.$ maior) e abaixo o pico referente ao cGaN (002). A estrutura cristalina cúbica do nitreto de gálio é dita metaestável, ou seja, possui energia maior do que um cristal de GaN hexagonal. Nas condições de crescimento típicas de um MBE é possível crescer cristais metaestáveis como c-GaN ou 3C-SiC, entretanto a energia de strain, devida em parte à incompatibilidade cristalina, gera uma perturbação no sistema durante o crescimento possibilitando o aparecimento de uma fase secundária de h-GaN. No mapa da figura 4.7 a presença de h-GaN na amostra pode ser identificada pelo prolongamento do pico do c-GaN na direção do pico (1011) da fase hexagonal. Pode-se estimar a fração de cada fase na amostra através da relação de intensidades dos picos de cada fase, obtidas pelo volume. A priori esse procedimento é pouco preciso pois, em uma direção arbitrária, os fatores de estrutura de fases diferentes não são necessariamente iguais, embora a relação seja útil para comparar amostras do mesmo material, medidas na mesma configuração. Obtemos através deste procedimento uma fração de fase hexagonal de aproximadamente $2 \%$ para a amostra referência 1 não tratada. 


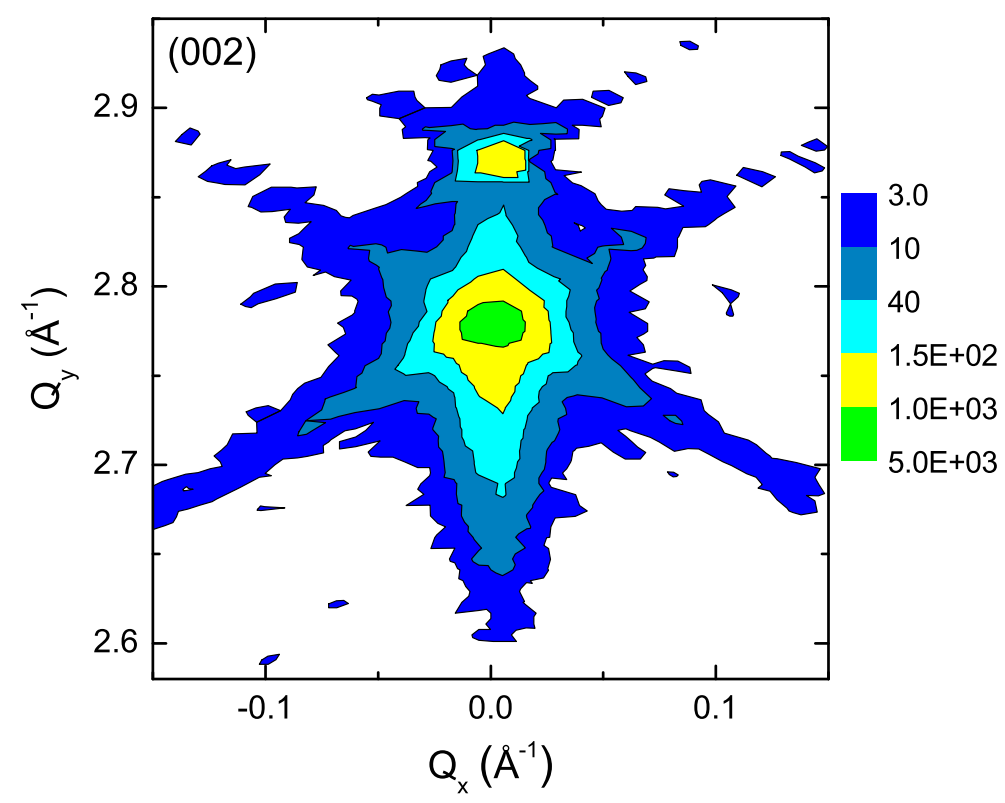

Figura 4.8: Mapa da rede recíproca (002) da referência 2a não tratada, em função dos vetores $Q_{x}$ e $Q_{y}$.

Vemos o mapa da rede recíproca da referência 2a não tratada na figura 4.8. Nota-se no mapa a ausência do prolongamento do pico referente ao GaN cúbico visto no mapa da figura 4.7, mostrando a ausência de fase hexagonal dentro da sensibilidade da técnica, evidência de um crescimento de melhor qualidade em comparação à amostra referência 1. Os mapas das figuras 4.7 e 4.8 foram obtidos com parâmetros ajustados especificamente para a avaliação de amostras de c-GaN após o crescimento, o que explica a grande intensidade obtida nos mesmos comparada à de outros mapas obtidos neste trabalho. 

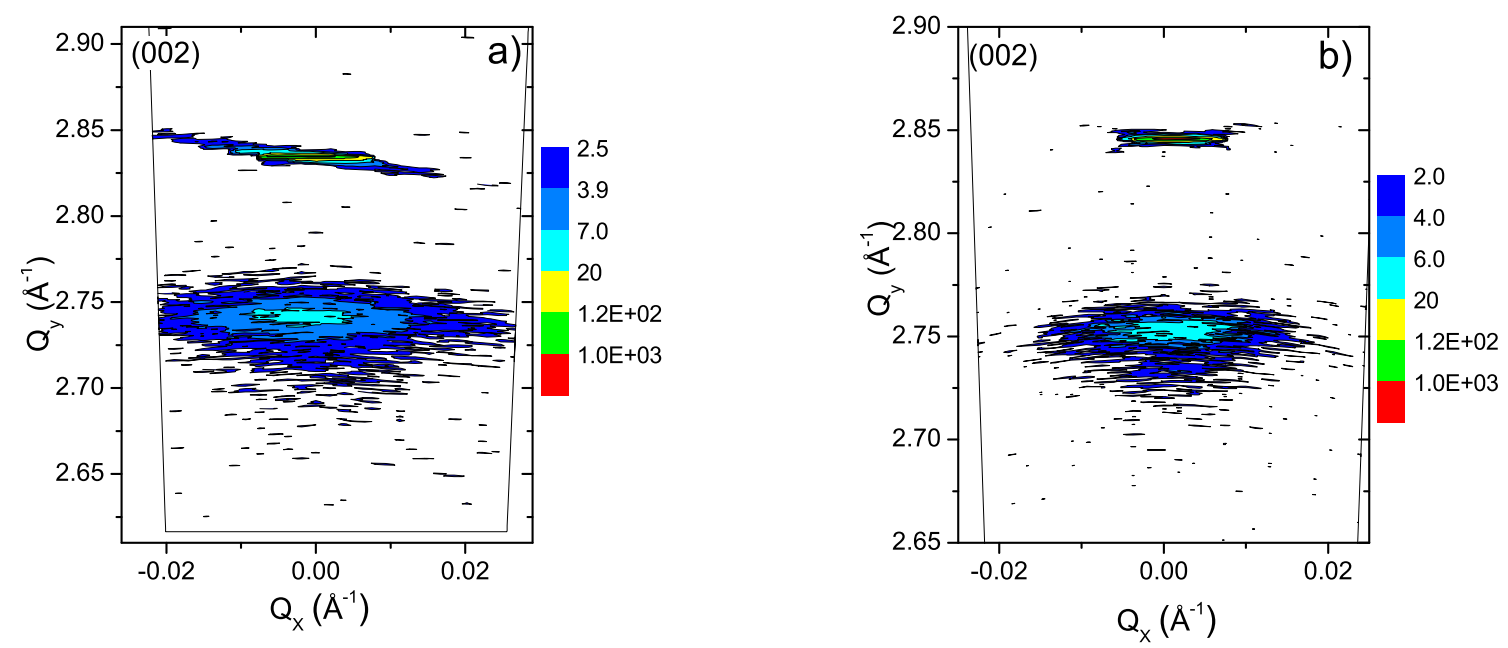

Figura 4.9: Mapas da rede recíproca das amostras Fe1 (a) e Mn2a (b) implantadas e não tratadas.
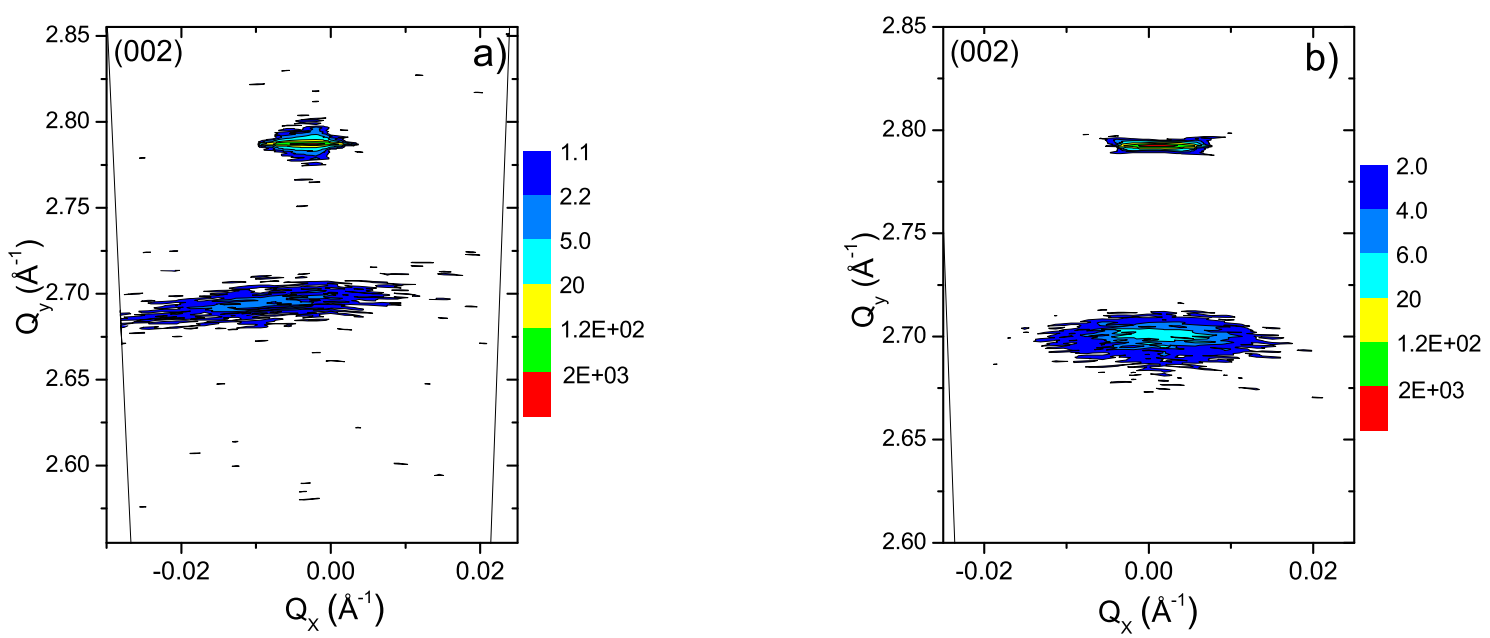

Figura 4.10: Mapas da rede recíproca das amostras Fe1 (a) e Mn2a (b) implantadas e tratadas termicamente.

Os mapas da rede recíproca obtidos para a amostra Fe1 implantada com baixa dosagem de ferro, pré e pós tratamento térmico são vistos nas figuras 4.9a e 4.10a. Assim como nas medidas realizadas na configuração $\omega-2 \theta$ observou-se nestas que o tratamento térmico realizado a $900{ }^{\circ} \mathrm{C}$ degradou consideravelmente esta amostra. Através da comparação entre os mapas da rede recíproca pré e pós tratamento térmico nota-se que além da diminuição da intensidade do pico do c-GaN o mesmo deslocou-se do eixo $Q_{y}$, o que indica não uniformidade e altos gradientes de tensionamento [46] características de camadas com elevada perda de cristalinidade.

Comparando-se os mapas da amostra Mn2a implantada com alta dosagem de manganês, pré e pós tratamento térmico (figuras $4.9 \mathrm{~b}$ e $4.10 \mathrm{~b}$ ) pode-se notar que o tratamento térmico acarretou num estreitamento em $Q_{y}$ do pico referente ao c-GaN, principalmente na região inferior do pico. Sendo esta cauda associada com a mosaicidade em filmes finos [47], pode-se concluir que o tratamento térmico foi efetivo na redução de defeitos do tipo mosaico da amostra Mn2a. 


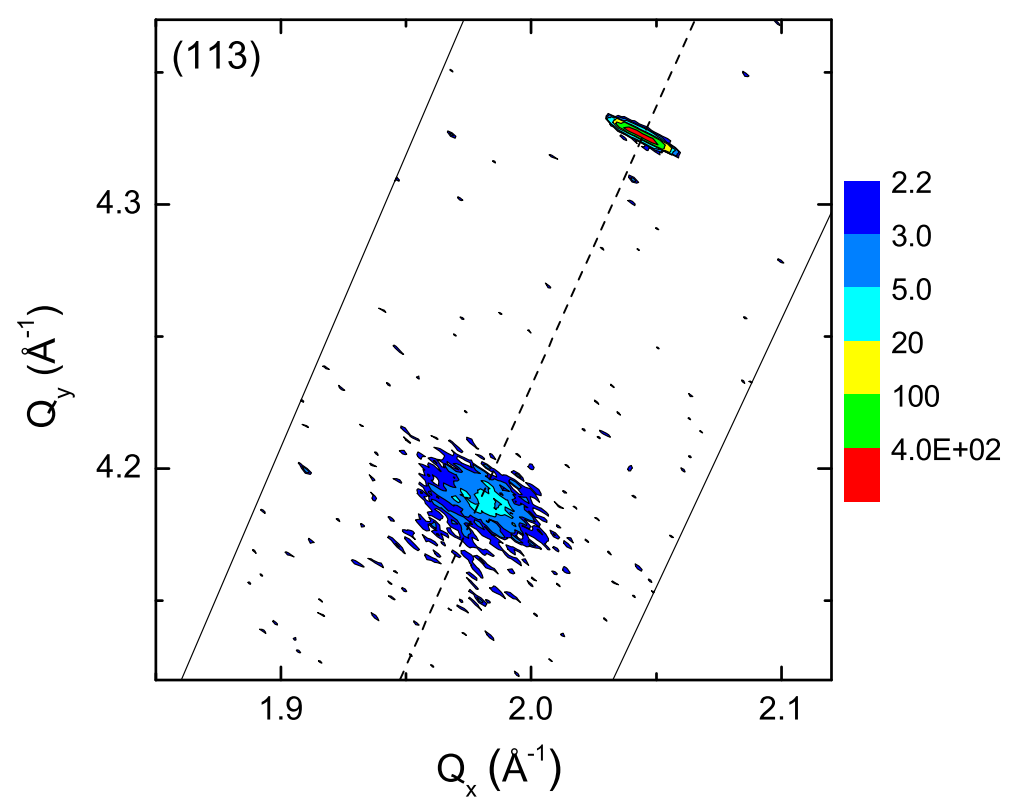

Figura 4.11: Mapa assimétrico da rede recíproca (113) da amostra Mn2b não tratada.

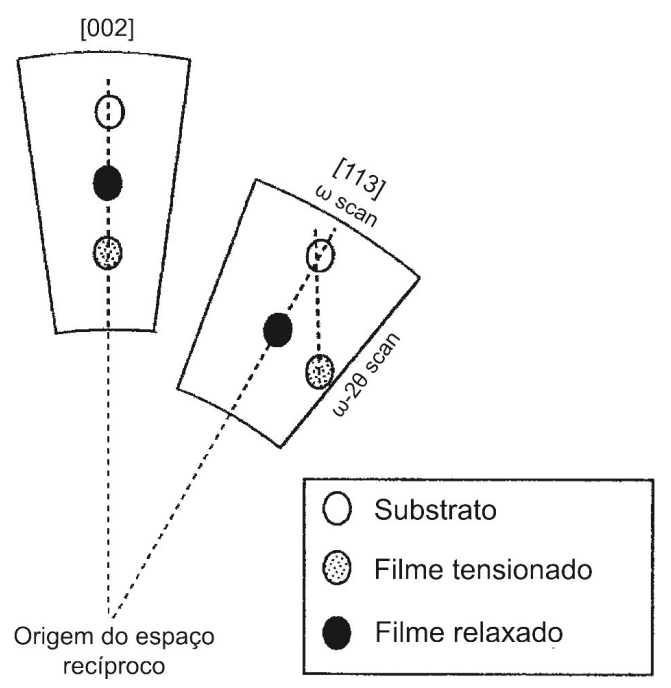

Figura 4.12: Exemplo de mapas da rede recíproca simétricos e assimétricos de amostras com duas camadas epitaxiais tensionadas e não tensionadas. Adaptado de [46].

Na figura 4.11 é apresentado um mapa da rede recíproca da região em torno das reflexões (113) do c-GaN para a amostra Mn2b não tratada. Um mapa não centrado em um eixo do espaço recíproco é dito assimétrico. Estas medidas são importantes pois fornecem informação sobre os parâmetros de rede paralelos à superfície que não seriam observáveis em configurações simétricas. Na figura 4.12 pode-se observar o efeito do tensionamento de camadas epitaxiais em mapas da rede recíproca simétricos e assimétricos. O tensionamento leva ao deslocamento do pico da camada do eixo que liga a origem do eixo recíproco ao pico referente ao substrato. Esse deslocamento não foi observado no mapa da amostra Mn2b visto na figura 4.11, indicativo de baixo 
tensionamento entre filme e substrato nesta amostra. Infelizmente o fator de estrutura destas reflexões assimétricas é muito baixo o que torna a medida demorada, assim não foi possível a obtenção de mapas assimétricos em outras amostras, o que seria interessante principalmente nas amostras do grupo 1 que apresentaram fase hexagonal após o crescimento.

\subsubsection{Bragg-Brentano}

Espectroscopia de raios X na configuração Bragg-Brentano $\theta-\theta$ foi utilizada para a busca de fases secundárias nas amostras implantadas. Nesta geometria a amostra permanece imóvel enquanto tanto o feixe incidente quanto o detetor se posicionam com ângulo de $\theta$ em relação ao vetor paralelo à superfície da amostra.

Apresentam-se na figura 4.13 os espectros de raios X medidos na Bragg-Brentano das amostras referência 1 tratada e referência $2 \mathrm{~b}$ não tratada termicamente. Observamos nos espectros os picos principais referentes às reflexões do conjunto de planos (002) do filme de c-GaN e do substrato de 3C-SiC, nota-se que a relação entre as intensidades dos picos de filme e substrato é maior para a amostra referência $2 b$, evidência da maior qualidade cristalina do filme desta amostra. Não foi possível a identificação nos espectros dos picos marcados com um asterisco $\left(^{*}\right)$ que também estão presentes em espectros das amostras implantadas e tratadas. Os mesmos não correspondem a nenhuma reflexão esperada de conjuntos de planos dos constituintes das amostras não implantadas e não puderam ser identificados com nenhuma possível impureza ou fase secundária em bases de dados cristalográficos.

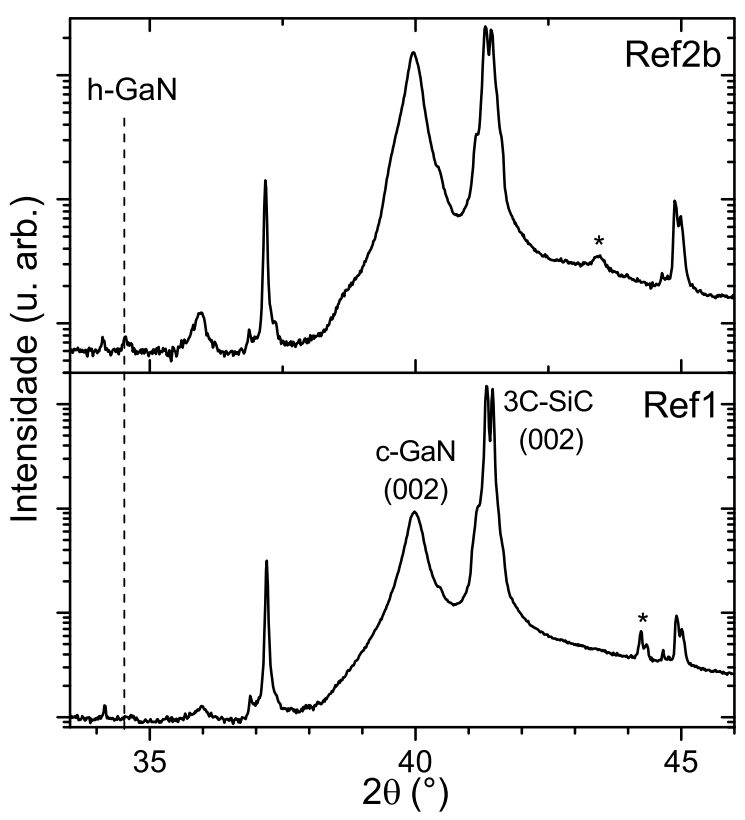

Figura 4.13: Espectros de raios $\mathrm{X}$ do tipo Bragg-Brentano das amostras referência 1 tratada e 2b não tratada.

Foi detectado um pequeno pico referente ao h-GaN no espectro da amostra referência $2 \mathrm{~b}$ não tratada, enquanto que este não foi evidenciado no espectro da referência 1 tratada. Como a presença de h-GaN foi detectada no mapa da rede recíproca da amostra Ref. 1, poderia-se inferir que o tratamento térmico reduziu a fração de h-GaN na amostra, no entanto o sinal do pico medido é muito reduzido e não é possível chegar a esta conclusão. Os outros dois picos não identificados são referentes ao $3 \mathrm{C}-\mathrm{SiC}\left(36.1^{\circ}\right)$ e camada de $\mathrm{Si}\left(37.3^{\circ}\right)$. 
Vemos na figura 4.14 os espectros de raios X medidos na Bragg-Brentano das amostras implantadas com Fe e tratadas termicamente: Fe2bRT (Fe2b retratada a $900{ }^{\circ} \mathrm{C}$ ), Fe2a e Fe1.

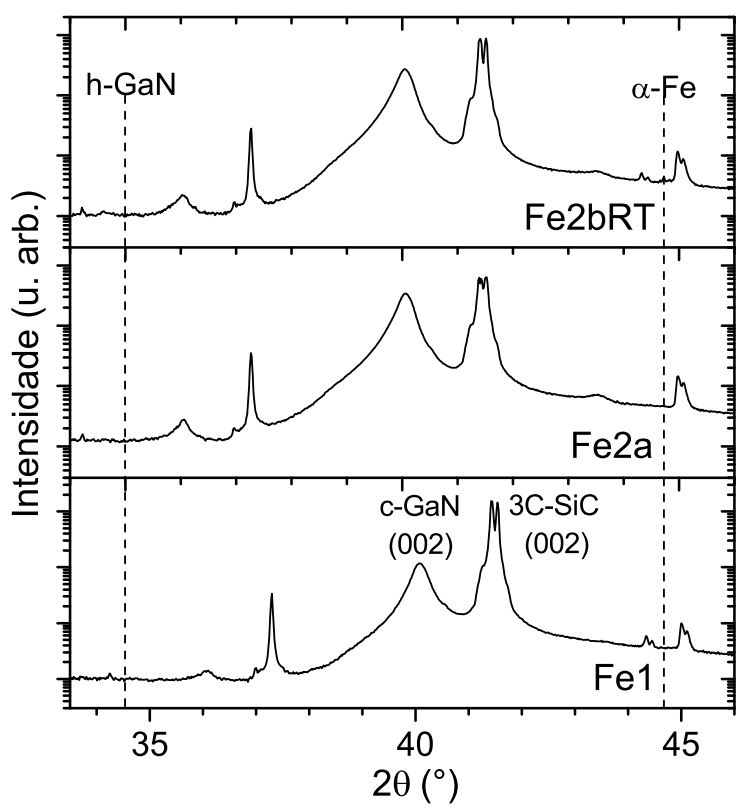

Figura 4.14: Espectros de raios X do tipo Bragg-Brentano das amostras Fe2bRT (retratada), Fe2a e Fe1 implantadas e tratadas termicamente.

Nos espectros das amostras implantadas com Fe não foram detectados picos referentes ao $\alpha$-Fe ou nitretos de Fe nem à fase hexagonal estável do filme de GaN, possíveis fases secundárias geradas pelos processos de implantação e tratamento térmico. Uma lista com possíveis fases secundárias formadas em amostras de GaN implantadas com Fe e Mn pode ser encontrada em [48]. Este resultado corrobora os estudos de implantação em altas doses de Fe em h-GaN onde somente foram detectados picos referentes ao Fe metálico [49] e nitretos de Fe [50] em amostras implantadas com doses a partir de $4 \times 10^{16} \mathrm{~cm}^{-2}$. A ausência de picos referentes a fases secundárias em espectros de difração de raios X não exclui a presença das mesmas no material já que podem ter sido formados microcristalitos com baixo fator de estrutura intrínseco, fato que os torna praticamente invisíveis à técnica de difração de raios X [51]. Não foi observado também o pico característico do Ga metálico em $\left(37.3^{\circ}\right)$ que pode ser formado pela degradação da rede cristalina do c-GaN com perda de $\mathrm{N}_{2}$ durante tratamento térmico.

$\mathrm{Na}$ figura 4.15 são apresentados os espectros Bragg-Brentano das amostras Mn2a e Cu2a tratadas termicamente a $900^{\circ} \mathrm{C}$.

Assim como nas amostras de Fe, não foram detectados nos espectros Bragg-Brentano das amostras Mn2a e Cu2a difração associável a alguma fase espúria possivelmente criada durante os processos de implantação iônica e tratamento térmico.

O trabalho de Kane et al. [52] sobre amostras de h-GaN implantadas com Mn, associou a presença de picos com $2 \theta=32.4^{\circ}$ com a formação de $\mathrm{Mn}_{8} \mathrm{Ga}_{5}$ ou $\mathrm{Mn}_{4-x} \mathrm{Ga}_{x} \mathrm{~N}_{1-y}$. Mesmo com condições semelhantes de implantação e tratamento térmico (com exceção da dose implantada, $20 \%$ menor) não obtivemos exito na reprodução deste resultado para o c-GaN. Outra fase já obtida por implantação na literatura o $\mathrm{Mn}_{4} \mathrm{~N}$, possui pico com $2 \theta=40.32^{\circ}$ [53] muito próximo ao pico (002) do c-GaN, impossibilitando sua observação.

Pouco pode ser encontrado na literatura sobre fases secundárias em amostras de GaN dopadas 


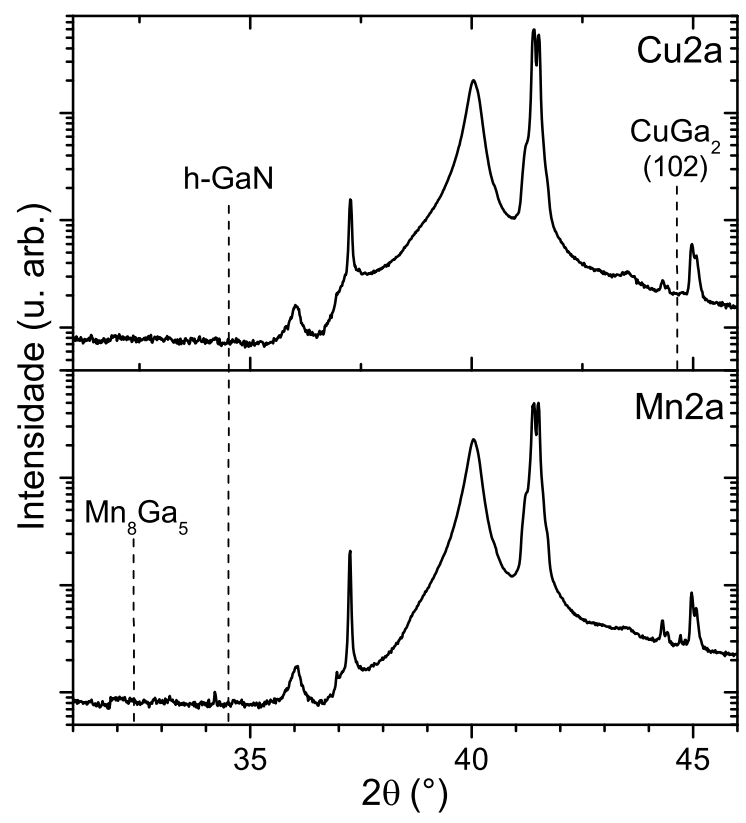

Figura 4.15: Espectros de raios X do tipo Bragg-Brentano das amostras Mn2a e Cu2a implantadas e tratadas termicamente.

com $\mathrm{Cu}$. $\mathrm{CuGa}_{2}$ foi detectado no trabalho de Lee et al. [54] sobre amostras de h-GaN implantadas com pico em $2 \theta=44.6^{\circ}$, porém esse resultado só foi obtido com doses extremas de $10^{17} \mathrm{~cm}^{-2}$, correspondente a concentrações de pico na ordem de $20 \%$. No presente trabalho este pico não foi observado no espectro Bragg-Brentano da amostra Cu2a.

\subsubsection{Considerações sobre as medidas de difratometria de raios $\mathrm{X}$}

A técnica de difração de raios $\mathrm{X}$ se mostrou importante na caracterização das amostras do presente estudo. As medidas em configuração $\omega-2 \theta$ avaliaram de maneira quantitativa a degradação da rede após a implantação iônica em diferentes doses e serviram de baliza para a avaliação da eficiência do processo de tratamento térmico. Os mapas da rede recíproca foram utilizados com sucesso para identificação de fases secundárias e análise de tensionamento entre filme e substrato. Medidas de Bragg-Brentano são muito utilizadas na literatura para a identificação de fases e foi aplicada para este fim na deteção de fase secundária de h-GaN e não deteção de nitretos de ferro e outros possíveis compostos nas amostras implantadas e tratadas.

\subsection{Espectroscopia de fotoluminescência}

$\mathrm{Na}$ figura 4.16 estão apresentados os espectros de fotoluminescência das amostras referência não tratadas termicamente. Observamos nos espectros das amostras referência picos referentes à emissão das transições doador-aceitador (DA) e excitônica (X) do c-GaN (cf. figura 2.6). Conforme esperado, em amostras de GaN de alta qualidade cristalina [55] a transição DA apresentou luminescência de maior intensidade em relação à transição excitônica nas amostras virgens.

$\mathrm{Na}$ tabela 4.2 estão apresentadas as energias dos picos DA e X extraídos dos espectros das amostras virgens da figura 4.16. As amostras referência $2 \mathrm{a}$ e $2 \mathrm{~b}$ não apresentaram deslocamento dos picos em comparação aos resultados da literatura [56]. Já no espectro da amostra Ref1 nota-se 


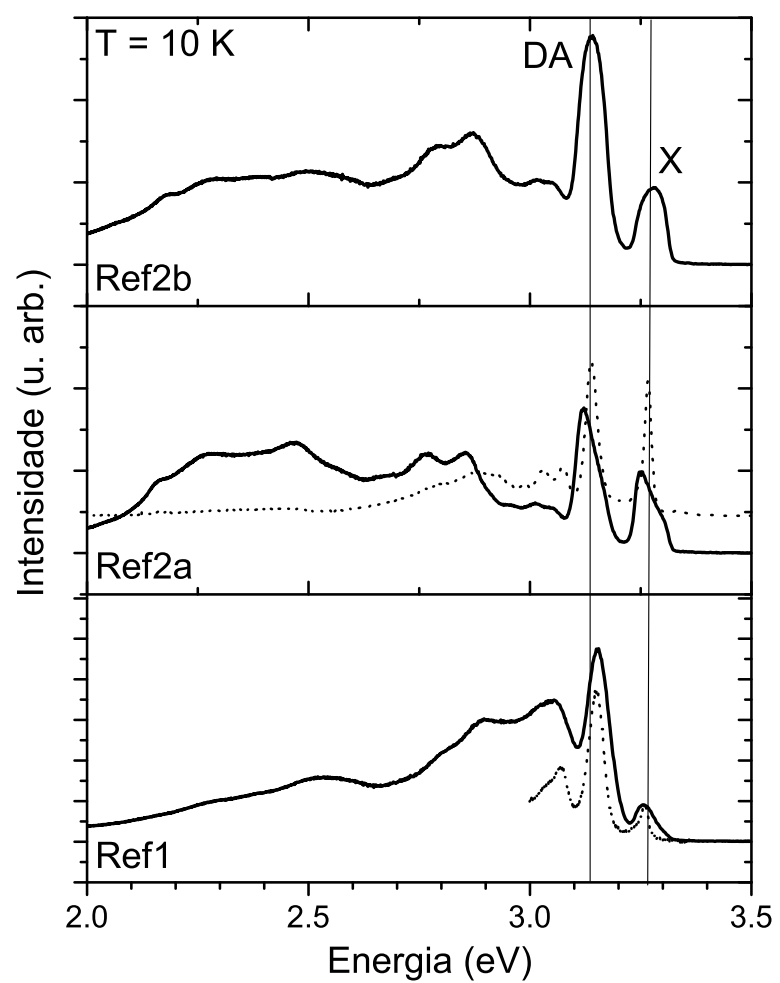

Figura 4.16: Espectros de fotoluminescência das amostras referência não tratadas termicamente, medidos na temperatura de $10 \mathrm{~K}$. As linhas pontilhadas correspondem os espectros das amostras referência tratadas, medidos a $15 \mathrm{~K}$ porém corrigidos pela expressão de Varshni (eq. 4.3) para comparação.

um deslocamento em energia dos dois picos observados. O deslocamento para o vermelho do pico excitônico é associado na literatura com a presença de tensionamento em h-GaN $[57,58]$. Tendo em vista a qualidade cristalina inferior desta amostra, evidenciada pelas medidas de espectroscopia de raios X (seção 4.1.1.1) este comportamento de fato é esperado já que o tensionamento é um fator importante na degradação da qualidade cristalina de amostras crescidas por MBE. Já deslocamentos do pico DA estão relacionados com a dopagem do material [59]. As vacâncias tanto de Ga como N agem efetivamente como dopantes e levam à formação de estados rasos dentro do gap do material.

\begin{tabular}{|c|c|c|}
\hline Amostra & $E_{\mathrm{DA}}(\mathrm{eV})$ & $E_{\mathrm{X}}(\mathrm{eV})$ \\
\hline Ref1 & 3.155 & 3.255 \\
Ref2a & 3.140 & 3.280 \\
Ref2b & 3.145 & 3.275 \\
\hline
\end{tabular}

Tabela 4.2: Energia dos picos DA e X, extraídos dos espectros de fotoluminescência das amostras referência não tratadas, medidos a $10 \mathrm{~K}$.

Após a implantação, apenas as amostras $\mathrm{Fe} 1$ e Cu1 apresentaram fotoluminescência mensurável. Vemos na figura 4.17 os espectros de fotoluminescência das amostras Fe1, Mn1 e Cu1 implantadas e não tratadas termicamente juntamente com o da Ref1 virgem para comparação, medidos na 
temperatura de $10 \mathrm{~K}$. A implantação do conjunto 1 não alterou significativamente a posição em energia dos picos DA e X. Os picos em 3.01, 3.08 e 3.31 eV nos espectros em baixa temperatura não são provenientes da amostra e sim da cola fixadora ao porta-amostras, que mesmo não incidida diretamente pelo feixe emitiu devido a reflexões nas janelas óticas.

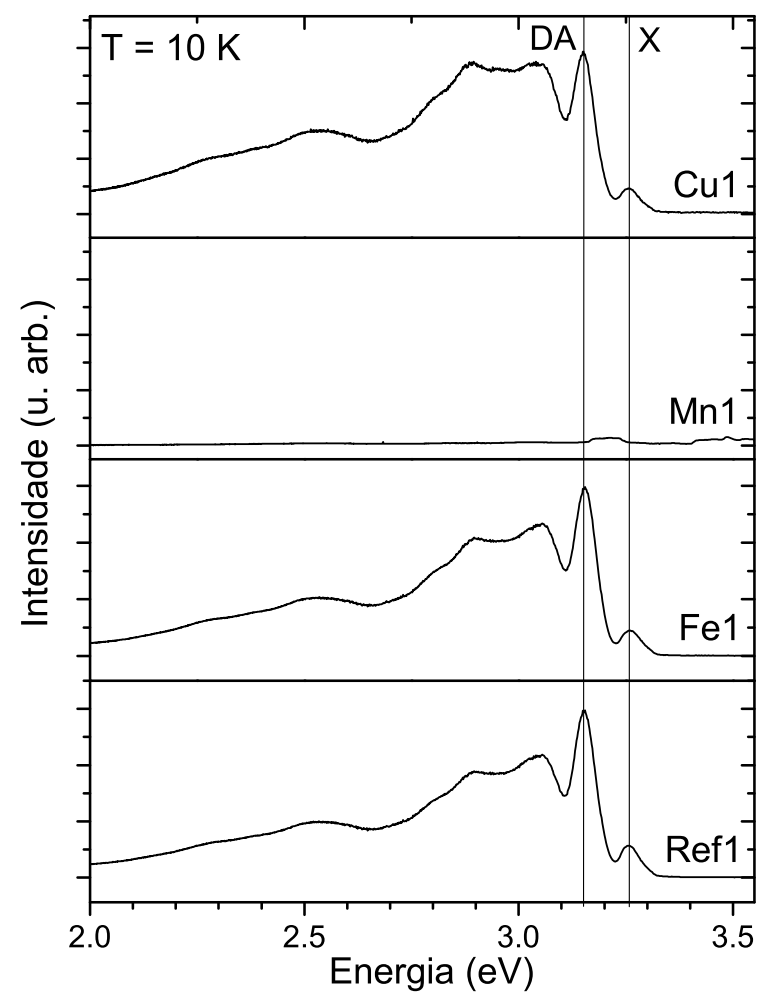

Figura 4.17: Espectros de fotoluminescência das amostras Ref1 virgem e Fe1, Mn1 e Cu1 implantadas e não tratadas termicamente, medidos na temperatura de $10 \mathrm{~K}$.

As amostras implantadas do conjunto $2 \mathrm{a}$ e $2 \mathrm{~b}$ não apresentaram picos característicos de fotoluminescência. Os espectros obtidos das amostras do conjunto $2 \mathrm{a}$, medidos a $10 \mathrm{~K}$, podem ser observados na figura 4.18. As amostras do conjunto $2 \mathrm{~b}$ apresentaram espectro semelhante. Este resultado é surpreendente tendo em vista que parte do filme não deve ter sido afetada pela implantação iônica. No entanto, uma característica do material contribuiu para este comportamento: o c-GaN possui coeficiente de absorção de aproximadamente $\alpha=1.6 \times 10^{5} \mathrm{~cm}^{-1}$ para radiação com comprimento de onda de $325 \mathrm{~nm}$ [60], próximo do máximo da curva de absorção [61]. Este coeficiente equivale a uma profundidade de penetração aproximada $(1 / \alpha)$ de apenas $60 \mathrm{~nm}$, o que leva a uma grande atenuação do sinal proveniente das regiões mais profundas do filme.

Os defeitos produzidos na rede pelos íons implantados em $\mathrm{GaN}$ agem efetivamente como centros de recombinação não radiativa [62], assim os espectros obtidos de amostras implantadas tem sua intensidade significativamente reduzida, proporcionalmente à dose, o que justifica parcialmente a luminescência emitida pelas amostras implantadas com baixa dosagem. Em nenhum dos espectros foi observada a ocorrência dos picos principais de fotoluminescência do h-GaN, esperados nas energias de $3.42 \mathrm{e} 3.46 \mathrm{eV}$ para a temperatura de $10 \mathrm{~K}$. Mesmo a amostra Ref1 com incrustações hexagonais comprovadas por mapa da rede recíproca não apresentou tais picos.

Com o tratamento térmico as amostras implantadas não recuperaram sinal de fotoluminescência. 


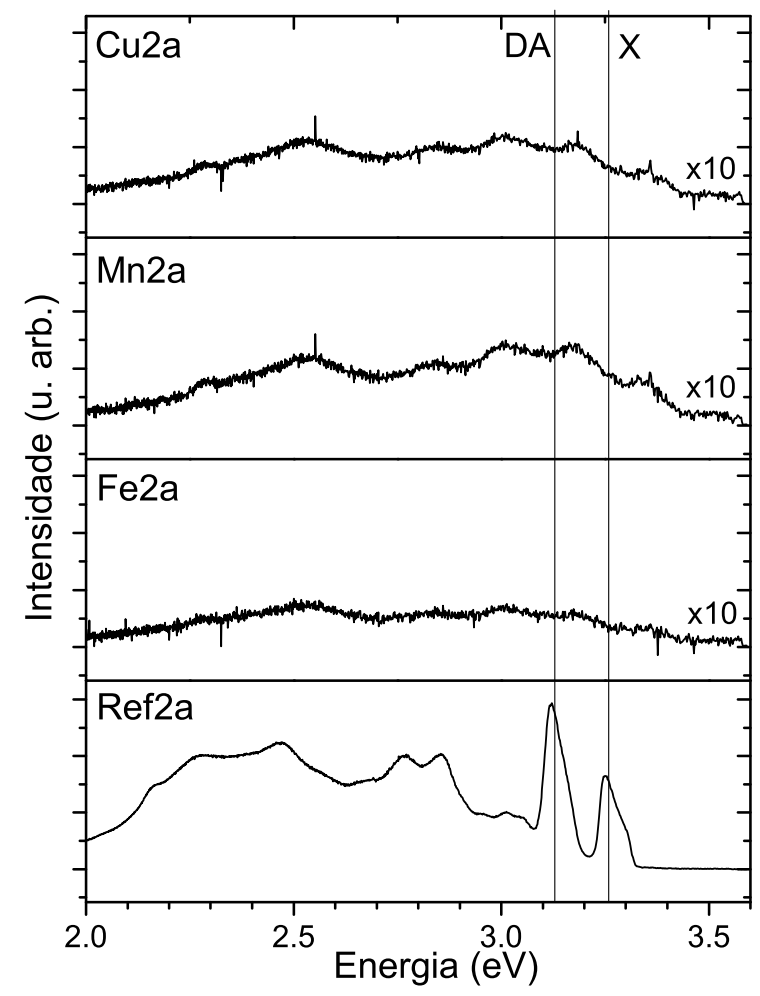

Figura 4.18: Espectros de fotoluminescência das amostras Ref2a virgem e Fe2a, Mn2a e Cu2a implantadas e não tratadas termicamente, medidos na temperatura de $10 \mathrm{~K}$.

Sendo grande a eficiência de absorção pelo c-GaN de fótons incidentes na região do ultravioleta o sinal dominante dos espectros obtidos vem da região mais próxima à superfície. Esse fato aliado à degradação preferencial da região durante o tratamento térmico reduzem a intensidade de luminescência das amostras tratadas. A amostra Fe1 que apresentava luminescência após a implantação deixou de fazê-lo com o tratamento térmico, resultado esperado considerando a grande degradação do filme desta amostra com o tratamento térmico, evidente nos mapas da rede recíproca das figuras $4.9 \mathrm{a}$ e $4.10 \mathrm{a}$. O tratamento térmico foi mais eficiente para a amostra $\mathrm{Cu} 1$ que continuou apresentando os picos característicos do c-GaN após o processo. Os espectros de fotoluminescência a $15 \mathrm{~K}$ da amostra Cu1 implantada e tratada termicamente e da amostra Ref1 também tratada são apresentados na figura 4.19 .

Na tabela 4.3 vemos a energia dos picos doador-aceitador e excitônico, extraídos da figura 4.19. Mesmo com o tratamento térmico as amostras Cu1 e Ref1 mantiveram o desvio em energia do pico DA. Considerando que este desvio está presente em todas as amostras do conjunto 1 estudadas independente da implantação iônica e tratamento térmico, é plausível que a amostra referente a este conjunto tenha sido involuntariamente dopada durante o crescimento. Amostras de c-GaN dopadas com baixa concentração de $\mathrm{C}$ apresentam deslocamento semelhante [63,64]. O tratamento térmico alterou a posição dos picos excitônicos das amostras Cu1 e Ref1 aproximando-os dos valores encontrados na literatura para o c-GaN. Esse deslocamento foi 10 e $15 \mathrm{meV}$ para as amostras Cu1 e Ref1 respectivamente. Estando o deslocamento para o vermelho do pico excitônico associado com o grau de strain das amostras, pode-se afirmar que o tratamento térmico reduziu o tensionamento interno da camada de $\mathrm{GaN}$, no entanto o tratamento térmico foi apenas parcialmente efetivo nesta 


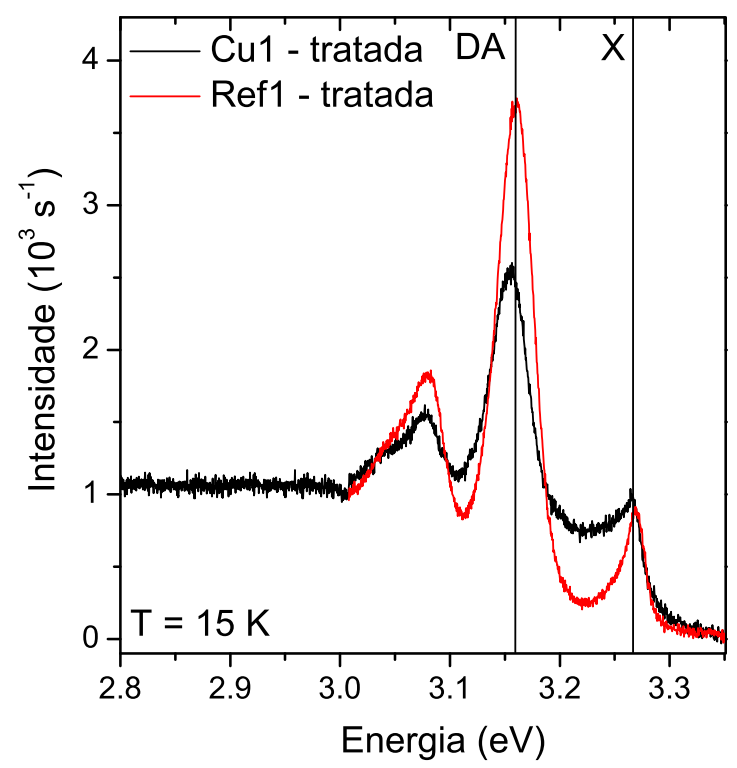

Figura 4.19: Espectros de fotoluminescência da amostra Cu1 e Ref1 pós tratamento térmico (900 $\left.{ }^{\circ} \mathrm{C}\right)$, obtidos na temperatura de $15 \mathrm{~K}$.

redução já que as amostras tratadas ainda apresentaram deslocamento de $10 \mathrm{meV}$ em relação às amostras referência $2 \mathrm{a}$ e $2 \mathrm{~b}$.

\begin{tabular}{|c|c|c|}
\hline Amostra & $E_{\mathrm{DA}}(\mathrm{eV})$ & $E_{\mathrm{X}}(\mathrm{eV})$ \\
\hline Cu1 & 3.155 & 3.265 \\
Ref1 & 3.160 & 3.270 \\
\hline
\end{tabular}

Tabela 4.3: Energia dos picos DA e X, extraídos dos espectros de fotoluminescência das amostras Cu1 e Ref1 tratadas, medidos a $15 \mathrm{~K}$.

Embora a amostra Cu2a não tenha emitido os picos característicos após o tratamento térmico foi observada uma larga banda de luminescência com energia em torno de $1.9 \mathrm{eV}$. Vemos na figura 4.20 o espectro de fotoluminescência da amostra Cu2a em torno desta região.

Esta banda de emissão é conhecida como banda RL (red luminescence) e é análoga [65] à banda YL (yellow luminescence) presente em amostras de h-GaN e já intensamente estudada [56]. A origem destas bandas ainda é controversa, um estudo pioneiro de Pankove e Hutchby [66] obteve espectros de fotoluminescência de amostras de h-GaN implantadas com 35 elementos diferentes e na grande maioria deles houve aparecimento ou fortalecimento da banda YL, fato que evidenciou o papel de defeitos nesta emissão. O trabalho de Ogino e Aoki [67] através de estudos de fotoluminescência em função da intensidade de excitação conclui que a banda YL possui características de emissão por recombinação doador-aceitador e a partir disso cria um modelo de bandas onde considera-se como doador o estado de vacâncias de nitrogênio $\left(V_{N}\right)$, assim a energia do estado aceitador pode ser obtida através da seguinte equação:

$$
E_{\text {pico }}=E_{\text {gap }}-\left(E_{D}+E_{A}\right)+E_{\text {coul }}
$$

Onde $E_{\text {pico }}$ é a energia do pico YL, $E_{D}$ e $E_{A}$ as energias de ionização do estado doador e aceitador 


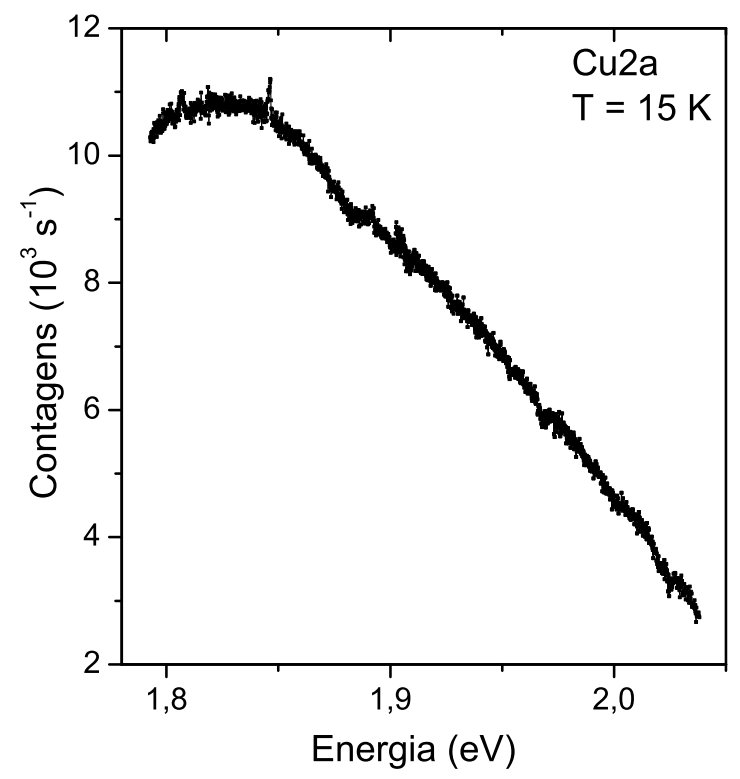

Figura 4.20: Espectro de fotoluminescência da amostra Cu2a pós tratamento térmico $\left(900{ }^{\circ} \mathrm{C}\right)$, obtido na temperatura de $15 \mathrm{~K}$.

e $E_{\text {coul }}$ um termo coulombiano inversamente proporcional à distância entre o par. Desta equação obtém-se tanto para h- como para o c-GaN valores altos de $E_{A}$ indicando um estado aceitador profundo, que Ogino e Aoki atribuem a um complexo de vacâncias de galio $\left(V_{G a}\right)$ com alguma impureza.

Estudou-se também o efeito da temperatura no espectro de fotoluminescência da amostra referência 2a tratada. Os espectros obtidos nas temperaturas de 15 e $300 \mathrm{~K}$ podem ser observados na figura 4.21 .

Com o aumento da temperatura os picos característicos doador-aceitador e excitônico dão lugar a um único pico com energia intermediária de $3.2 \mathrm{eV}$. Sabe-se que $E_{\text {gap }}$ de um material semicondutor varia com a temperatura e esta variação pode ser descrita aproximadamente pela expressão de Varshni:

$$
E_{\text {gap }}=E_{\text {gap }}(0)-\frac{\alpha T^{2}}{T+\beta}
$$

Onde $E_{\text {gap }}(0)$ é a energia do gap em temperatura zero, $\alpha$ e $\beta$ constantes características do material semicondutor.

A curva experimental de $E_{\text {gap }}$ em função da temperatura para o c-GaN com a expressão de Varshni ajustada é apresentada na figura 4.22. obtida por Ramírez-Flores et al. [68].

Sabemos que a energia do pico excitônico é igual a $E_{\text {gap }}$ menos a energia coulombiana de ligação do exciton $E_{\text {lig }}$, esta praticamente independente da temperatura. A energia do pico excitônico $\left(E_{X}\right)$ está portanto diretamente relacionada com $E_{\text {gap }}$ e deve possuir dependência com a temperatura do mesmo tipo da vista na figura 4.22. Nos espectros medidos da amostra Ref2a o deslocamento entre o pico excitônico em $15 \mathrm{~K}$ e o pico medido em temperatura ambiente foi de $50 \mathrm{meV}$ e coincide com a variação da energia do gap obtido experimentalmente por Ramírez-Flores et al. Assim podemos afirmar que o pico observado nos espectros de fotoluminescência da amostra Ref2a a $300 \mathrm{~K}$ é o pico excitônico $(\mathrm{X})$ deslocado por efeito da temperatura. Mais uma vez foram observados picos em 


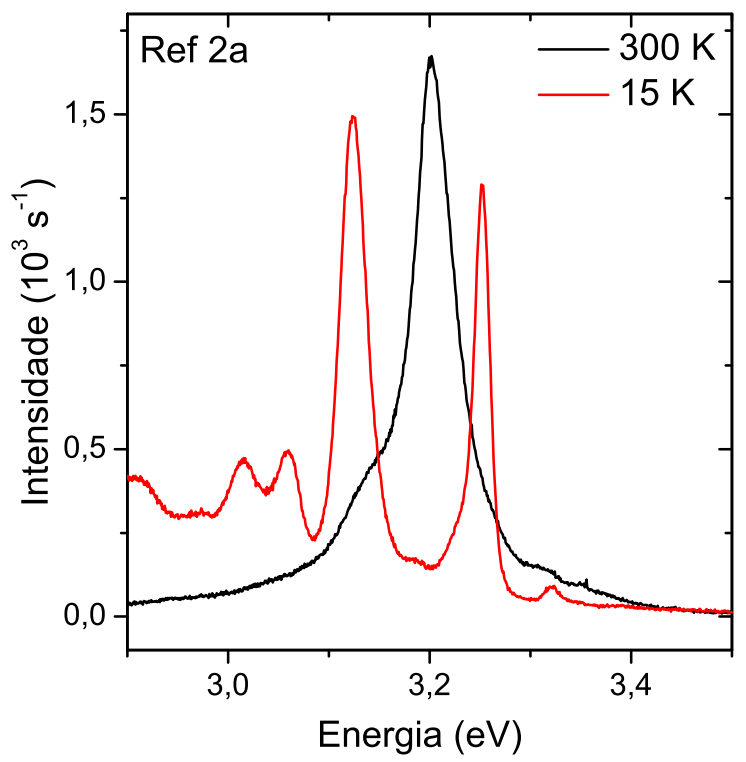

Figura 4.21: Espectros de fotoluminescência da amostra Ref2a tratada termicamente nas temperaturas de $15 \mathrm{~K}$ e $300 \mathrm{~K}$.

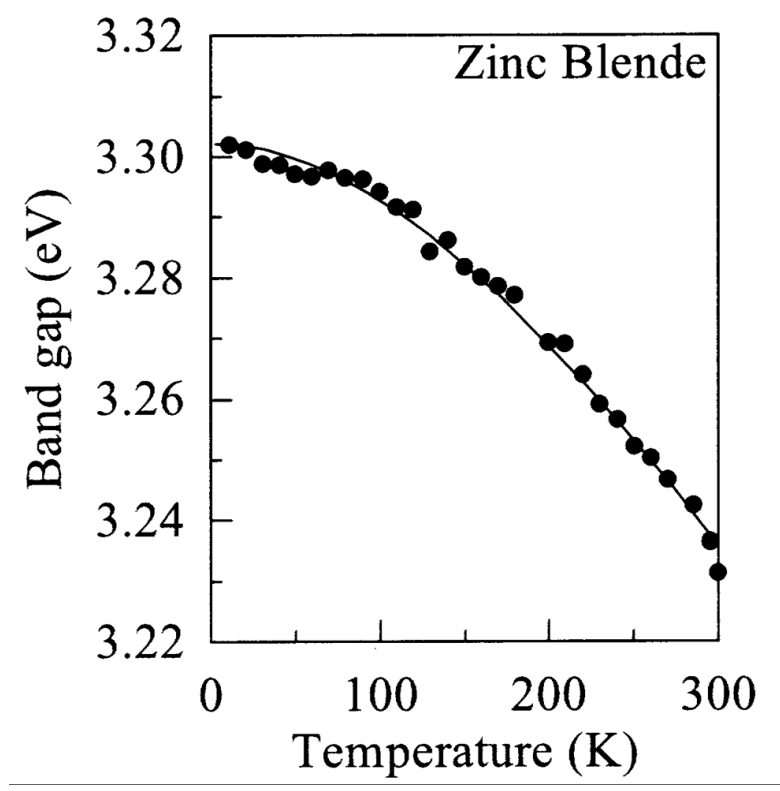

Figura 4.22: Curva experimental de $E_{\text {gap }}$ em função da temperatura para o c-GaN com expressão de Varshni ajustada. Retirada de Ramírez-Flores et al. [68].

3.01, 3.08 e $3.31 \mathrm{eV}$, estes não provenientes da amostra e sim da cola fixadora ao porta-amostras, que mesmo não incidida diretamente pelo feixe emitiu devido a reflexões nas janelas óticas, este problema não afetou a medida em alta temperatura, realizada com o criostato aberto. 


\subsection{Espectroscopia Raman}

O baixo coeficiente de absorção $(\alpha)$ da amostra para as duas linhas de laser utilizadas nas medidas de espectroscopia Raman $(\lambda=514$ e $568 \mathrm{~nm})$ permite a medição da emissão Raman proveniente de todas as suas camadas constituintes, em contraste com a espectroscopia de fotoluminescência que extrai informação apenas do GaN. Todas as medidas Raman foram realizadas à temperatura ambiente.

Vemos na figura 4.23 os espectros Raman das amostras referência dos conjuntos 1, 2a e 2b não tratadas termicamente, obtidos na linha $514 \mathrm{~nm}$.

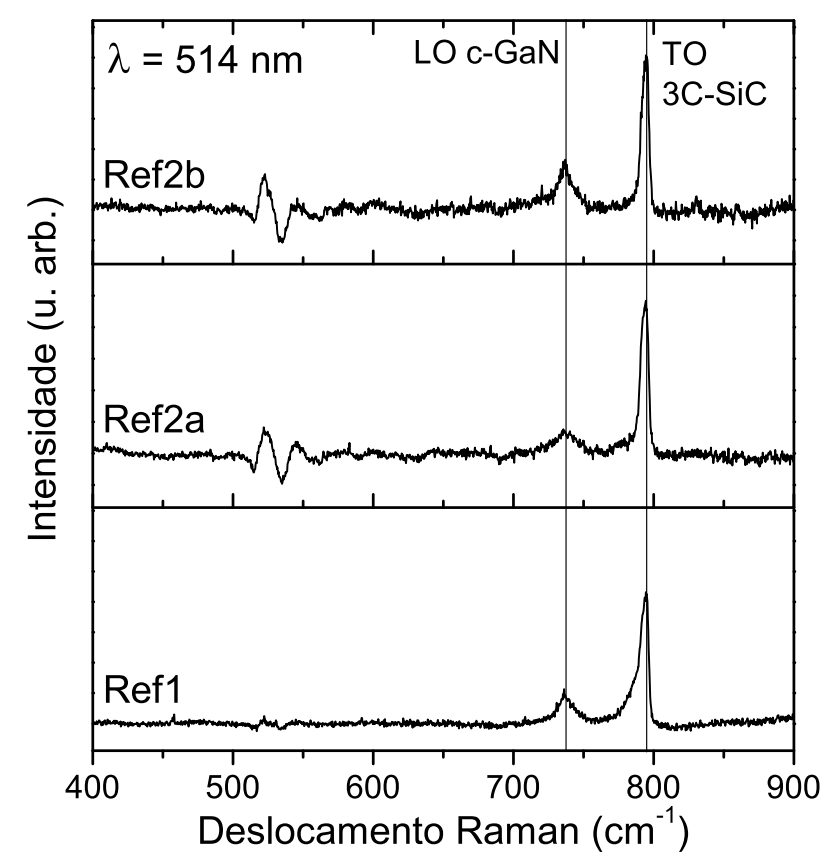

Figura 4.23: Espectros Raman das amostras de referência não tratadas dos três conjuntos, medidos à temperatura ambiente na linha $514 \mathrm{~nm}$.

O pico observado com deslocamento Raman de aproximadamente $730 \mathrm{~cm}^{-1}$ é referente ao espalhamento Raman pelos fônons do tipo longitudinal ótico (LO) do c-GaN [69]. De acordo com as regras de seleção da tabela 2.3 o pico referente ao modo LO do GaN deve de fato ser observado em um espectro não polarizado, já que o mesmo é permitido na configuração cruzada $(z[x, y] \bar{z})$. O alto ruido decorrente da subtração da banda de luminescência dos espectros obtidos na linha $514 \mathrm{~nm}$ tornou inviável a análise de larguras à meia altura dos picos referentes ao c-GaN. Com deslocamento Raman de $797 \mathrm{~cm}^{-1}$ observou-se o pico correspondente ao espalhamento Raman pelos fônons transversais óticos (TO) do substrato de 3C-SiC. Possuindo a estrutura da blenda de zinco, o 3C-SiC está sujeito às regras de seleção da tabela 2.3 e o espalhamento pelo modo TO é proibido na configuração medida. No entanto, as regras de seleção pressupõem que todos os graus de simetria do cristal estejam preservados. Em um cristal real a presença de defeitos e impurezas na rede cristalina provoca quebras localizadas nesta simetria e consequentemente a violação das regras de seleção vibracionais [30]. Mesmo proibido o pico TO do substrato foi o mais intenso em todos os espectros obtidos, reflexo da maior espessura do substrato em relação ao filme de GaN. Não foi observada variação significativa entre as amostras no deslocamento Raman de ambos os picos. As oscilações presentes em torno de $530 \mathrm{~cm}^{-1}$ nos espectros da figura 4.23 são artefatos 
gerados por defeito no sistema de monocromação que efetivamente impediram o estudo da região afetada.

Com a implantação iônica algumas amostras obtiveram significativa alteração de seu espectro Raman. Estão apresentados nas figuras 4.24 e 4.25 os espectros Raman das amostras dos conjuntos 1, 2a e $2 \mathrm{~b}$ não tratadas termicamente, obtidos na linha $514 \mathrm{~nm}$, medidos à temperatura ambiente.

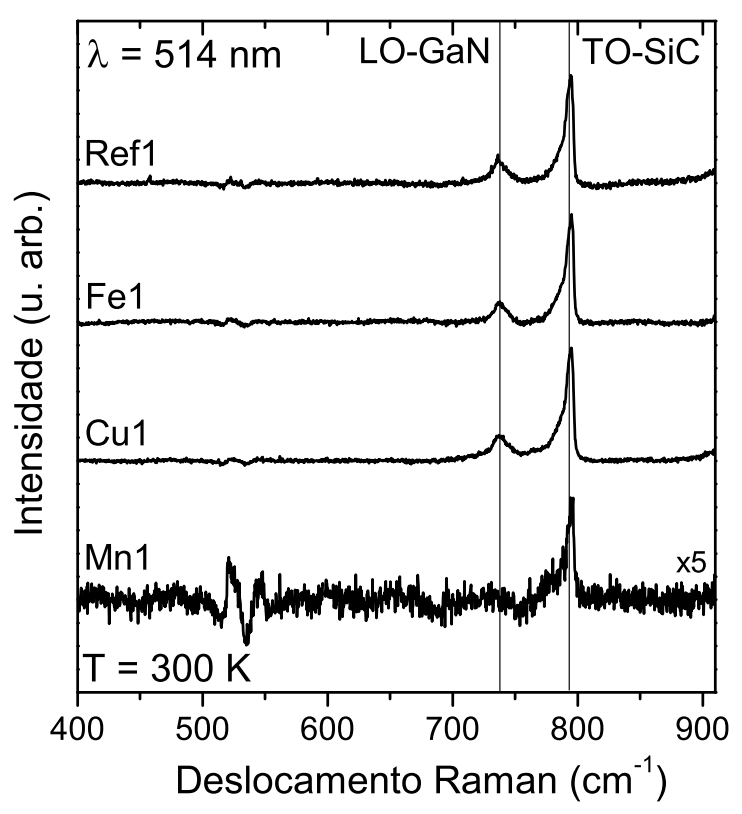

Figura 4.24: Espectros Raman das amostras do conjunto 1 implantadas e não tratadas com a referência para comparação. Medidos à temperatura ambiente na linha $514 \mathrm{~nm}$.

Nos espectros das amostras implantadas com baixa dose $\left(1.2 \times 10^{16} \mathrm{~cm}^{-2}\right)$ da figura 4.24 observamos que com o processo, as amostras implantadas com $\mathrm{Fe}$ e $\mathrm{Cu}$ apresentaram os picos LO c-GaN e TO 3C-SiC preservados, indicando que a implantação nesta dose manteve cristalinidade suficiente do filme para a observação do modo LO. Já a amostra Mn1 apresentou sinal Raman menos intenso em relação as demais do mesmo conjunto, apenas o pico referente ao substrato foi detectado no espectro. Os espectros obtidos para as amostras implantadas com alta dosagem encontram-se na figura 4.25. Nota-se que a implantação com alta dosagem suprimiu efetivamente a presença de picos nos espectros de todas as amostras dos grupos $2 \mathrm{a}$ e $2 \mathrm{~b}$, exceção ao pico TO 3C-SiC detectado nas amostras implantadas com Fe.

Com o tratamento térmico realizado na temperatura de $900{ }^{\circ} \mathrm{C}$ as amostras do conjunto 2a recuperaram significativamente a intensidade do espectro. Vemos na figura 4.26 a comparação entre os espectros Raman da amostra Fe2a, obtidos pré e pós tratamento térmico em $900{ }^{\circ} \mathrm{C}$.

Para as medidas das amostras tratadas o defeito no sistema de monocromação gerador do artefato previamente observado em torno de $530 \mathrm{~cm}^{-1}$ foi solucionado, assim os picos referentes ao espalhamento Raman pelos modos de vibração TO do c-GaN $\left(555 \mathrm{~cm}^{-1}\right), \mathrm{E}_{2}$ do h-GaN (566 $\left.\mathrm{cm}^{-1}\right)$ [70] e LO do $\mathrm{Si}\left(520 \mathrm{~cm}^{-1}\right)$ puderam ser observados. O pico TO do c-GaN é proibido pelas regras de seleção e sua observação só é possível devido à impurezas e defeitos no filme. Em comparação ao espectro da amostra Fe2a implantada, a maior intensidade do pico LO do cGaN obtido após o tratamento tornou-o claramente discernível do ruido de medição, evidência da recuperação da rede cristalina do filme de GaN com o tratamento térmico. Observou-se também 

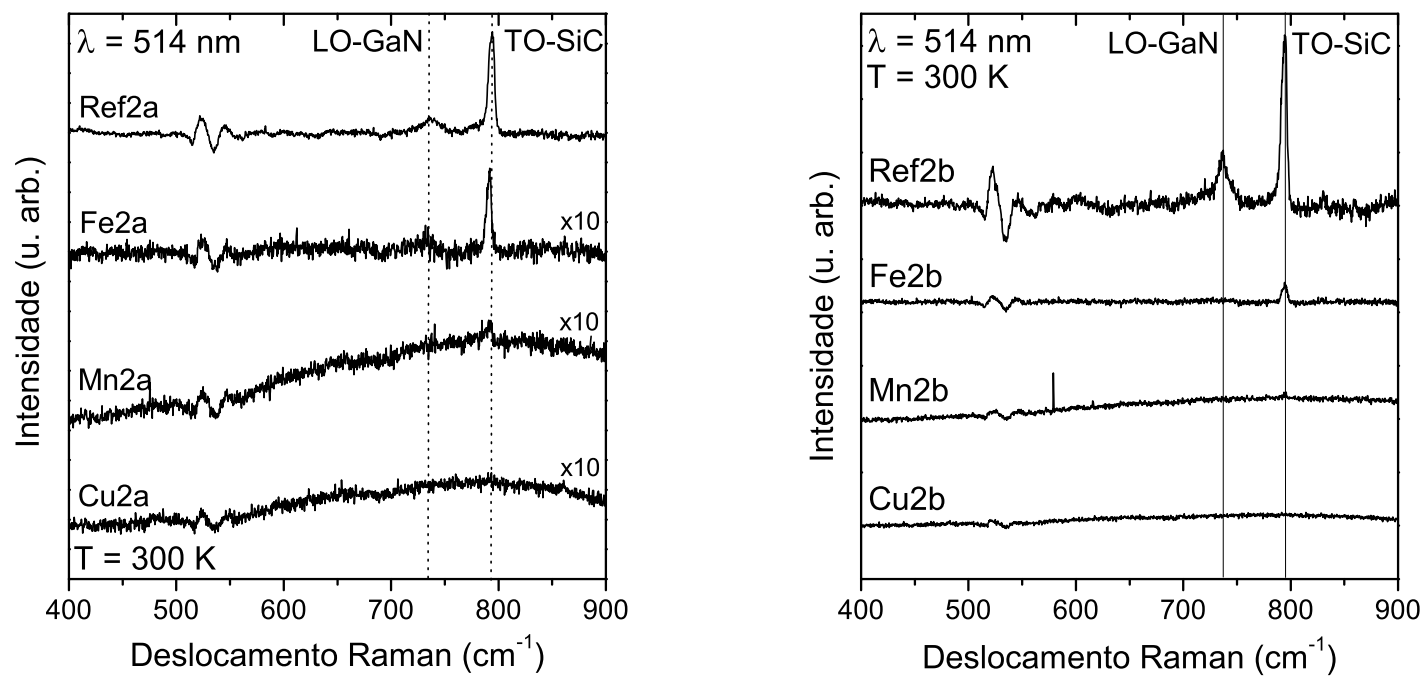

Figura 4.25: Espectros Raman das amostras dos conjuntos 2a e 2b implantadas e não tratadas termicamente e de suas respectivas amostras referência. Espectros medidos à temperatura ambiente na linha $514 \mathrm{~nm}$.

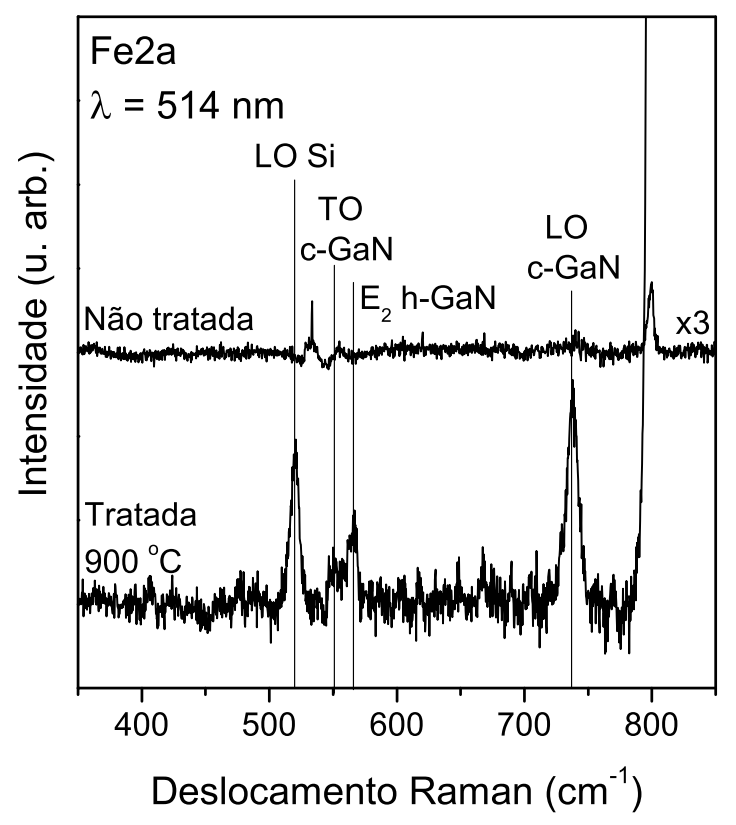

Figura 4.26: Espectros Raman da amostra Fe2a antes e após tratamento térmico $\left(900{ }^{\circ} \mathrm{C}\right)$, medidos à temperatura ambiente na linha $514 \mathrm{~nm}$.

que o sinal proveniente de todas as camadas da amostra foi atenuado pela implantação iônica, não apenas o sinal da região implantada, uma maior absorção de fótons pelo filme com o aumento da desordem cristalina é responsável por este efeito [62].

Recuperação semelhante com o tratamento térmico evidenciou-se nos espectros Raman obtidos 
para as outras amostras implantadas do grupo 2a, apresentados na figura 4.27. Ambos os picos LO e TO do c-GaN foram detectados, alem do pico $\mathrm{E}_{2}$ do h-GaN, demonstrando a presença de fase hexagonal após o tratamento térmico. Para a comparação dos sinais foi utilizado o mesmo tempo de acumulação na medida das amostras tratadas e não tratadas. $\mathrm{O}$ aumento da intensidade do pico TO 3C-SiC, devido ao tratamento térmico, fez com que a contagem ultrapassasse o limite de saturação do detetor CCD, impedindo sua observação.

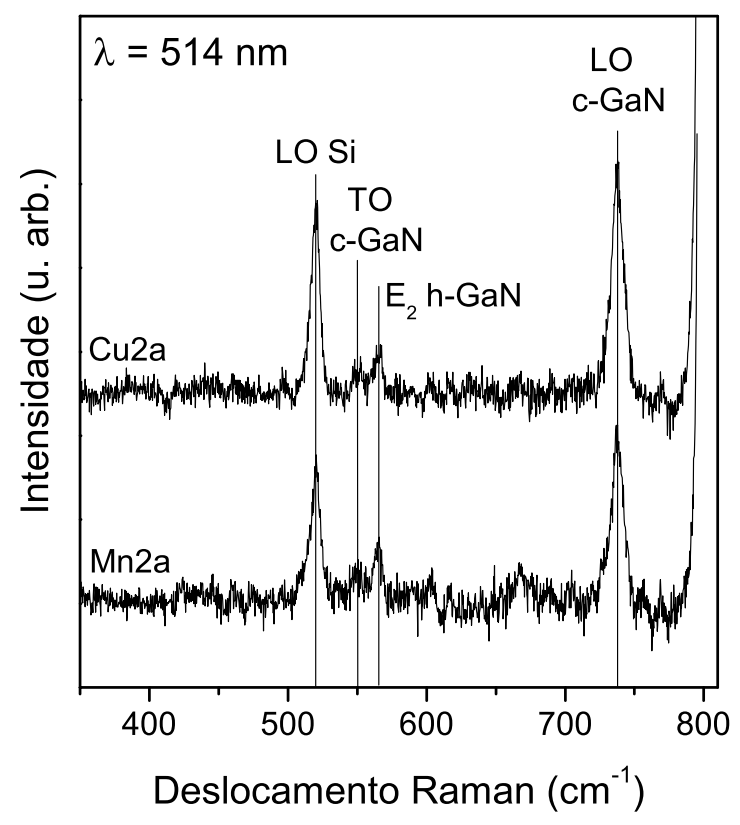

Figura 4.27: Espectros Raman das amostras Mn2a e Cu2a após tratamento térmico $\left(900{ }^{\circ} \mathrm{C}\right)$, medidos à temperatura ambiente na linha $514 \mathrm{~nm}$.

A luminescência do substrato detectada nas medidas realizadas na linha de $514 \mathrm{~nm}$ comprometeu consideravelmente o sinal destes espectros. Dois fatores principais provocaram esta degradação: a incerteza provocada pela remoção da linha base e o aumento na intensidade medida que reduziu o tempo máximo de integração do sinal, determinado pela saturação da CCD. Com a utilização da linha $568 \mathrm{~nm}$ como fonte este problema não ocorre, já que seus fótons possuem menor energia e não geram uma banda de luminescência intensa no intervalo de energia estudado. Esta solução só foi encontrada após o tratamento térmico das amostras e portanto não foi possível a medição das amostras não tratadas na linha de $568 \mathrm{~nm}$. Na figura 4.28 tem-se uma comparação entre os espectros da amostra referência 2a tratada obtidos nas linhas 514 e $568 \mathrm{~nm}$.

O espectro obtido na linha de $568 \mathrm{~nm}$ destaca-se pelo menor ruido em relação ao obtido na linha $514 \mathrm{~nm}$. Nota-se também que a intensidade dos picos referentes ao filme e ao substrato é maior no espectro obtido com a linha $514 \mathrm{~nm}$, isso ocorreu pois a potência máxima do laser quando utilizado na linha $568 \mathrm{~nm}$ é menor do que a potência utilizada para a obtenção dos espectros com a linha $514 \mathrm{~nm}$. Entretanto, a comparação direta entre intensidades raramente é utilizada na análise de espectros Raman, sendo mais importante a medida da largura à meia altura, cuja análise para os picos referentes ao filme e ao substrato não mostrou diferença significativa entre os dois comprimentos de onda utilizados. O mesmo não ocorreu para o pico TO da camada de Si presente no verso das amostras, que teve sua intensidade relativa aos outros picos fortemente reduzida no espectro obtido na linha $514 \mathrm{~nm}$. Com a energia de $2.41 \mathrm{eV}$ os fótons da linha $514 \mathrm{~nm}$ tem maior 


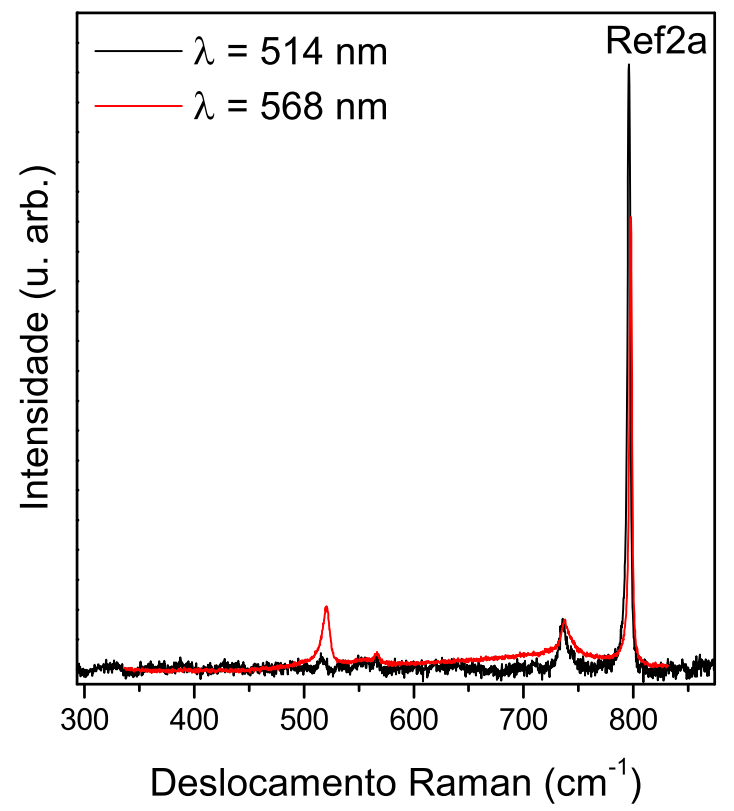

Figura 4.28: Espectros Raman obtidos da amostra Ref2a tratada termicamente nas linhas 514 e $568 \mathrm{~nm}$.

probabilidade de serem absorvidos pelo $3 \mathrm{C}-\mathrm{SiC}\left(E_{\text {gap }}=2.36 \mathrm{eV}\right)$ do que os fótons da linha 568 $\mathrm{nm}$, que possuem energia menor que $E_{\text {gap }}(2.18 \mathrm{eV})$. É possível que a forte luminescência pelo substrato atenue o feixe incidente reduzindo o sinal Raman proveniente das regiões mais profundas da amostra.

$\mathrm{Na}$ figura 4.29 encontram-se os espectros Raman obtidos na linha $568 \mathrm{~nm}$ para as amostras do conjunto 1 e 2 a tratadas termicamente à $900{ }^{\circ} \mathrm{C}$ e para a amostra Fe2b tratada em duas etapas primeiro a $800{ }^{\circ} \mathrm{C}$ e posteriormente a $900{ }^{\circ} \mathrm{C}$.

Nota-se no espectro da amostra Ref2a a presença do pico $\mathrm{E}_{2}$ do h-GaN $\left(566 \mathrm{~cm}^{-1}\right)$, não observado no espectro da amostra Ref1, de maneira que inverteram-se os resultados observados nas amostras virgens onde apenas a amostra Ref1 demonstrou fase hexagonal através de seu mapa da rede recíproca. Seguindo os resultados das respectivas referências as amostras Mn2a e Cu2a apresentaram sinal referente a fase hexagonal, enquanto nas amostras com baixa dosagem apenas no espectro da amostra Fe1 foi detectada a presença do pico $\mathrm{E}_{2}$ do h-GaN. Sabe-se que a degradação das amostras por perda de $\mathrm{N}_{2}$ com o tratamento térmico é proporcional a dose implantada [71].

Com o aumento da qualidade dos espectros torna-se possível uma análise quantitativa da qualidade cristalina do filme de c-GaN através da largura à meia altura de seu pico LO. As amostras implantadas do conjunto 2a apresentaram larguras em torno de $9(1) \mathrm{cm}^{-1}$ enquanto a referência $2 \mathrm{a}$ também tratada termicamente apresentou largura de $6(1) \mathrm{cm}^{-1}$. O mesmo não aconteceu com as amostras implantadas do conjunto 1 que, com exceção da amostra Mn1, não apresentaram diferença significativa de largura do pico em relação à amostra referência $\left(10(1) \mathrm{cm}^{-1}\right)$. Tendo em vista os espectros Raman obtidos antes do tratamento térmico esse resultado é esperado já que as amostras implantadas com alta dosagem apresentaram sinal Raman fortemente atenuado, o mesmo não ocorrendo com as amostras Fe1 e Cu1, no entanto, a aparente boa qualidade cristalina da amostra Fe1 contradiz os resultados de espectroscopia de raios X e de fotoluminescência que indicam uma degradação da mesma pelo tratamento térmico o que evidencia a diferença de sensibilidade entre 

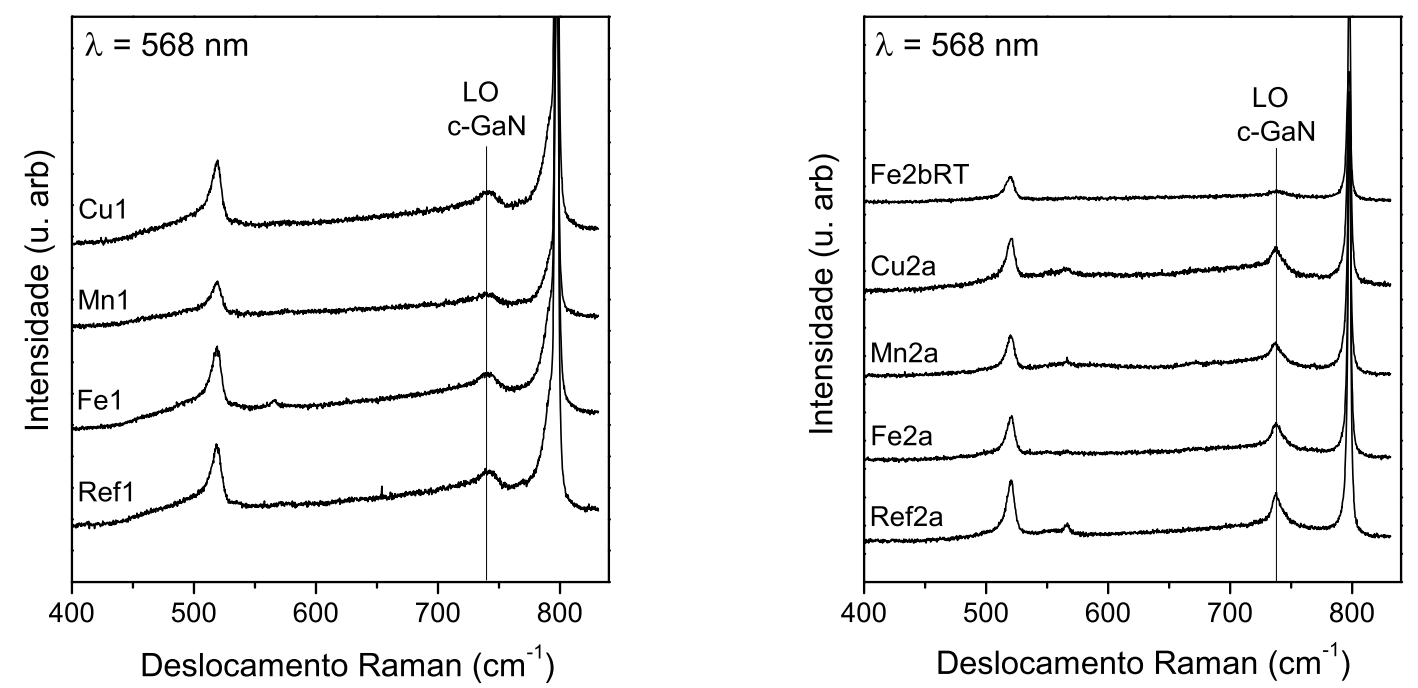

Figura 4.29: Espectros Raman das amostras dos conjuntos 1 e 2a tratadas termicamente e da amostra Fe2b retratada. Espectros medidos à temperatura ambiente na linha $568 \mathrm{~nm}$.

as técnicas. A intensidade do espectro da amostra Fe2b retratada foi muito inferior à das demais amostras, evidenciando a degradação resultante de um tempo de tratamento maior.

Vemos na tabela $4.4 \mathrm{um}$ resumo qualitativo dos resultados de caracterização estrutural obtidos para as todas as amostras de c-GaN implantadas. Em geral observou-se que as técnicas concordaram entre si, com exceção dos dados de difração de raios-x e espectroscopia Raman da amostra Mn1 tratada que apresentaram resultados conflitantes.

\begin{tabular}{|c|c|c|c|c|c|c|}
\hline Amostra & RX implant. & RX trat. & PL implant. & PL trat. & Raman implant. & Raman trat. \\
\hline Fe2a & D & R & D & - & D & R \\
Mn2a & D & R & D & - & D & R \\
Cu2a & D & R & D & - & D & R \\
Fe2b & D & - & D & - & D & - \\
Mn2b & D & - & D & - & D & - \\
Cu2b & D & - & D & - & D & - \\
Fe1 & D & D & N & D & N & N \\
Mn1 & D & D & D & - & D & R \\
Cu1 & D & D & N & N & N & N \\
\hline
\end{tabular}

Tabela 4.4: Tabela resumo com os resultados das técnicas de caracterização estrutural de cada amostra. D - deterioração da rede, R - recuperação da rede, N - Espectro presente mas não indica recuperação nem deterioração, - - espectro ausente ou não aplicável. 


\subsection{Magnetometria SQUID}

A caracterização magnética de todas as amostras estudadas foi realizada com auxílio de um magnetômetro SQUID. Com estas medidas buscou-se a descrição de alguns fenômenos magnéticos gerados pela implantação de íons magnéticos (Fe e $\mathrm{Mn}$ ) e não magnéticos $(\mathrm{Cu})$ nas amostras de c-GaN. Estudando amostras implantadas com diferentes dosagens procurou-se avaliar o efeito da variação da concentração de dopantes e do dano à rede cristalina, ambos proporcionais à dose implantada, já com a implantação de íons não magnéticos investigou-se a influência de defeitos no magnetismo das amostras.

\subsubsection{Amostras de referência}

Todas as camadas que formam uma amostra recém crescida (figura 2.4) são constituídas de materiais diamagnéticos; assim as amostras referência devem apresentar apenas respostas diamagnéticas a um campo aplicado.
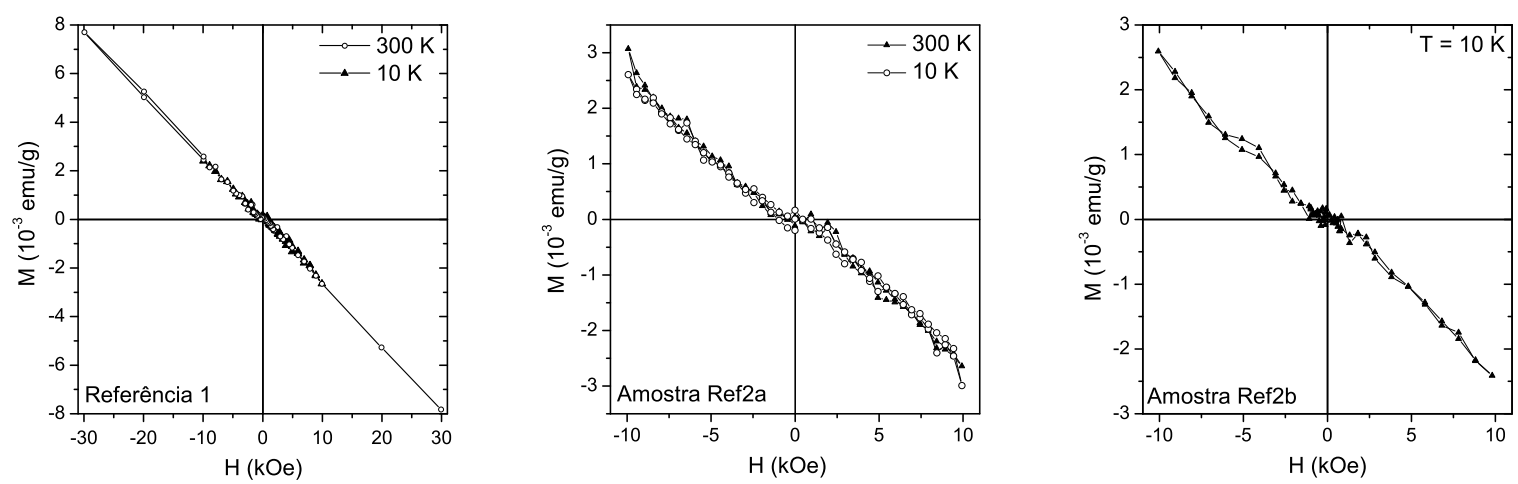

Figura 4.30: Medidas de magnetização por campo aplicado das amostras Ref1 e Ref2a não tratadas obtidas nas temperaturas de 10 e $300 \mathrm{~K}$ e da amostra Ref2b também não tratada obtida na temperatura de $10 \mathrm{~K}$.

Na figura 4.30 apresentamos as medidas de magnetização por campo nas temperaturas de 10 e $300 \mathrm{~K}$ para a amostra referência dos grupos 1 e 2a não tratadas e da amostra Ref2b também não tratada obtida na temperatura de $10 \mathrm{~K}$. Possuindo a mesma ordem de grandeza as susceptibilidades de filme e substrato, o 3C-SiC é responsável pela quase totalidade do sinal magnético das amostras referência em virtude da maior espessura de sua camada. Os valores de susceptibilidade obtidos para as referências são compatíveis com o valor do carbeto de silício encontrado na literatura [72]. A incerteza elevada em baixos campos gerou um aparente momento de saturação no espectro da amostra Ref2a, no entanto, o caráter diamagnético da amostra foi comprovado pelo SQUID em através de medidas em campos altamente estabilizados. Não observou-se variação significativa da susceptibilidade total das amostras Ref1 e Ref2a entre 10 e $300 \mathrm{~K}$, indicando ausência de paramagnetismo dentro da incerteza estimada no ajuste.

Para atestar que o processo de tratamento térmico não foi fonte de nenhuma contaminação magnética nas amostras as referências 1 e 2 a foram tratadas concomitantemente às amostras implantadas do mesmo conjunto. Nas medidas realizadas em função do campo não observou-se mudança significativa na resposta magnética das amostras referência devido ao tratamento térmico, que permaneceram apenas diamagnéticas sem variação significativa de susceptibilidade, sendo justificado assim o estudo das mudanças no magnetismo das amostras implantadas geradas pelo processo. Vemos na figura 4.31 a comparação entre as medidas de magnetização por campo aplicado da amostra 
Ref2a pré e pós tratamento térmico, obtidas na temperatura de $10 \mathrm{~K}$.

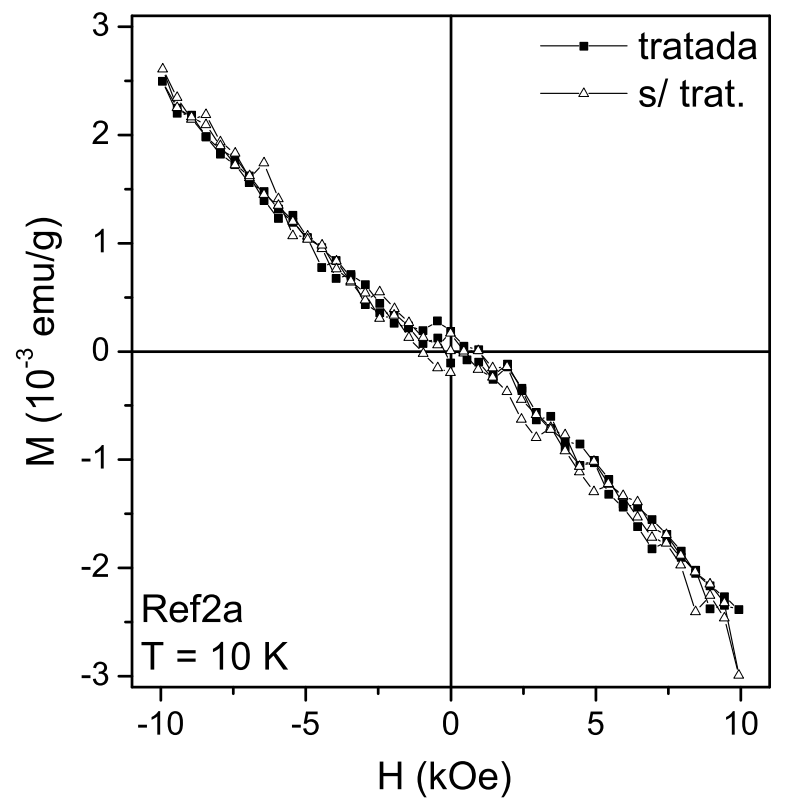

Figura 4.31: Comparação entre as medidas de magnetização por campo aplicado da amostra Ref2a não tratada e tratada obtidas na temperatura de $10 \mathrm{~K}$.

Os Valores de $\chi_{T}$ e momento de saturação das amostras referência, extraídas das medidas de magnetização em função do campo a $10 \mathrm{~K}$ encontram-se na tabela 4.5.

\begin{tabular}{|c|c|c|}
\hline & Pré Tratamento & Pós Tratamento \\
\hline Amostra & $\chi_{T}\left(10^{-7} \mathrm{emu} /\right.$ Oe.g $)$ & $\chi_{T}\left(10^{-7} \mathrm{emu} /\right.$ Oe.g $)$ \\
\hline Ref1 & -2.70 & -2.63 \\
Ref2a & -2.75 & -2.75 \\
Ref2b & -2.65 & - \\
3C-SiC [72] & -2.67 & -2.67 \\
\hline
\end{tabular}

Tabela 4.5: Valores de $\chi_{T}$ pré e pós tratamento térmico das amostras referência, extraídas das medidas de magnetização em função do campo na temperatura de $10 \mathrm{~K}$, juntamente com o valor tabelado da susceptibilidade por massa do 3C-SiC [72].

\subsubsection{Amostras implantadas com Fe}

Realizou-se a implantação de íons de Fe principalmente tendo em vista o seu elevado momento magnético no estado de oxidação 3+. Baseando-se na proposta de Dietl et al. [3], buscamos a formação de um semicondutor magnético diluído através da interação direta ou indireta entre os íons localizados, em substituição de átomos de gálio. Estudos em h-GaN apontam que esse é de fato o processo de incorporação predominante em amostras implantadas com Fe e tratadas termicamente [73]. Muito do trabalho exercido no desenvolvimento de semicondutores magnéticos através da dopagem de semicondutores comuns teve como preocupação evitar a formação de 
fases secundárias nestes materiais. Acredita-se que estas fases dificultariam a injeção de corrente polarizada [74], fundamental para a construção de dispositivos. No entanto estudos sobre $(\mathrm{Ga}, \mathrm{Fe}) \mathrm{N}$ indicam que os átomos dopantes possuem também tendências de aglomeração [75, 76]. Mesmo assumindo-se distribuição ordenada a presença de ferromagnetismo por interação entre os dopantes é controversa. Estudos teóricos preveem interação antiferromagnética entre os íons magnéticos $[77,78]$. Trabalhos sobre amostras de GaN implantadas com Fe não excluem a possibilidade de formação de precipitados de nitretos de Fe [50] e de Fe metálico [49] durante a implantação e posterior tratamento térmico. Muitos dos possíveis compostos formados são ferro ou ferrimagnéticos tornando mais complexo o estudo de outros possíveis processos geradores de magnetismo.

\subsubsection{Medidas em função do campo}

Todas as amostras implantadas com Fe foram caracterizadas magneticamente através de medidas de magnetização em função do campo magnético aplicado. Tabelas resumindo os valores importantes extraídos das medidas em função do campo encontram-se no final da seção.

Com a implantação iônica da amostra Fe1 realizada com dose $1.2 \times 10^{16} \mathrm{~cm}^{-2}$, houve o aparecimento de comportamento ferromagnético, sem variação significativa de $\chi_{T}$ entre as temperaturas de 10 e $300 \mathrm{~K}$. As medidas de magnetização por campo magnético da amostra Fe1, implantada e não tratada, nas temperaturas de 10 e $300 \mathrm{~K}$ estão apresentadas na figura 4.32.

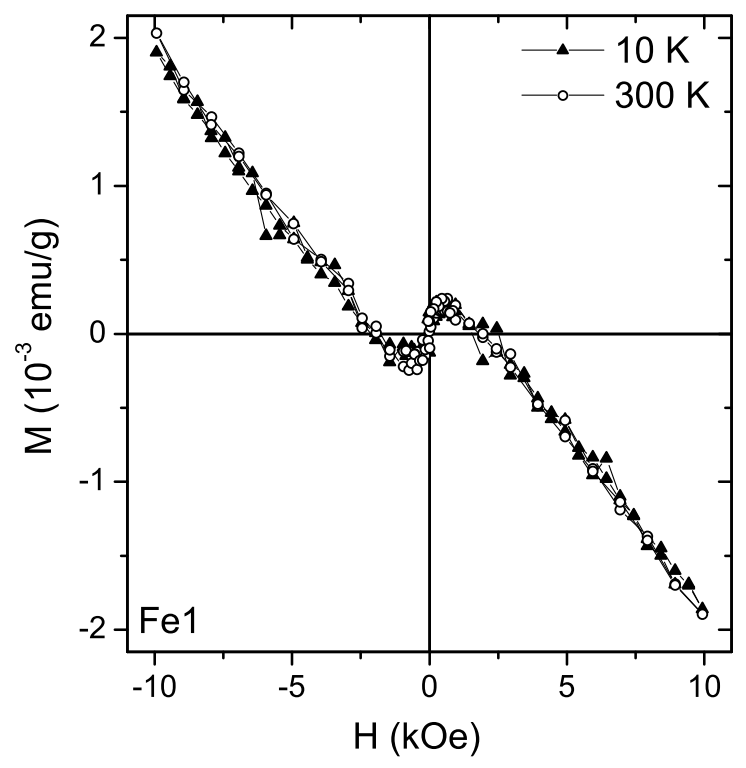

Figura 4.32: Medidas de magnetização por campo aplicado nas temperaturas de 10 e $300 \mathrm{~K}$ da amostra Fe1 não tratada.

Após o tratamento térmico realizado na mesma amostra à temperatura de $900{ }^{\circ} \mathrm{C}$ a magnetização de saturação foi a zero e a amostra voltou a mostrar comportamento diamagnético dentro da incerteza.

O desaparecimento do ferromagnetismo não foi acompanhado por aumento da resposta paramagnética da amostra a $10 \mathrm{~K}$. Na curva de magnetização por campo a $2 \mathrm{~K}$ observamos uma diferença de $\chi_{T}$ apreciável, que equivaleria ao momento magnético de aproximadamente $80 \%$ dos íons previamente responsáveis pelo momento de saturação do material a $300 \mathrm{~K}$, mas de fato não 


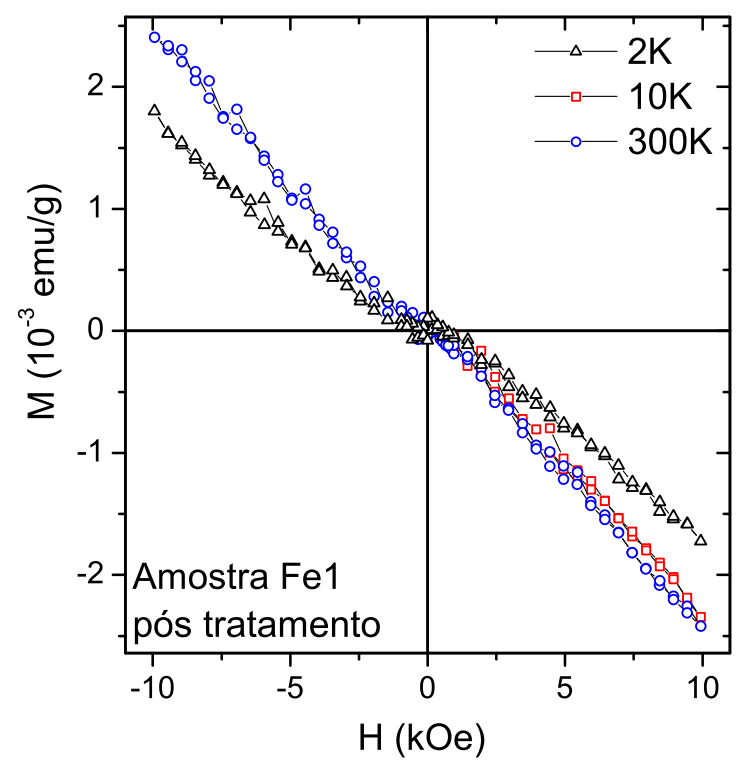

Figura 4.33: Medidas de magnetização por campo aplicado nas temperaturas de 2, 10 e $300 \mathrm{~K}$ para a amostra Fe1 tratada termicamente a $900{ }^{\circ} \mathrm{C}$.

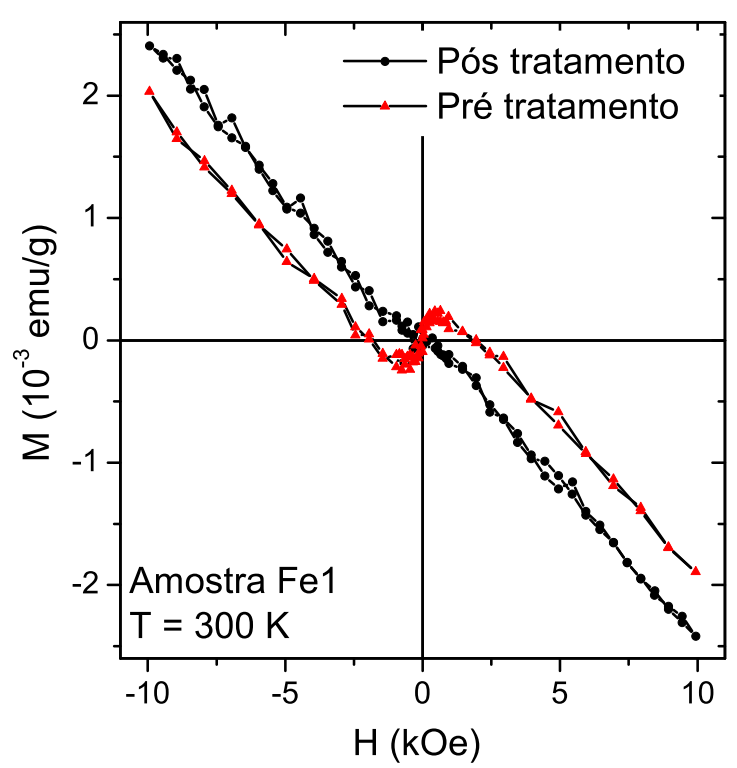

Figura 4.34: Comparação das medidas de magnetização por campo aplicado pré e pós tratamento térmico realizadas na temperatura de $300 \mathrm{~K}$. Amostra Fe1.

é possível uma comparação adequada pois não foram realizadas medidas a $2 \mathrm{~K}$ das amostras não tratadas termicamente. Tendo em vista os resultados obtidos na caracterização estrutural que indicaram uma degradação elevada da superfície da amostra Fe1 com o tratamento térmico, é possível levantar algumas hipóteses sobre o desaparecimento do sinal. A dissociação do GaN com perda de 
$\mathrm{N}_{2}$ pode ter facilitado a perda de Fe na região superficial por evaporação, fenômeno já observado no GaN para outros íons [79]. Outra possível explicação para a redução na resposta ferromagnética com o tratamento é a dissociação, durante o processo, de partículas de Fe metálico formadas durante a implantação iônica [80], estas seriam então responsáveis pelo momento de saturação da amostra implantada e não tratada. Um problema com a última hipótese é que não foi comprovado um aumento de resposta paramagnética da amostra, esperado com o aumento do número de íons de Fe não interagentes.

Ao contrário da amostra Fe1, as amostras implantadas com Fe com dose $2\left(2.4 \times 10^{16} \mathrm{~cm}^{-2}\right)$ apresentaram paramagnetismo e apenas um fraco comportamento ferromagnético após a implantação iônica, implicando que, ao contrário do resultado de Kim et al. [80] não foi criada densidade apreciável de Fe metálico nas amostras recém implantadas com alta dose. O tratamento térmico porém levou a um aumento na resposta ferromagnética das amostras, possivelmente devido a formação de microcristalitos de fases secundárias [49] [81] invisíveis à espectroscopia de difração de raios X, a técnica, em tese, mais apropriada para deteção de fases utilizada neste trabalho. As curvas de magnetização por campo aplicado das amostras implantadas com alta dose e tratadas termicamente estão apresentadas das figuras 4.35 e 4.36 .
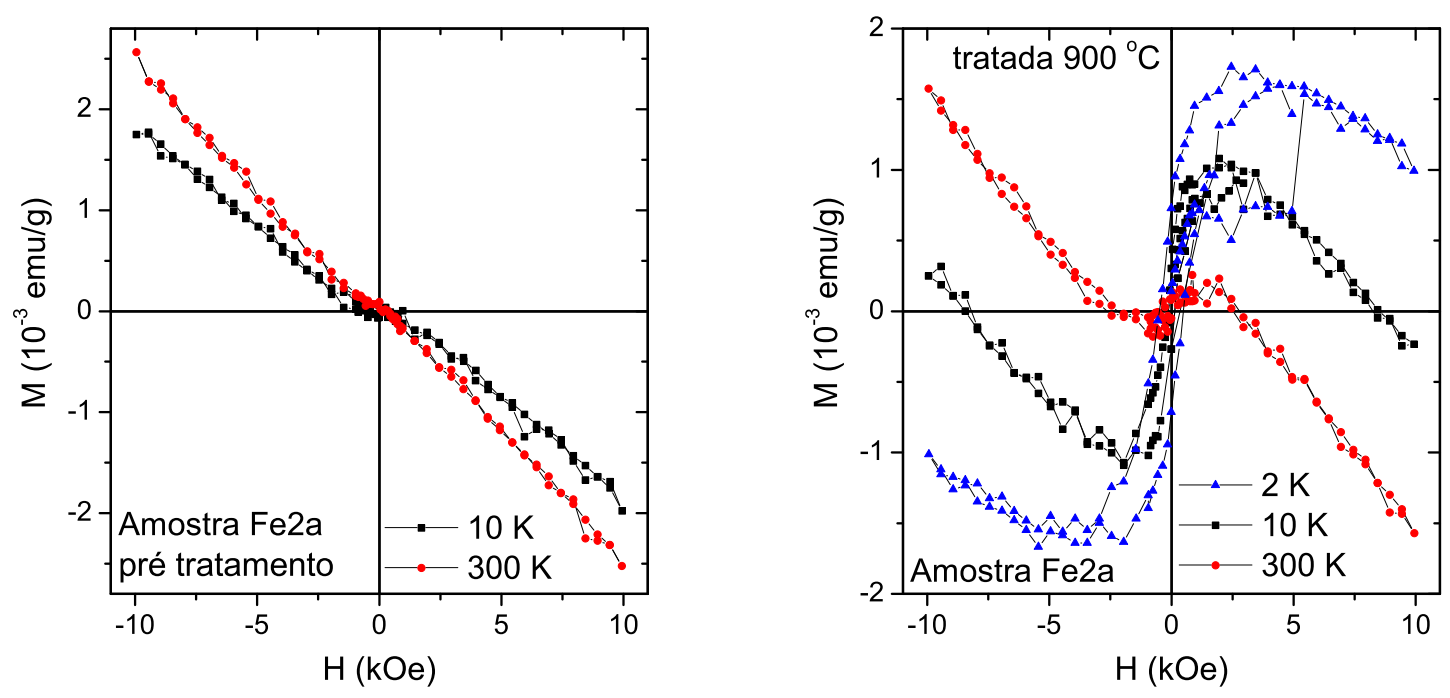

Figura 4.35: Medidas de magnetização por campo aplicado para a amostra Fe2a não tratada nas temperaturas de 10 e $300 \mathrm{~K}$ e amostra Fe2a tratada termicamente a $900{ }^{\circ} \mathrm{C}$, nas temperaturas de 2,10 e $300 \mathrm{~K}$.

Ambas as temperaturas de tratamento térmico utilizadas resultaram no aumento expressivo da resposta ferromagnética nas amostras implantadas com alta dosagem, justamente o oposto do ocorrido com a amostra Fe1, implantada com $50 \%$ desta dose. Comportamento semelhante é encontrado na literatura em amostras com dopagem concomitante ao crescimento [82], no entanto apenas os resultados das amostras tratadas podem ser comparados já que poucos trabalhos apresentam o comportamento magnético das amostras não tratadas termicamente. Em todas as medidas o campo coercivo e o momento magnético de saturação diminuem com o aumento da temperatura devido ao efeito térmico de randomização do alinhamento de spins [81].

O re-tratamento térmico já foi aplicado com sucesso [83] em amostras de GaN implantadas com Fe. Com este método busca-se reduzir a degradação da amostra reduzindo o tempo de tratamento nas temperaturas mais altas e adicionando uma etapa de tratamento em baixa temperatura. Neste 


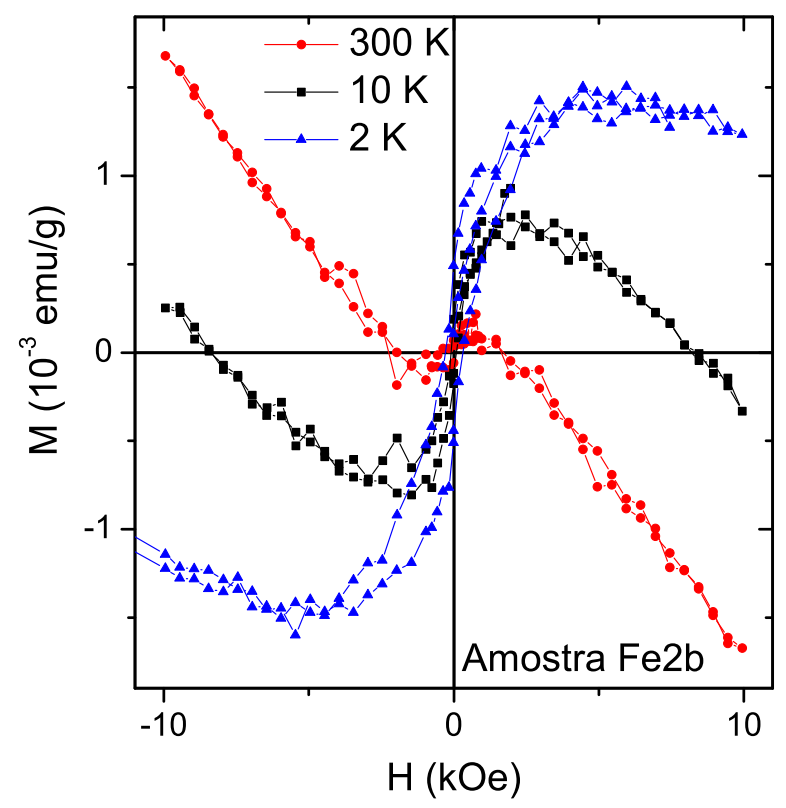

Figura 4.36: Medidas de magnetização por campo aplicado para a amostra Fe2b tratada termicamente a $800{ }^{\circ} \mathrm{C}$, realizadas nas temperaturas de 2,10 e $300 \mathrm{~K}$.

trabalho o retratamento térmico foi realizado na amostra $\mathrm{Fe} 2 \mathrm{~b}$, tratada inicialmente a $800{ }^{\circ} \mathrm{C}$ por 5 minutos, que foi tratada novamente a $900{ }^{\circ} \mathrm{C}$ pelo mesmo tempo. A amostra retratada recebeu o sufixo RT sendo identificada então como amostra Fe2bRT. Na figura 4.37 apresentam-se as medidas de magnetização em função do campo para a amostra Fe2bRT nas temperaturas de 2,10 e $300 \mathrm{~K}$.

Com o mesmo tempo de tratamento utilizado nas duas etapas a amostra Fe2bRT foi tratada pelo dobro do tempo das demais, esse período extra levou a uma degradação acentuada de sua rede cristalina conforme evidenciado pelos espectros Raman da figura 4.29. Mesmo causando a deterioração da rede o retratamento térmico levou a um aumento no momento de saturação da amostra. Vemos na figura 4.38 a comparação entre as medidas de magnetização das amostras Fe2b e Fe2bRT nas temperaturas de 2, 10 e $300 \mathrm{~K}$.

Estes resultados corroboram a hipótese de formação de compostos magnéticos secundários. Neste caso esperaria-se que o retratamento formasse fases secundárias magnéticas com parte dos íons de Fe ainda não interagentes após o primeiro tratamento, o que resultaria em aumento do momento de saturação e da susceptibilidade magnética total, que foi de fato observado. Se a magnetização da amostra Fe2b dependesse da interação entre os íons de Fe localizados, esperaríamos uma diminuição de $M_{s}$ e de $\chi_{T}$ com o retratamento, já que estudos apontam forte dependência da intensidade de efeitos coletivos com a cristalinidade em semicondutores magnéticos diluídos [84].

Os dados de susceptibilidade magnética total $\left(\chi_{T}\right)$ e magnetização de saturação $\left(M_{s}\right)$ das amostras implantadas com Fe, extraídos das medidas em função do campo nas temperaturas de 2, 10 e $300 \mathrm{~K}$, estão resumidos nas tabelas 4.6, 4.7 e 4.8. Os ajustes lineares para a obtenção de $\chi_{T}$ das amostras ferromagnéticas foram realizados em altos campos, acima da saturação da fase ferromagnética. A incerteza nos ajustes lineares para a obtenção de $\chi_{T}$ foi estimada em $3 \times 10^{-9}$ emu/Oe.g.

Considerando que íons $\mathrm{Fe}^{3+}$ são responsáveis pelo ferromagnetismo do material pode-se obter a contribuição média dos íons implantados na unidade $\mu_{B} /$ íon. O cálculo é realizado convertendo- 


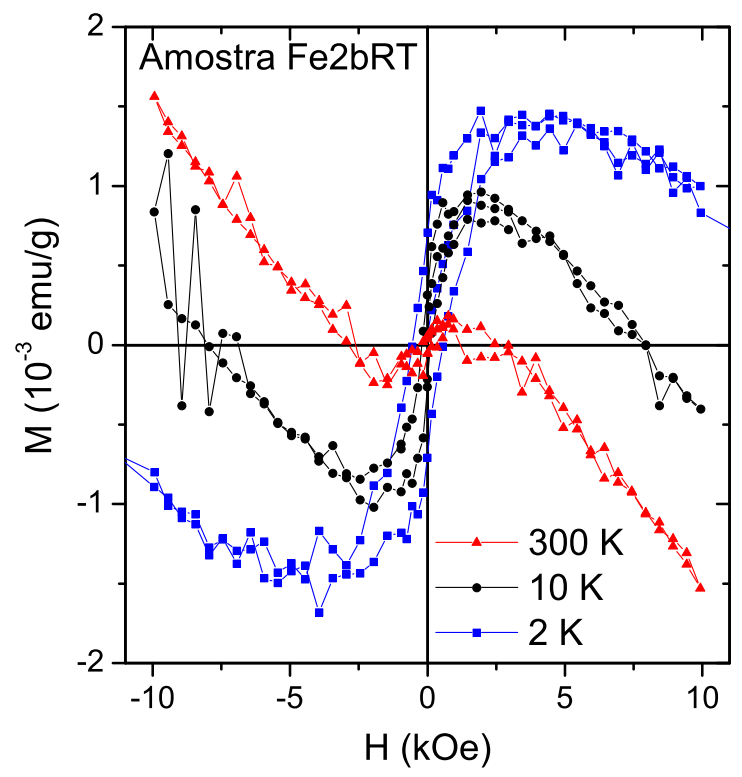

Figura 4.37: Medidas de magnetização por campo aplicado para a amostra Fe2bRT tratada termicamente a $800{ }^{\circ} \mathrm{C}$ e retratada a $900{ }^{\circ} \mathrm{C}$, realizadas nas temperaturas de 2,10 e $300 \mathrm{~K}$.
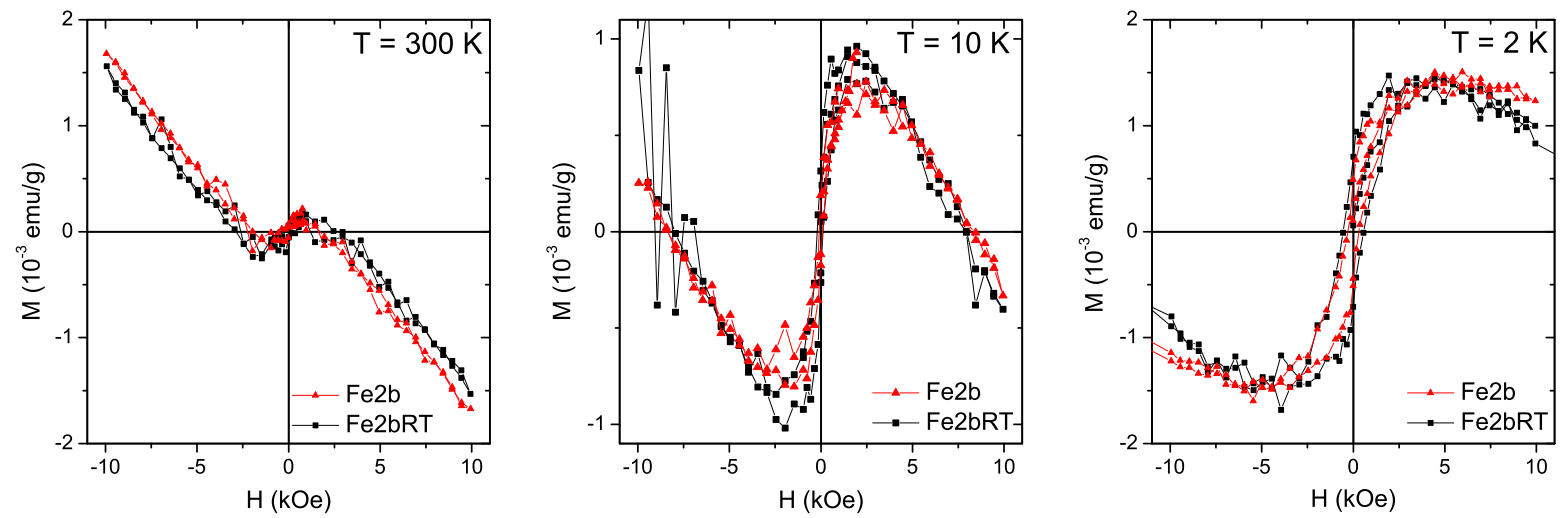

Figura 4.38: Comparação das medidas de magnetização por campo aplicado realizadas a 2, 10 e $300 \mathrm{~K}$ das amostras Fe2b tratada a $800{ }^{\circ} \mathrm{C}$ e Fe2b retratada a $900{ }^{\circ} \mathrm{C}$.

se o momento magnético de saturação da amostra para a unidade de magneton de Bohr $\left(\mu_{B}\right)$. Como o número de íons em cada amostra pode ser calculado através da dose implantada e de sua massa, a contribuição média pode ser simplesmente calculada pela razão do momento magnético de saturação medido pelo número de íons contidos na amostra.

Vemos na tabela 4.9 os valores de campo coercivo e momento magnético de saturação por íon das amostras implantadas com Fe e tratadas termicamente, extraídos das medidas de magnetização em função do campo realizadas nas temperaturas de 2 e $300 \mathrm{~K}$.

Concluímos dos valores de momento magnético por íon e campo coercivo obtidos que o tratamento realizado na amostra $\mathrm{Fe} 2 \mathrm{~b}\left(800{ }^{\circ} \mathrm{C}\right)$ foi significativamente menos efetivo na geração de ferromagnetismo em baixas temperaturas, em relação ao tratamento a $900{ }^{\circ} \mathrm{C}$ realizado na amos- 


\begin{tabular}{|c|c|c|c|c|}
\hline & \multicolumn{2}{|c|}{ Pré Tratamento } & \multicolumn{2}{c|}{ Pós Tratamento } \\
\hline Amostra & $\chi_{T}\left(10^{-7} \mathrm{emu} /\right.$ Oe.g $)$ & $M_{s}\left(10^{-4} \mathrm{emu} / \mathrm{g}\right)$ & $\chi_{T}\left(10^{-7} \mathrm{emu} /\right.$ Oe.g $)$ & $M_{s}\left(10^{-4} \mathrm{emu} / \mathrm{g}\right)$ \\
\hline Ref1 & -2.71 & 0 & -2.75 & 0 \\
Fe1 & -2.55 & 5.90 & -2.59 & 0 \\
Fe2a & -2.67 & 0 & -2.25 & 6.88 \\
Fe2b & -2.54 & 3.69 & -2.18 & 6.88 \\
Fe2bRT & - & - & -2.15 & 6.61 \\
\hline
\end{tabular}

Tabela 4.6: Valores de $\chi_{T}$ e magnetização de saturação pré e pós tratamento térmico das amostras implantadas com Fe e amostra referência extraídas das medidas de magnetização em função do campo na temperatura de $300 \mathrm{~K} . M_{s}=0$ indica que a amostra é para- e/ou diamagnética.

\begin{tabular}{|c|c|c|c|c|}
\hline & \multicolumn{2}{|c|}{ Pré Tratamento } & \multicolumn{2}{c|}{ Pós Tratamento } \\
\hline Amostra & $\chi_{T}\left(10^{-7} \mathrm{emu} /\right.$ Oe.g $)$ & $M_{s}\left(10^{-4} \mathrm{emu} / \mathrm{g}\right)$ & $\chi_{T}\left(10^{-7} \mathrm{emu} /\right.$ Oe.g $)$ & $M_{s}\left(10^{-4} \mathrm{emu} / \mathrm{g}\right)$ \\
\hline Ref1 & -2.70 & 0 & -2.63 & 0 \\
Fe1 & -2.55 & 6.31 & -2.53 & 0 \\
Fe2a & -2.00 & 0 & -1.80 & 15.3 \\
Fe2b & -1.84 & 3.92 & -1.58 & 13.2 \\
Fe2bRT & - & - & -1.89 & 14.6 \\
\hline
\end{tabular}

Tabela 4.7: Valores de $\chi_{T}$ e magnetização de saturação pré e pós tratamento térmico das amostras implantadas com $\mathrm{Fe}$ e amostra referência, extraídos das medidas de magnetização em função do campo na temperatura de $10 \mathrm{~K} . M_{s}=0$ indica que a amostra é para- e/ou diamagnética.

\begin{tabular}{|c|c|c|}
\hline Amostra & $\chi_{T}\left(10^{-7} \mathrm{emu} /\right.$ Oe.g $)$ & $M_{s}\left(10^{-4} \mathrm{emu} / \mathrm{g}\right)$ \\
\hline Fe1 & -1.91 & 0 \\
Fe2a & -1.09 & 21.5 \\
Fe2b & -0.51 & 17.3 \\
Fe2bRT & -1.06 & 20.2 \\
\hline
\end{tabular}

Tabela 4.8: Valores de $\chi_{T}$ e magnetização de saturação pós tratamento térmico das amostras implantadas com Fe, extraídos das medidas de magnetização em função do campo na temperatura de $2 \mathrm{~K} . M_{s}=0$ indica que a amostra é para- e/ou diamagnética

\begin{tabular}{|c|c|c|c|c|}
\hline & \multicolumn{2}{|c|}{$2 \mathrm{~K}$} & \multicolumn{2}{c|}{$300 \mathrm{~K}$} \\
\hline Amostra & $H_{c}(\mathrm{Oe})$ & $m_{s}\left(\mu_{B} /\right.$ íon $)$ & $H_{c}(\mathrm{Oe})$ & $m_{s}\left(\mu_{B} /\right.$ íon $)$ \\
\hline Fe2a & 490 & 0.50 & 150 & 0.16 \\
Fe2b & 260 & 0.42 & 150 & 0.12 \\
Fe2bRT & 550 & 0.46 & 170 & 0.15 \\
\hline
\end{tabular}

Tabela 4.9: Campo coercivo $\left(H_{c}\right)$ e momento magnético de saturação $\left(m_{s}\right)$ das amostras implantadas com Fe, dados extraídos das medidas de magnetização em função do campo a 2 e $300 \mathrm{~K}$.

tra Fe2a. Porém, o retratamento da amostra Fe2b aumentou $H_{c}$ da amostra Fe2b em mais de duas vezes, embora $m_{s}$ tenha crescido apenas marginalmente $(25 \%)$. Comparando os dados das amostras Fe2a e Fe2bRT pode-se concluir que o tratamento em duas etapas não foi mais efetivo na geração de ferromagnetismo no material. No entanto é importante salientar que as amostras não 
eram idênticas inicialmente o que pode levar a diferenças em parâmetros possivelmente relevantes na geração do magnetismo, como densidade de defeitos, discutido na seção 4.4.4. Tendo em conta principalmente os altos campos coercivos obtidos nas amostras tratadas a $900{ }^{\circ} \mathrm{C}$, pode-se concluir dos dados em função da temperatura de tratamento que o tratamento a $900{ }^{\circ} \mathrm{C}$ foi mais eficiente na geração de ferromagnetismo nas amostras implantadas com alta dosagem de Fe. Possuindo o íon $\mathrm{Fe}^{3+}$ um momento magnético de $5 \mu_{B}$ observamos que, em todas as amostras com alta dosagem de Fe tratadas, aproximadamente um décimo dos íons implantados contribuíram para o momento magnético de saturação em baixas temperaturas, resultado semelhante ao obtido em outros estudos sobre GaN hexagonal dopado com Fe, tanto com dopagem durante o crescimento [82] quanto por implantação iônica [80].

\subsubsection{Medidas em função da temperatura}

Foram realizadas medidas em função da temperatura em dois campos acima do campo de saturação do ferromagnetismo para todas as amostras implantadas com Fe, antes e depois do tratamento térmico, com exceção da amostra $\mathrm{Fe} 1$ não tratada que não apresentou paramagnetismo nas medidas em função do campo. De estudos de GaN dopado com Fe sabemos que os átomos dopantes se apresentam basicamente em dois estados $\mathrm{Fe}^{2+}$ e $\mathrm{Fe}^{3+}$ [82]. Como o íon $\mathrm{Fe}^{2+}$ possui momento angular total nulo podemos atribuir o paramagnetismo das amostras aos íons $\mathrm{Fe}^{3+}$.

A figura 4.39 mostra a dependência da magnetização com a temperatura, nos campos de $10 \mathrm{e}$ $20 \mathrm{kOe}$, da amostra Fe2b tratada termicamente a $800{ }^{\circ} \mathrm{C}$ e retratada a $900{ }^{\circ} \mathrm{C}$. As barras de erro são calculadas através do desvio padrão das medidas obtidas pelo SQUID em cada temperatura.

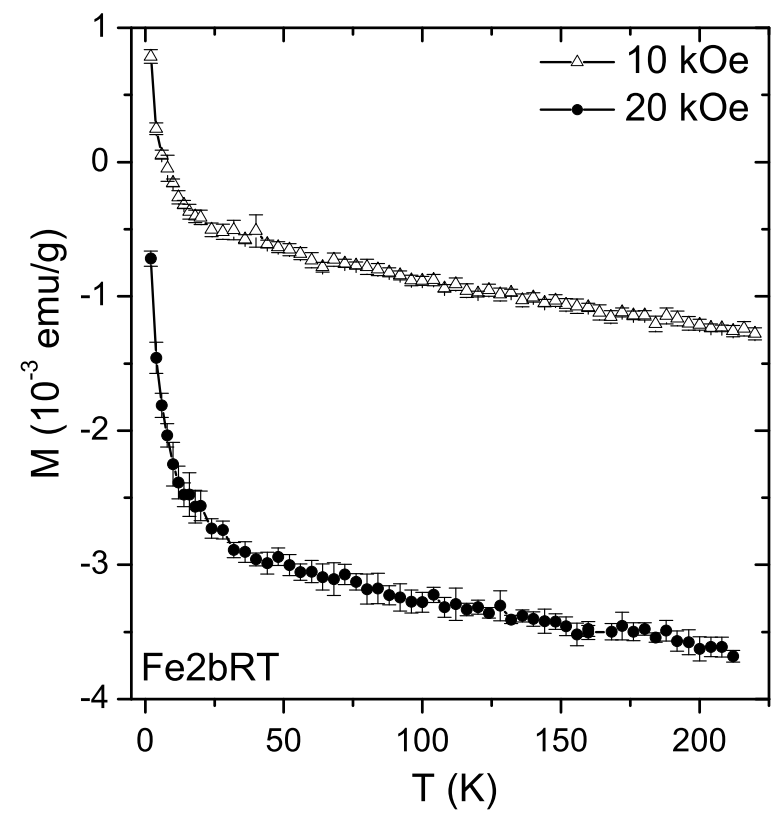

Figura 4.39: Medidas da magnetização em função da temperatura para a amostra Fe2b tratada termicamente a $800{ }^{\circ} \mathrm{C}$ e retratada a $900{ }^{\circ} \mathrm{C}$, obtidas nos campos de 10 e $20 \mathrm{kOe}$.

Como espera-se que a magnetização da fase ferromagnética não varie entre os campos de 10 e 20 kOe pode-se remover esta contribuição dos dados. Na figura 4.40 vemos a curva de susceptibilidade magnética corrigida em função da temperatura para a amostra Fe2b retratada, obtida através 
da razão da diferença das medidas de magnetização da figura 4.39 pela diferença dos campos magnéticos aplicados em cada uma delas, no caso 10 e $20 \mathrm{kOe}$.

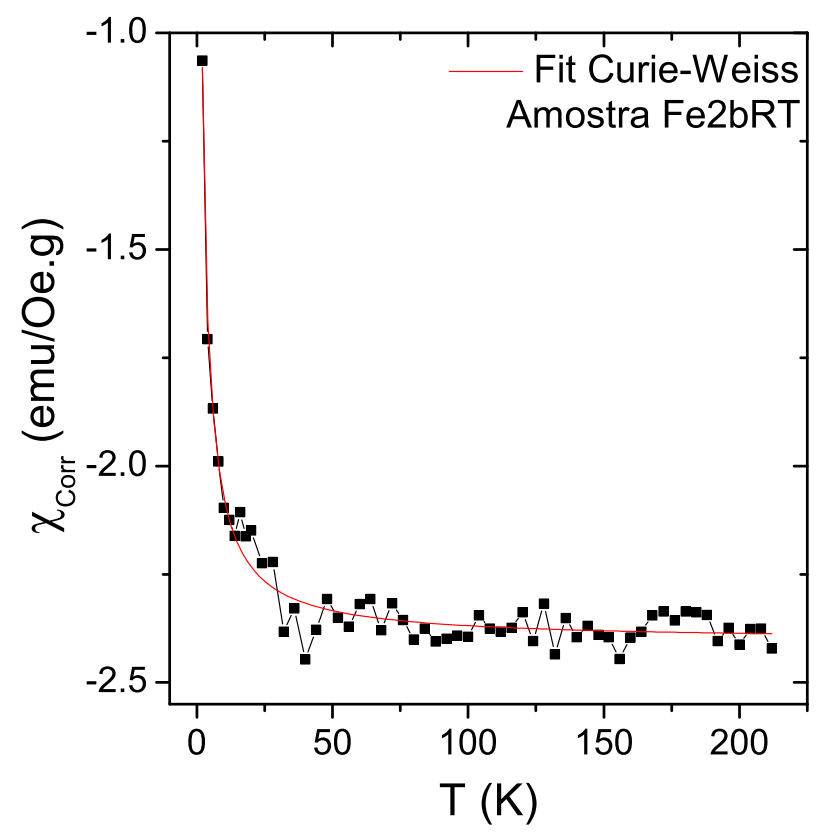

Figura 4.40: Curva de susceptibilidade corrigida em função da temperatura para a amostra Fe2b retratada com ajustes da função de Curie-Weiss.

De posse da susceptibilidade magnética corrigida pode-se ajustar aos dados uma função de Curie-Weiss para a obtenção da constante de Curie $(C)$, dada pela equação 2.16.

Através da massa das amostras e da dose implantada podemos obter o número de íons magnéticos presentes em cada uma delas. O processo consiste na obtenção da área das amostras através da sua massa total e da densidade e espessura das camadas constituintes (a camada de Si é fina suficiente para ser desprezada), o número de íons então é simplesmente o produto da área da amostra pela dose implantada. Podemos então com a constante de Curie determinar um momento angular efetivo $J_{\text {eff }}$ relativo aos íons que contribuem para a interação paramagnética. Através da razão entre $J_{\text {eff e }} J\left(5 / 2\right.$ para o $\left.\mathrm{Fe}^{3+}\right)$ obtém-se a fração de íons no material responsáveis pela resposta paramagnética. Os resultados obtidos da análise do paramagnetismo das amostras implantadas com Fe podem ser encontrados na tabela 4.10.

A figura 4.41 contém as curvas de susceptibilidade magnética corrigida para a amostras Fe1 e Fe2a tratadas a $900{ }^{\circ} \mathrm{C}$.

Observou-se uma diminuição de $J_{\text {eff }}$ com o tratamento térmico na amostra Fe2a e Fe2b, resultado esperado tendo em vista que o ferromagnetismo destas amostras teve um aumento expressivo. No entanto, a variação foi maior que a esperada. Na amostra Fe2a, por exemplo, aproximadamente $10 \%$ dos íons implantados passaram a contribuir com o ferromagnetismo após o tratamento térmico, já a variação na constante de Curie indica que em torno de $35 \%$ dos íons deixaram de contribuir com o paramagnetismo do material após o processo. Alguns fatores podem ter contribuído para essa discrepância. Por depender de tratamento de dados e um ajuste de função não linear a determinação da constante de Curie incorre em um erro maior do que o simples ajuste linear nos dados brutos realizado para a obtenção dos valores de magnetização de saturação, sendo portanto menos confiável. A perda de íons implantados durante o tratamento térmico também já foi observada na 

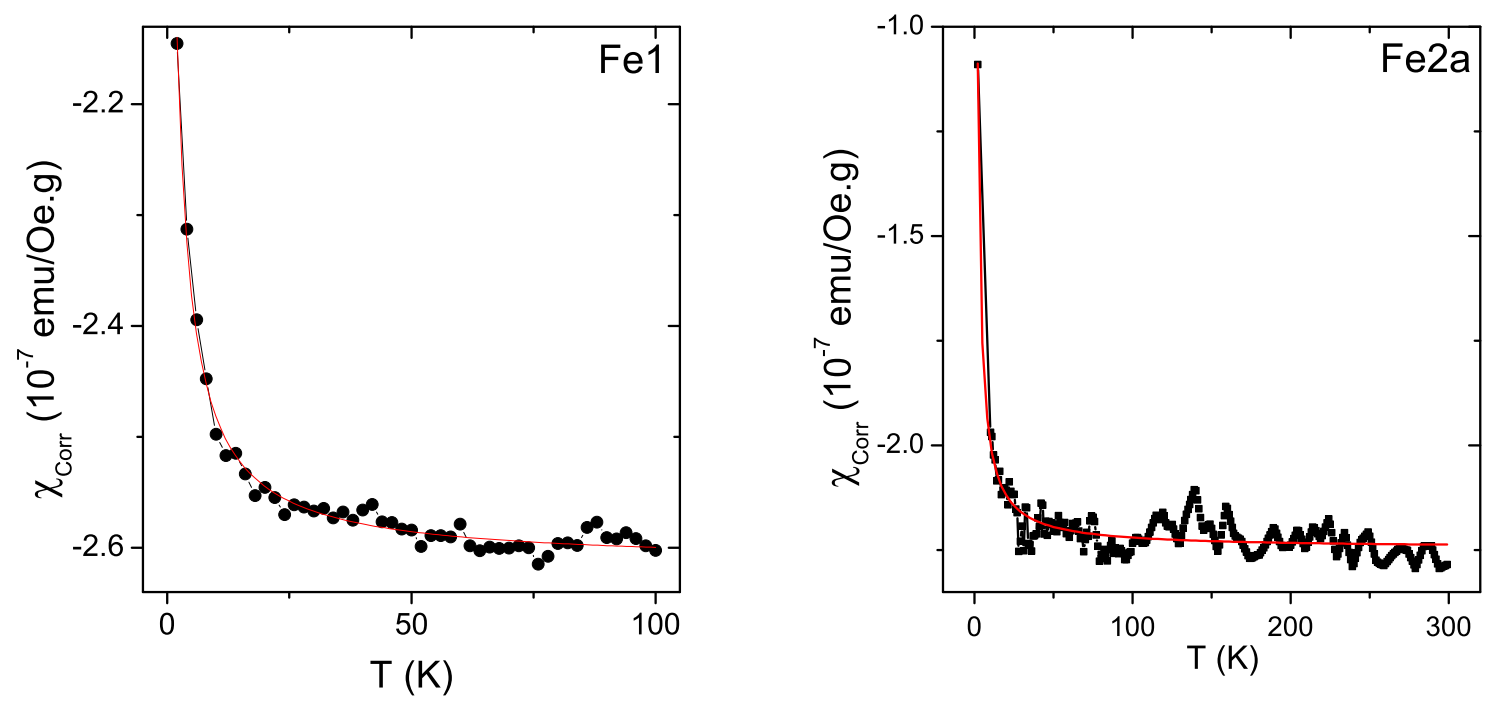

Figura 4.41: Curvas de susceptibilidade magnética corrigida em função da temperatura para as amostras Fe1 e Fe2a tratadas termicamente com ajustes da função de Curie-Weiss.

literatura e não pode ser descartada. Observou-se um aumento de $\mathrm{C}_{\text {Curie }}$ com o retratamento da amostra Fe2b em contradição com o aumento da magnetização de saturação decorrente do processo, no entanto, os valores são próximos e a diferença não é significativa.

\begin{tabular}{|c|c|c|c|c|}
\hline & \multicolumn{2}{|c|}{ Pré Tratamento } & \multicolumn{2}{c|}{ Pós Tratamento } \\
\hline Amostra & $\mathrm{C}_{\text {Curie }}\left(10^{-7} \mathrm{~cm}^{3} \mathrm{~K} / \mathrm{g}\right)$ & $J_{\text {eff }}$ & $C_{\text {Curie }}\left(10^{-7} \mathrm{~cm}^{3} \mathrm{~K} / \mathrm{g}\right)$ & $J_{\text {eff }}$ \\
\hline Fe1 & $\mathrm{FM}$ & $\mathrm{N} / \mathrm{A}$ & 1.46 & 0.34 \\
Fe2a & 8.46 & 0.99 & 2.55 & 0.30 \\
Fe2b & 10.07 & 1.18 & 3.42 & 0.40 \\
Fe2bRT & - & - & 3.54 & 0.42 \\
\hline
\end{tabular}

Tabela 4.10: Valores de $\mathrm{C}_{\text {Curie }}$ e $\mathrm{J}_{\text {eff }}$ para as amostras implantadas com Fe pré e pós tratamento térmico.

A magnetização de saturação da amostra é outro resultado que pode ser extraído das curvas de magnetização em função da temperatura, se medidas acima do campo de saturação do ferromagnetismo. Este valor é obtido do ajuste linear dos dois valores de magnetização em um gráfico em função do campo, o cruzamento da reta com o eixo y em cada temperatura determina $M_{s}$ na mesma. A curva de magnetização de saturação em função da temperatura para a amostra Fe2b retratada termicamente é apresentada na figura 4.42. Os valores obtidos por este método concordam razoavelmente com os resultados obtidos através das medidas em função do campo. Observou-se nessa amostra uma variação significativa da magnetização de saturação com a temperatura, assim como observado nas medidas em função do campo.

Na figura 4.43 vemos a medida de magnetização de saturação em função da temperatura para a amostra Fe2a implantada e não tratada. Apesar da grande incerteza na extrapolação a partir das medidas de magnetização em função da temperatura, observa-se que os valores de $M_{s}$ não apresentam queda brusca entre as temperaturas de 2 e $60 \mathrm{~K}$ e são próximos do valor obtido $\left(M_{s}=\right.$ 


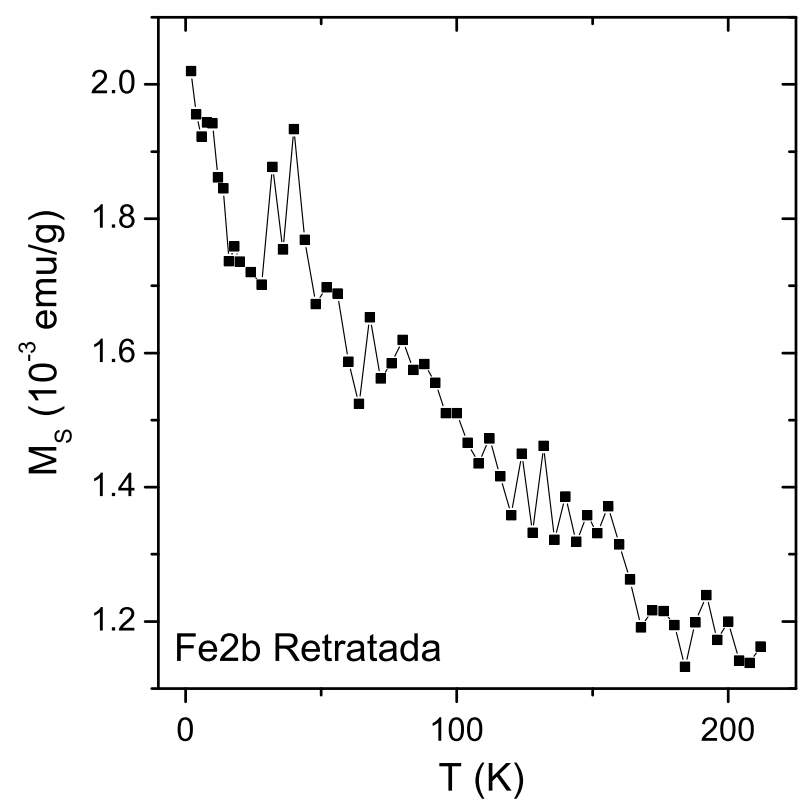

Figura 4.42: Magnetização de saturação em função da temperatura para a amostra Fe2b retratada termicamente. Dados extrapolados das medidas de magnetização em função da temperatura, com exceção do valor em $2 \mathrm{~K}$, obtido da medida de magnetização em função do campo.

$2 \times 10^{-4} \mathrm{emu} / \mathrm{g}$ ) através de medida em função do campo na temperatura de $300 \mathrm{~K}$. Essas medidas indicam uma elevada $T_{c}$ desta amostra o que reforça a tese de que o ferromagnetismo seja gerado por Fe metálico nas amostras implantadas com Fe e não tratadas.

O tratamento térmico alterou de maneira expressiva o momento de saturação da amostra Fe2a, conforme a curva mostrada na figura 4.44. Assim como para a amostra Fe2bRT, observou-se variação do momento magnético de saturação com a temperatura para a amostra Fe2a pós tratamento térmico.

Comparando as curvas de susceptibilidade corrigida $\left(\chi_{\text {Corr }}\right)$ de amostras implantadas com diferentes doses (Fig. 4.45) observa-se uma diminuição da susceptibilidade independentemente da temperatura com o aumento da concentração de Fe. O fenômeno permanece até $300 \mathrm{~K}$ já que $\chi$ Corr não varia significativamente entre as temperaturas de 100 e $300 \mathrm{~K}$ (cf figura. 4.40). Esse comportamento é atribuído na literatura [34] [82] a paramagnetismo do tipo van-Vleck, independente da temperatura. Nestes trabalhos o comportamento paramagnético é atribuído aos íons $\mathrm{Fe}^{2+}$ não interagentes.

Foram realizadas medidas de magnetização em função da temperatura do tipo zero-field-cooled field-cooled (ZFC-FC) das amostras Fe2a, Fe2b e Fe2bRT tratadas termicamente. O procedimento consiste inicialmente no resfriamento da amostra de $300 \mathrm{~K}$ até $2 \mathrm{~K}$ em campo zero; com a amostra em baixa temperatura aplica-se um campo e em seguida realizam-se medidas de magnetização em função da temperatura elevando-a até $300 \mathrm{~K}$, obtém-se desta maneira a curva ZFC. A curva FC é obtida de maneira semelhante porém nesta medida resfria-se a amostra de $300 \mathrm{~K}$ até $2 \mathrm{~K}$ mantendo o campo aplicado, realizando-se posteriormente as medidas de magnetização em função da temperatura com o mesmo campo, medidas estas que configuram a curva FC. A presença de diferença entre as duas curvas é sinal de irreversibilidade no magnetismo da amostra, esse fenômeno ocorre para diversas ordens magnéticas: ferromagnetismo, antiferromagnetismo e ferrimagnetismo 


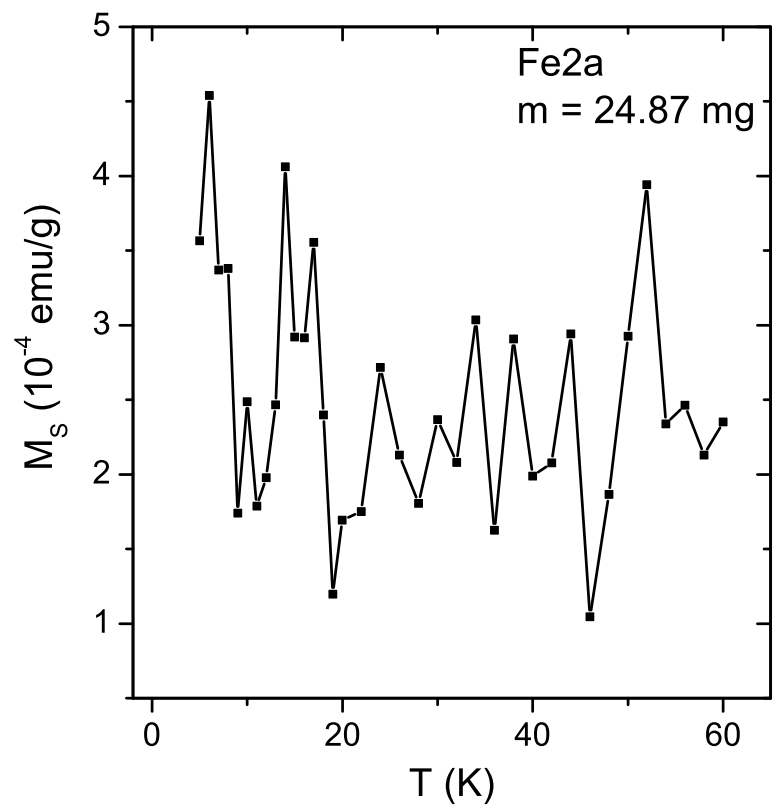

Figura 4.43: Medida de magnetização de saturação em função da temperatura para a amostra Fe2a implantada e não tratada. Dados extrapolados de medidas em função da temperatura.

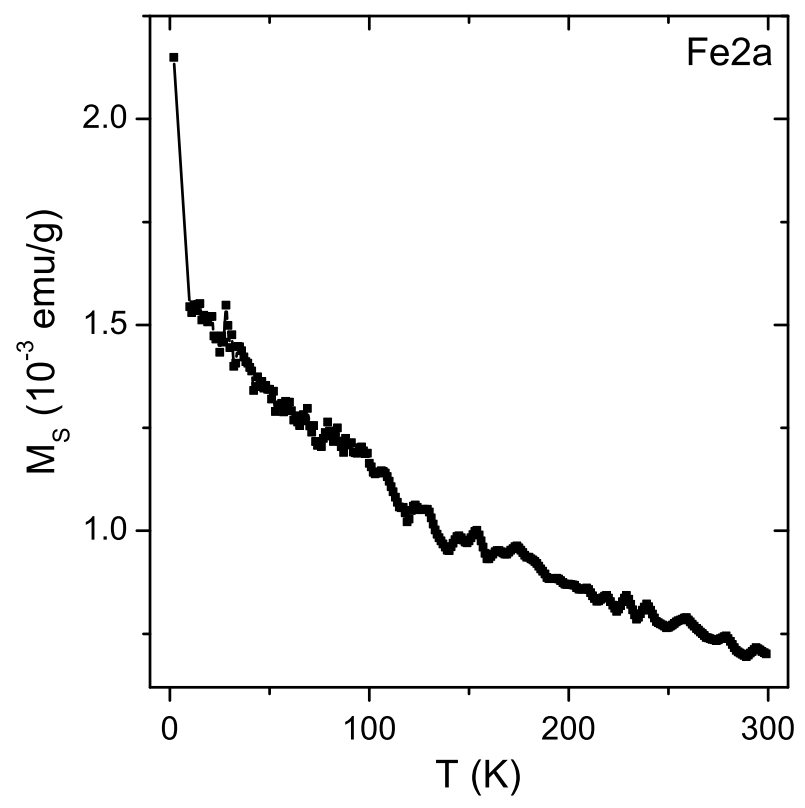

Figura 4.44: Magnetização de saturação em função da temperatura para a amostra Fe2a tratada termicamente. Dados extrapolados das medidas de magnetização em função da temperatura, com exceção do valor em $2 \mathrm{~K}$, obtido da medida de magnetização em função do campo. 


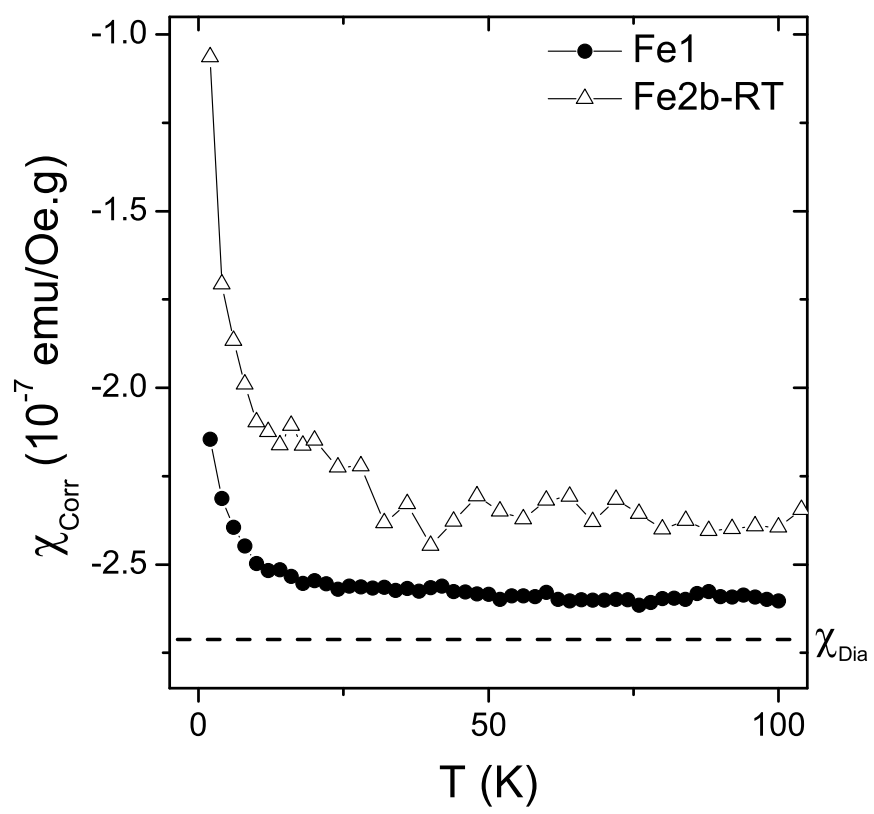

Figura 4.45: Curvas de susceptibilidade corrigida em função da temperatura para as amostras Fe1 tratada termicamente e Fe2b retratada. A linha pontilhada marca a susceptibilidade magnética média das amostras referência.

[85]. Nas temperaturas onde a diferença entre as curvas é nula o comportamento magnético da amostra é considerado reversível. Na figura 4.46 encontram-se as medidas ZFC-FC da amostra Fe2a realizadas com campo aplicado de 500 Oe. A incerteza foi obtida através do desvio padrão das medições. Optou-se pelo campo aplicado de 500 Oe para as medidas ZFC-FC por dois motivos: facilidade de comparação com outros dados da literatura e por razões de intensidade do sinal já que em campos mais baixos a incerteza nas medidas mostrou-se demasiado elevada em temperaturas acima de $100 \mathrm{~K}$.

Observa-se na figura 4.46 uma diferença significativa entre as curvas até aproximadamente a temperatura de $250 \mathrm{~K}$. Este valor de temperatura crítica é frequentemente encontrado na literatura de implantação de Fe em GaN [80] [86]. Analisando a temperatura crítica dos possíveis nitretos de Fe formados durante a implantação que já foram confirmados em outros estudos chega-se ao $\mathrm{Fe}_{3} \mathrm{~N}$ como candidato mais provável, já que o mesmo mostrou temperatura critica de $250 \mathrm{~K}$ em medidas ZFC-FC realizadas com campo de 500 Oe em outros estudos [87], no entanto, a presença de $\mathrm{Fe}_{3} \mathrm{~N}$ não foi confirmada pelas medidas de difração de raios X na configuração Bragg-Brentano.

Estudou-se também o efeito do campo aplicado nas medidas de irreversibilidade. Na figura 4.47 estão apresentadas as medidas ZFC-FC da amostra Fe2a realizadas com campo aplicado de 750 Oe.

Observa-se que com o campo aplicado de 750 Oe a amostra passou a apresentar temperatura crítica de apenas $50 \mathrm{~K}$, em comparação com a medida realizada com campo de 500 Oe pode-se notar uma grande influência do campo aplicado na irreversibilidade do sistema magnético.

Vemos na figura 4.48 a medida ZFC-FC em 500 Oe para a amostra Fe2b, tratada termicamente a $800{ }^{\circ} \mathrm{C}$ e retratada a $900{ }^{\circ} \mathrm{C}$. Observamos que embora o retratamento térmico tenha aumentado o momento de saturação da amostra, a diferença entre as curvas ZFC e FC foi apenas fracamente alterada com o processo, indicando que a natureza da irreversibilidade do magnetismo desta amostra 


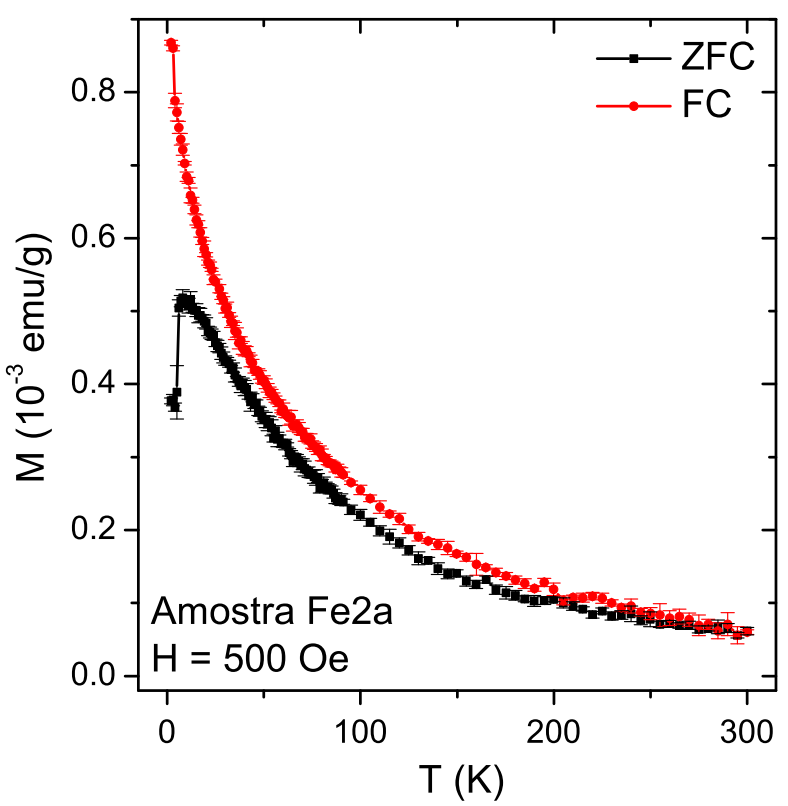

Figura 4.46: Medidas de magnetização em função da temperatura do tipo ZFC-FC com campo aplicado de 500 Oe para a amostra Fe2a implantada e tratada termicamente.

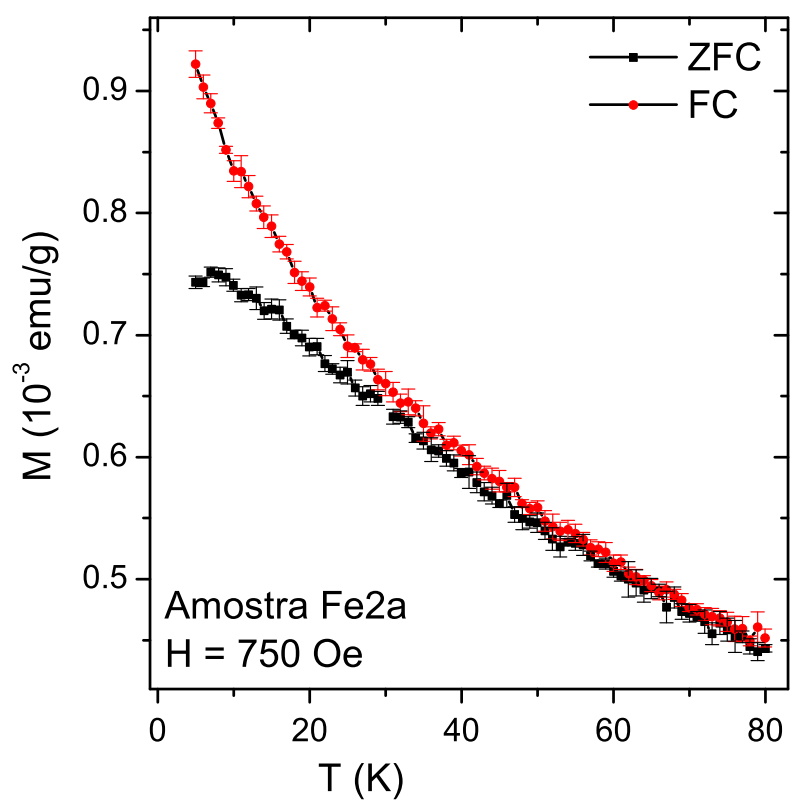

Figura 4.47: Medidas de magnetização em função da temperatura do tipo ZFC-FC com campo aplicado de 750 Oe para a amostra Fe2a tratada termicamente.

permaneceu a mesma. 

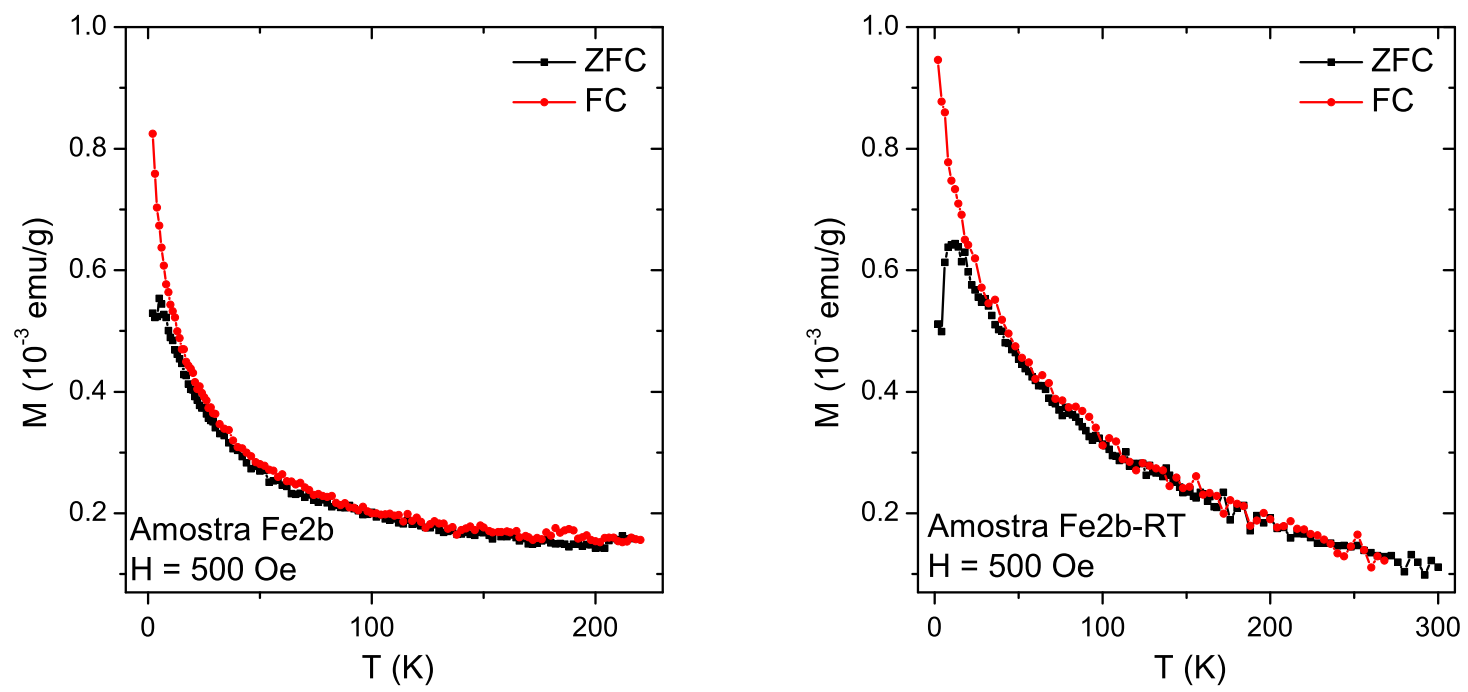

Figura 4.48: Medidas de magnetização em função da temperatura do tipo ZFC-FC com campo aplicado de 500 Oe para a amostra Fe2b tratada termicamente a $800{ }^{\circ} \mathrm{C}$ e Fe2bRT retratada a 900 ${ }^{\circ} \mathrm{C}$.

Outro fenômeno encontrado nas medidas ZFC-FC realizadas com campo de 500 Oe das amostras Fe2a e Fe2bRT foi um aumento da magnetização com o aumento na temperatura da curva ZFC entre as temperaturas de 2 e $20 \mathrm{~K}$. Isso indica que com a redução da temperatura sem a presença da campo magnético, os momentos do material se "congelaram" em uma posição desordenada. A energia térmica introduzida com o aumento da temperatura leva à quebra gradual do estado desordenado e o alinhamento dos spins até a chamada temperatura de bloqueio, onde a magnetização volta a diminuir devido à efeitos térmicos. Este comportamento está associado com o fenômeno de vidro de spin [88] ou superparamagnetismo [89].

Observou-se que a implantação de íons de Fe em alta dosagem foi efetiva na formação de ferromagnetismo em amostras de c-GaN, quando associada à tratamento térmico. Já a implantação com baixa dose levou a formação de ferromagnetismo apenas antes do tratamento térmico. Através das medidas em função da temperatura determinou-se, no entanto, que a maior parte dos íons implantados contribuiu com o paramagnetismo das amostras. Foi estudada também a temperatura crítica do sistema ferromagnético através de medidas ZFC-FC em diferentes campos aplicados, sendo observada irreversibilidade em temperaturas de até $250 \mathrm{~K}$. 


\subsubsection{Amostras implantadas com Mn}

Ao contrário das amostras implantadas com Fe, trabalhos apontam para a formação de um semicondutor magnético diluído da forma $\mathrm{Ga}_{x} \mathrm{Mn}_{1-x} \mathrm{~N}$, tanto com dopagem durante o crescimento como por implantação iônica, responsável ao menos em parte pelo ferromagnetismo de amostras de GaN tanto na forma cúbica como hexagonal. A começar, a previsão teórica pelo modelo de Zener para amostras de c-GaN dopadas com $5 \%$ de $\mathrm{Mn}$ e com concentração de buracos de $3.5 \times 10^{20}$ buracos $/ \mathrm{cm}^{3}$ é de interação ferromagnética com $\mathrm{T}_{c}$ acima da temperatura ambiente [3]. O primeiro trabalho sobre implantação de $\mathrm{Mn}$ em GaN [86] já apontou o $\mathrm{Ga}_{x} \mathrm{Mn}_{1-x} \mathrm{~N}$ como responsável pelo ferromagnetismo encontrado $\left(\mathrm{T}_{c}=250 \mathrm{~K}\right)$ em amostras tipo $p$. No entanto, como ferromagnetismo acima da temperatura ambiente foi encontrado também em amostras GaN condutoras tipo $n$ [90], outros processos geradores de magnetismo devem atuar nestes materiais. No trabalho de Cui et al. [91] amostras de $\mathrm{Ga}_{x} \mathrm{Mn}_{1-x} \mathrm{~N}$ de alta qualidade, com dopagem de $\mathrm{Mn}$ concomitante ao crescimento em concentrações de até $x=0.03$, não apresentaram ferromagnetismo, o que indica a influência de defeitos na geração do magnetismo. Além de estudos sobre a fase hexagonal, ferromagnetismo à temperatura ambiente em amostras de c-GaN crescidas sobre GaAs e dopadas através de implantação de Mn já foi demonstrado [92].

\subsubsection{Medidas em função do campo}

Vemos nas figuras 4.49a e 4.49b as medidas de magnetização pelo campo da amostra Mn1 pré e pós tratamento térmico. Após a implantação iônica realizada com dose de $1.2 \times 10^{16} \mathrm{~cm}^{-2}$ a amostra Mn1 apresentou resposta ferromagnética fraca e independente da temperatura entre 10 e $300 \mathrm{~K}$, com momentos de saturação baixos próximos do valor de $2 \times 10^{-4} \mathrm{emu} / \mathrm{g}$ no limite da incerteza estipulada para a caracterização de ferromagnetismo. O comportamento magnético da amostra Mn1 nas temperaturas de 10 e $300 \mathrm{~K}$ foi alterado com o tratamento térmico, com variações de $M_{s}$ e $\chi_{T}$ indicando aumento das interações ferro e paramagnéticas respectivamente. Foi realizada também uma medida da amostra Mn1 tratada na temperatura de $2 \mathrm{~K}$ que evidencia o seu comportamento ferromagnético através do aumento expressivo de $M_{s}$. Comparando-se as medidas nas diversas temperaturas nota-se também a presença de paramagnetismo na amostra Mn1 pré e pós tratamento térmico, evidenciada pela diminuição de $\chi_{T}$ com o aumento da temperatura.

A amostra Mn2a não apresentou ferromagnetismo dentro da incerteza logo após a implantação iônica com dose $2.4 \times 10^{16} \mathrm{~cm}^{-2}$. Os espectros obtidos nas temperaturas de 10 e $300 \mathrm{~K}$ são mostrados na figura 4.50a. Com o tratamento térmico notou-se uma elevação do momento de saturação das amostras a 10 e $300 \mathrm{~K}$, porém novamente o valor medido foi baixo, apontando apenas um fraco ferromagnetismo nestas temperaturas. Na medida da amostra tratada termicamente realizada a 2 $\mathrm{K}$ da figura $4.50 \mathrm{~b}$, no entanto, nota-se claramente o comportamento ferromagnético desta amostra em baixa temperatura. A diminuição de $\chi_{T}$ com o aumento da temperatura causada pelo paramagnetismo também foi detectada na amostra Mn2a e não foi alterada significativamente com o tratamento térmico.

Vemos na figura 4.51 as medidas de magnetização pelo campo da amostra Mn2b não tratada termicamente, nas temperaturas de 10 e $300 \mathrm{~K}$. Ao contrário da amostra Mn2a, a amostra Mn2b apresentou ferromagnetismo após a implantação iônica, além de comportamento paramagnético. No entanto a mesma não foi tratada termicamente dificultando a comparação com as outras amostras.

Encontram-se nas tabelas 4.12 a 4.13 os dados extraídos de medidas de magnetização em função do campo realizadas nas amostras implantadas com Mn pré e pós tratamento térmico realizado na temperatura de $900{ }^{\circ} \mathrm{C}$.

Na tabela 4.14 apresentam-se os valores de momento magnético de saturação ferromagnético por íon implantado, extraídos das medidas de magnetização em função do campo a 10 e $300 \mathrm{~K}$ para as amostras Mn1 e Mn2a implantadas e tratadas termicamente. 

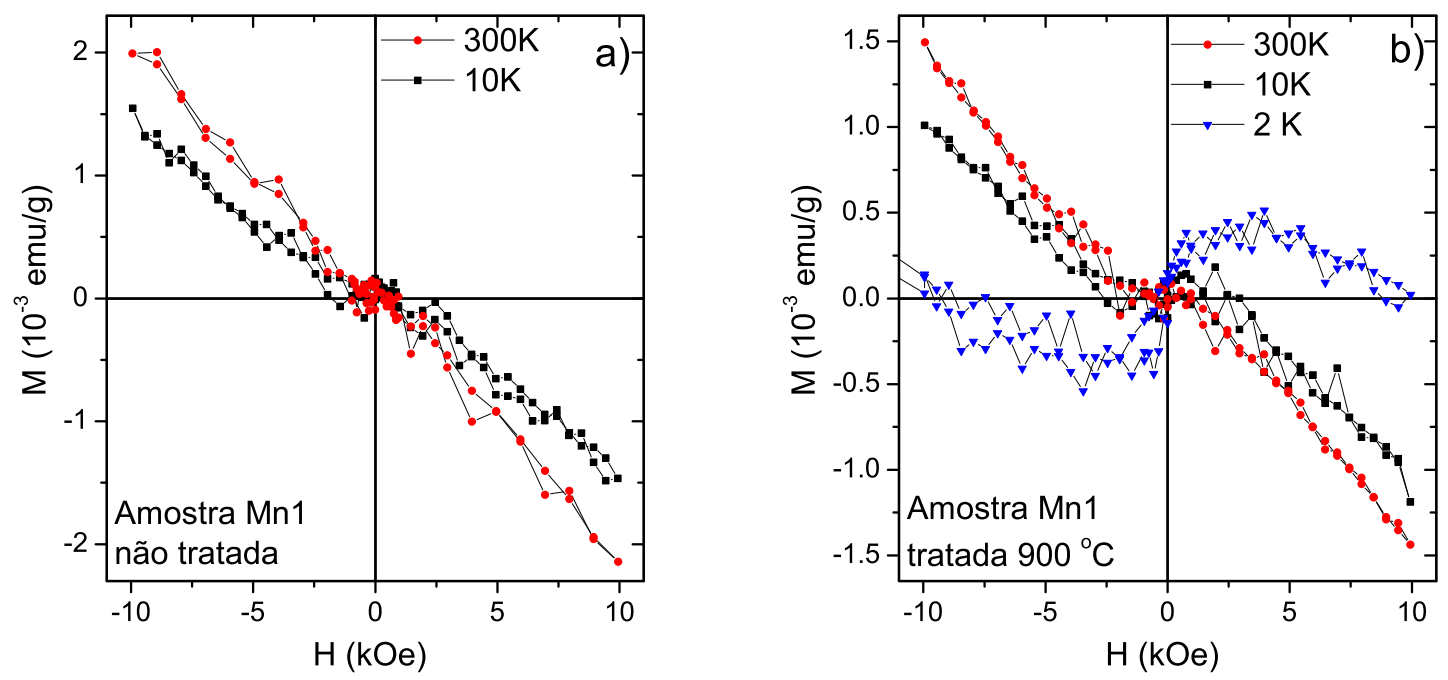

Figura 4.49: Medidas de magnetização por campo aplicado nas temperaturas de 10 e $300 \mathrm{~K}$ da amostra Mn1 não tratada (a) e nas temperaturas de 2, 10 e $300 \mathrm{~K}$ da amostra Mn1 tratada (b).
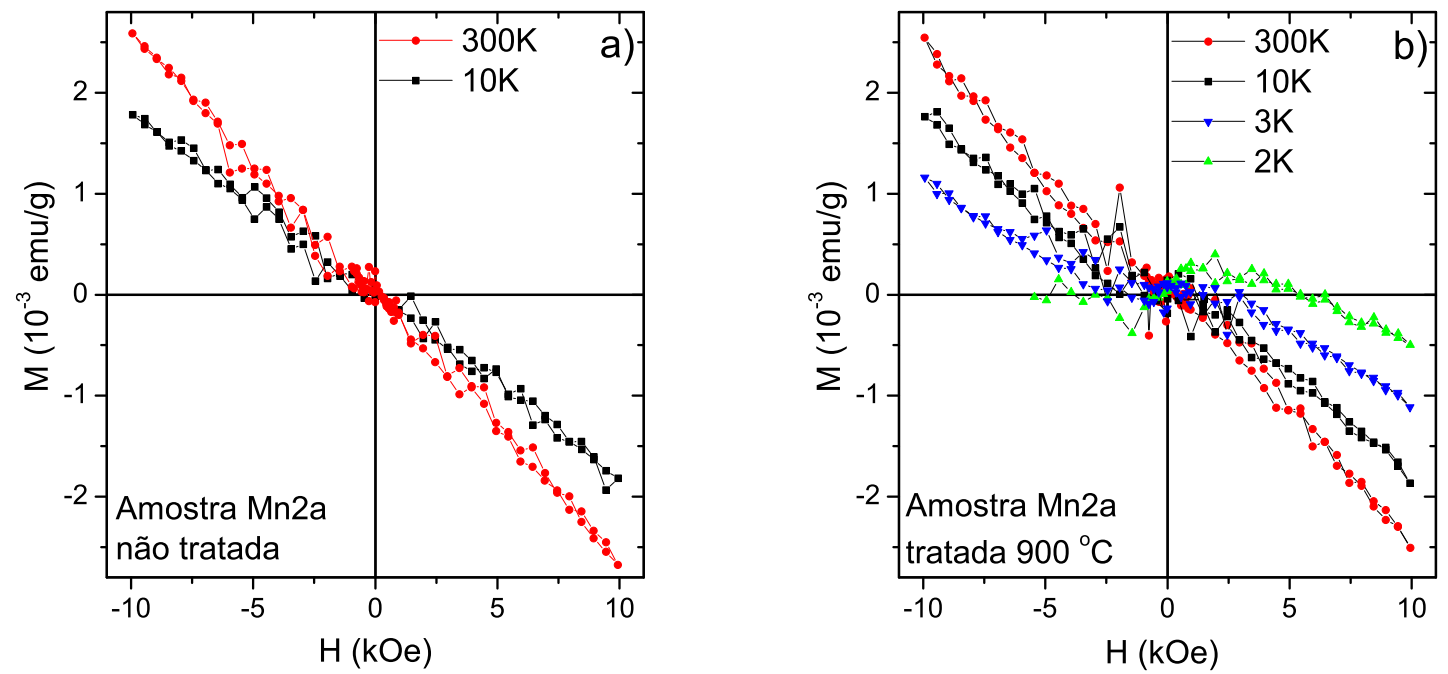

Figura 4.50: Medidas de magnetização por campo aplicado nas temperaturas de 10 e $300 \mathrm{~K}$ da amostra Mn2a não tratada (a) e nas temperaturas de 2, 3, 10 e $300 \mathrm{~K}$ da amostra Mn1 tratada (b).

A amostra Mn1 implantada com baixa dosagem apresentou os maiores valores de momento magnético de saturação por íon das amostras implantadas com Mn mesmo apresentando qualidade cristalina inicial inferior às demais como visto na seção 4.1.1.1, indício de influência da relativa preservação de sua rede cristalina pela implantação com menor dose. No entanto o maior valor apresentado, de $0.2 \mu_{B}$ /íon após tratamento térmico, implica que apenas $5 \%$ dos íons implantados estão contribuindo com o ferromagnetismo. A implantação foi efetiva na geração de ferromagnetismo nas amostras, porém em escala muito menor do que a observada nas amostras implantadas com Fe. Uma interpretação para este fato é de que o magnetismo nas amostras implantadas com 


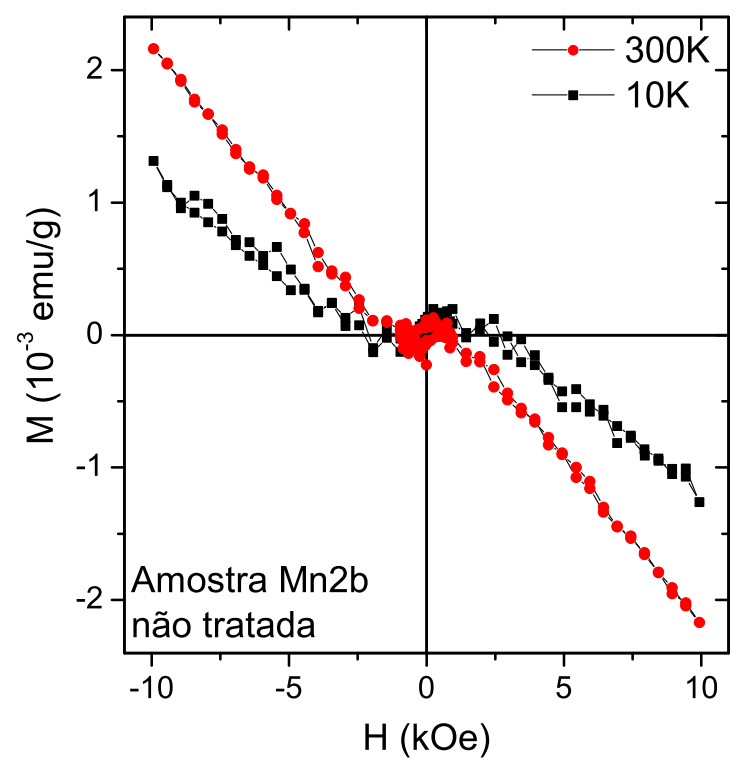

Figura 4.51: Medidas de magnetização por campo aplicado nas temperaturas de 10 e $300 \mathrm{~K}$ da amostra Mn2b não tratada.

\begin{tabular}{|c|c|c|c|c|}
\hline & \multicolumn{2}{|c|}{ Pré Tratamento } & \multicolumn{2}{c|}{ Pós Tratamento } \\
\hline Amostra & $\chi_{T}\left(10^{-7} \mathrm{emu} /\right.$ Oe.g $)$ & $M_{s}\left(10^{-4} \mathrm{emu} / \mathrm{g}\right)$ & $\chi_{T}\left(10^{-7} \mathrm{emu} /\right.$ Oe.g $)$ & $M_{s}\left(10^{-4} \mathrm{emu} / \mathrm{g}\right)$ \\
\hline Mn1 & -1.66 & 2.23 & -1.35 & 3.20 \\
Mn2a & -1.99 & 0 & -2.05 & 2.54 \\
Mn2b & -1.60 & 3.87 & - & - \\
\hline
\end{tabular}

Tabela 4.11: Valores de $\chi_{T}$ e magnetização de saturação pré e pós tratamento térmico das amostras implantadas com Mn, extraídas das medidas de magnetização em função do campo na temperatura de $10 \mathrm{~K} . M_{s}=0$ indica que a amostra é para- e/ou diamagnética.

\begin{tabular}{|c|c|c|c|c|}
\hline & \multicolumn{2}{|c|}{ Pré Tratamento } & \multicolumn{2}{c|}{ Pós Tratamento } \\
\hline Amostra & $\chi_{T}\left(10^{-7} \mathrm{emu} /\right.$ Oe.g $)$ & $M_{s}\left(10^{-4} \mathrm{emu} / \mathrm{g}\right)$ & $\chi_{T}\left(10^{-7} \mathrm{emu} /\right.$ Oe.g $)$ & $M_{s}\left(10^{-4} \mathrm{emu} / \mathrm{g}\right)$ \\
\hline Mn1 & -2.36 & 2.27 & -1.75 & 2.97 \\
Mn2a & -2.76 & 0 & -2.70 & 2.28 \\
Mn2b & -2.54 & 3.55 & - & - \\
\hline
\end{tabular}

Tabela 4.12: Valores de $\chi_{T}$ e magnetização de saturação pré e pós tratamento térmico das amostras implantadas com Mn, extraídas das medidas de magnetização em função do campo na temperatura de $300 \mathrm{~K} . M_{s}=0$ indica que a amostra é para- e/ou diamagnética.

Mn é proveniente de interação entre os íons localizados, ao contrário do ferromagnetismo gerado nas amostras implantadas com Fe, possivelmente causado pela formação de fases secundárias durante os processos de implantação e tratamento térmico. Outra fonte possível para o ferromagnetismo é sua geração através de defeitos no material, discutida mais adiante na seção 4.4.4. 


\begin{tabular}{|c|c|c|}
\hline Amostra & $\chi_{T}\left(10^{-7} \mathrm{emu} /\right.$ Oe.g $)$ & $M_{s}\left(10^{-4} \mathrm{emu} / \mathrm{g}\right)$ \\
\hline Mn1 & -0.65 & 6.60 \\
Mn2a & -1.08 & 6.05 \\
\hline
\end{tabular}

Tabela 4.13: Valores de $\chi_{T}$ e magnetização de saturação pós tratamento térmico das amostras implantadas com Mn, extraídos das medidas de magnetização em função do campo na temperatura de $2 \mathrm{~K}$.

\begin{tabular}{|c|c|c|}
\hline & $2 \mathrm{~K}$ & $300 \mathrm{~K}$ \\
\hline Amostra & $m_{s}\left(\mu_{B} /\right.$ íon $)$ & $m_{s}\left(\mu_{B} /\right.$ íon $)$ \\
\hline Mn1 & 0.20 & 0.12 \\
Mn2a & 0.16 & 0.06 \\
\hline
\end{tabular}

Tabela 4.14: Momento magnético de saturação $\left(m_{s}\right)$ por íon implantado das amostras Mn1 e Mn2a, dados extraídos das medidas de magnetização em função do campo na temperatura de 2 e $300 \mathrm{~K}$.

\subsubsection{Medidas em função da temperatura}

Para uma melhor descrição do paramagnetismo das amostras implantadas com Mn foram realizadas medidas em função da temperatura nas mesmas. Na figura 4.52a vemos as medidas de magnetização de saturação em função da temperatura para a amostra Mn2b implantada e não tratada nos campos de 10 e 15 kOe. De uma maneira semelhante à descrita na análise das medidas em função da temperatura das amostras de Fe pode-se remover o ferromagnetismo das medidas, obtendo-se como resultado uma curva de susceptibilidade magnética corrigida em função da temperatura vista na figura 4.52b. Ajustando-se a função de Curie-Weiss à curva de susceptibilidade extrai-se a constante de Curie $\left(\mathrm{C}_{\text {Curie }}\right)$ que contem informação sobre o número de íons na amostra contribuintes.
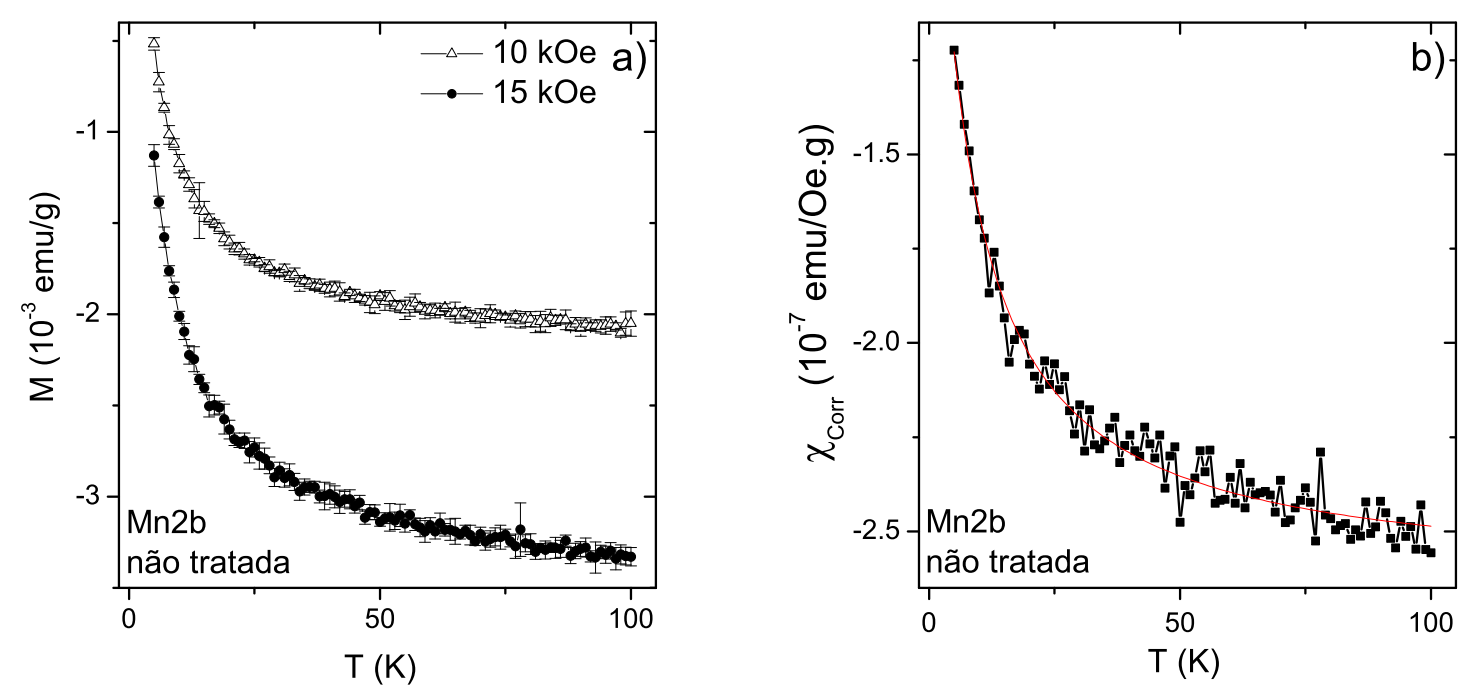

Figura 4.52: Medidas da magnetização em função da temperatura para a amostra Mn2b sem tratamento térmico obtidas nos campos de 10 e 15 kOe (a) e de susceptibilidade magnética corrigida (b) obtida das curvas de magnetização. 
Encontram-se na tabela 4.15 os dados obtidos das medidas em função da temperatura das amostras implantadas com Mn. Os valores de momento angular total efetivo $\left(J_{\text {eff }}\right)$ foram calculadose considerando que íons $\mathrm{Mn}^{2+}$ são responsáveis pela resposta paramagnética. Obteve-se um valor de $J_{\text {eff }}$ de 1.58 para a amostra Mn2b, que implica em aproximadamente $65 \%$ dos íons implantados contribuindo com o paramagnetismo desta amostra. A amostra Mn1 também apresentou uma alta porcentagem de íons implantados contribuindo para o paramagnetismo, em torno de $70 \%$. O mesmo não ocorreu com a amostra Mn2a onde apenas 38\% do íons geraram paramagnetismo pela análise de $J_{\text {eff }}$. Como esperado o tratamento térmico realizado nas amostras de Mn reduziu a intensidade do paramagnetismo nas mesmas. Em ambas as amostras tratadas $J_{\text {eff }}$ foi reduzido em 0.2, no entanto assim como ocorrido com as amostras implantadas com Fe, esta redução não foi acompanhada de um o aumento proporcional do ferromagnetismo.

\begin{tabular}{|c|c|c|c|c|}
\hline & \multicolumn{2}{|c|}{ Pré Tratamento } & \multicolumn{2}{c|}{ Pós Tratamento } \\
\hline Amostra & $C_{\text {Curie }}\left(10^{-7} \mathrm{~cm}^{3} \mathrm{~K} / \mathrm{g}\right)$ & $J_{\text {eff }}$ & $C_{\text {Curie }}\left(10^{-7} \mathrm{~cm}^{3} \mathrm{~K} / \mathrm{g}\right)$ & $J_{\text {eff }}$ \\
\hline Mn1 & 8.44 & 1.70 & 7.31 & 1.51 \\
Mn2a & 9.40 & 0.95 & 7.51 & 0.75 \\
Mn2b & 15.9 & 1.58 & - & - \\
\hline
\end{tabular}

Tabela 4.15: Valores de $\mathrm{C}_{\text {Curie }}$ e $\mathrm{J}_{\text {eff }}$ para as amostras implantadas com Mn pré e pós tratamento térmico.

As medidas de susceptibilidade magnética corrigida das amostras Mn1 e Mn2a tratadas termicamente estão apresentadas na figura 4.53. Verificou-se que os valores de susceptibilidade extraídos das medidas em função da temperatura para as amostras Mn1 e Mn2a tratadas estão de acordo com os valores de $\chi_{T}$ obtidos pelas medidas em função do campo.
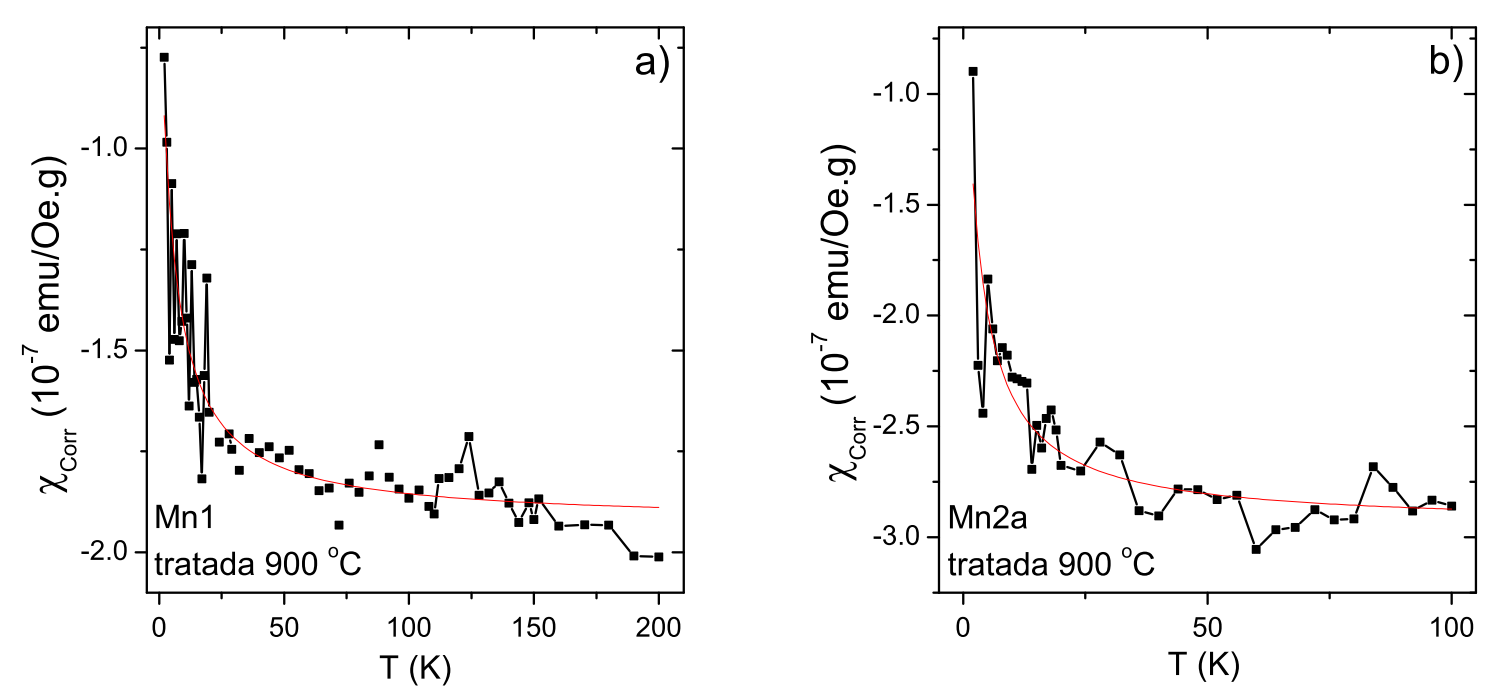

Figura 4.53: Medidas de susceptibilidade magnética corrigida das amostras Mn1 (a) e Mn2a (b) tratadas termicamente. Determinadas através de medidas de magnetização em função da temperatura nos campos de 10 e $15 \mathrm{kOe}$.

Apesar de seu elevado momento magnético, as amostras implantadas com íons de Mn apre- 
sentaram respostas ferromagnéticas menores do que as obtidas nas amostras implantadas com Fe. De uma maneira geral observou-se das medidas em função da temperatura e em função do campo que a grande maioria dos íons de Mn implantados permaneceram não interagentes, ou seja, não contribuíram para a geração de ferromagnetismo nas amostras de c-GaN. 


\subsubsection{Amostras implantadas com $\mathrm{Cu}$}

A utilização de $\mathrm{Cu}$ como metal de transição para dopagem de semicondutores é interessante devido ao elemento possuir fase metálica não ferromagnética, assim como todas as possíveis fases secundárias formadas durante sua implantação em GaN [93]. Não obstante, diversos trabalhos reportaram o aparecimento de ferromagnetismo em amostras de h-GaN implantadas com $\mathrm{Cu}$. O trabalho de Lee et al. [54] foi pioneiro na obtenção de ferromagnetismo à temperatura ambiente com a obtenção de amostras de h-GaN com magnetização de saturação de até $0.27 \mu_{B}$ /íon, porém com uma alta dose implantada de $1 \times 10^{17} \mathrm{~cm}^{-2}$. Zhang et al. [93] estendeu o estudo para doses menores, com intuito de reduzir a amorfização das amostras, demonstrando ferromagnetismo com campo coercivo acima de 200 Oe em doses tão baixas quanto $10^{16} \mathrm{~cm}^{-2}$. Ferromagnetismo também foi encontrado em amostras dopadas com íons de $\mathrm{Cu}$ durante o crescimento [94] com intensidade praticamente independente da temperatura entre 10 e $290 \mathrm{~K}$ indicando $T_{c}$ acima de $400 \mathrm{~K}$, descartando a alta densidade de defeitos gerada pela implantação iônica como fonte do magnetismo. Nanofios de GaN dopados com Cu em concentrações de 1\% e 2.5\% também apresentaram ferromagnetismo à temperatura ambiente [95]. A literatura a respeito de magnetismo em amostras dopadas com cobre é rica para o óxido de zinco $(\mathrm{ZnO})$. Para este material ficou demonstrada a importância de defeitos pontuais de vacância no aparecimento de ferromagnetismo [96].

Apresentam-se na figura 4.54 as medidas de magnetização por campo aplicado nas temperaturas de 10 e $300 \mathrm{~K}$ da amostra Cu1 pré (a) e pós (b) tratamento térmico a $900{ }^{\circ} \mathrm{C}$.
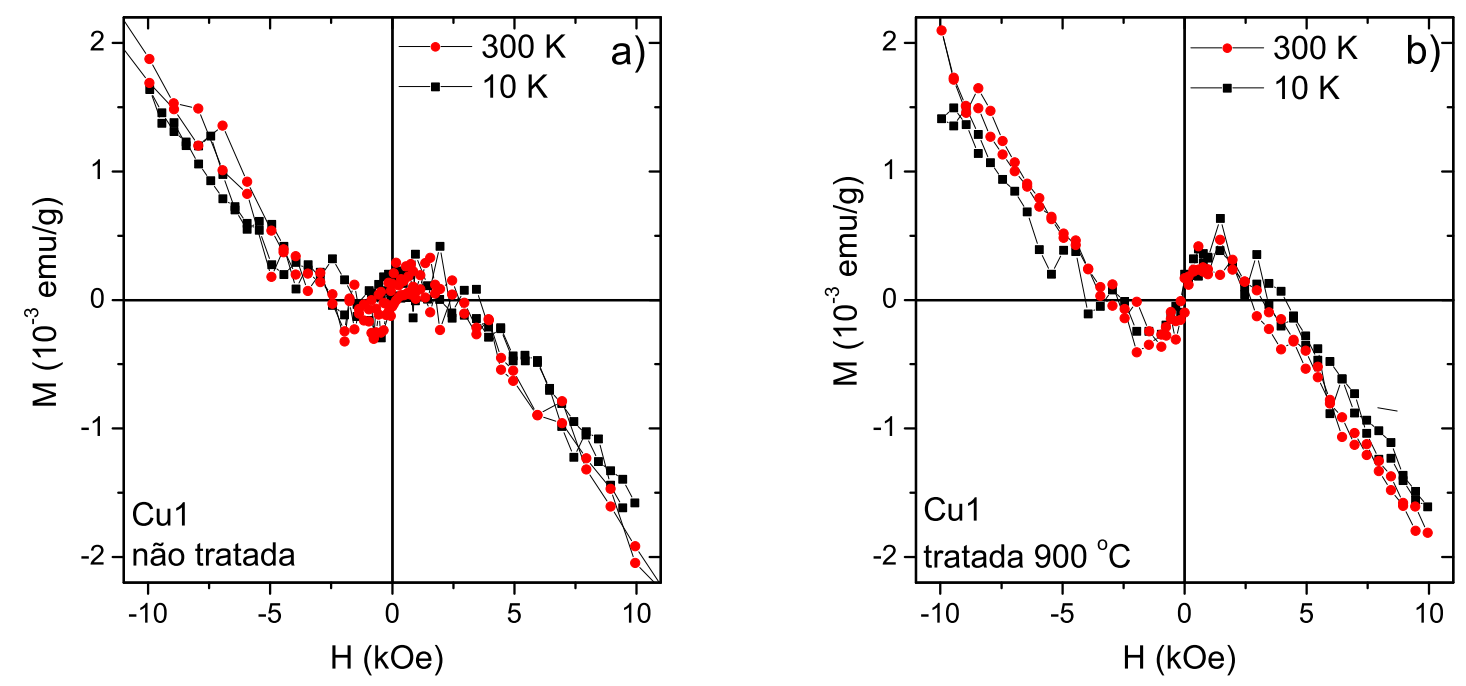

Figura 4.54: Medidas de magnetização por campo aplicado nas temperaturas de 10 e $300 \mathrm{~K}$ da amostra Cu1 não tratada (a) e tratada a $900{ }^{\circ} \mathrm{C}(\mathrm{b})$.

Com a implantação iônica a amostra Cu1 apresentou ferromagnetismo com momento de saturação em torno de $10^{-3} \mathrm{emu} / \mathrm{g}$. Calculando-se o momento magnético de saturação por íon através de procedimento já descrito para as amostras implantadas com $\mathrm{Fe}$, obtemos um valor de aproximadamente $0.35 \mu_{B}$ /íon para a amostra Cu1 (usando $g=2, S=5 / 2$ ).

Após tratamento térmico o valor de magnetização de saturação não foi alterado significativamente para a amostra Cu1. Como provavelmente são defeitos nativos da amostra e também criados pela implantação os responsáveis pela geração de ferromagnetismo, era esperado que o tratamento térmico reduzisse o ferromagnetismo nesta amostra. 
As curvas de magnetização por campo aplicado nas temperaturas de 10 e $300 \mathrm{~K}$ da amostra Cu2a pré e pós tratamento térmico estão apresentadas na figura 4.55.
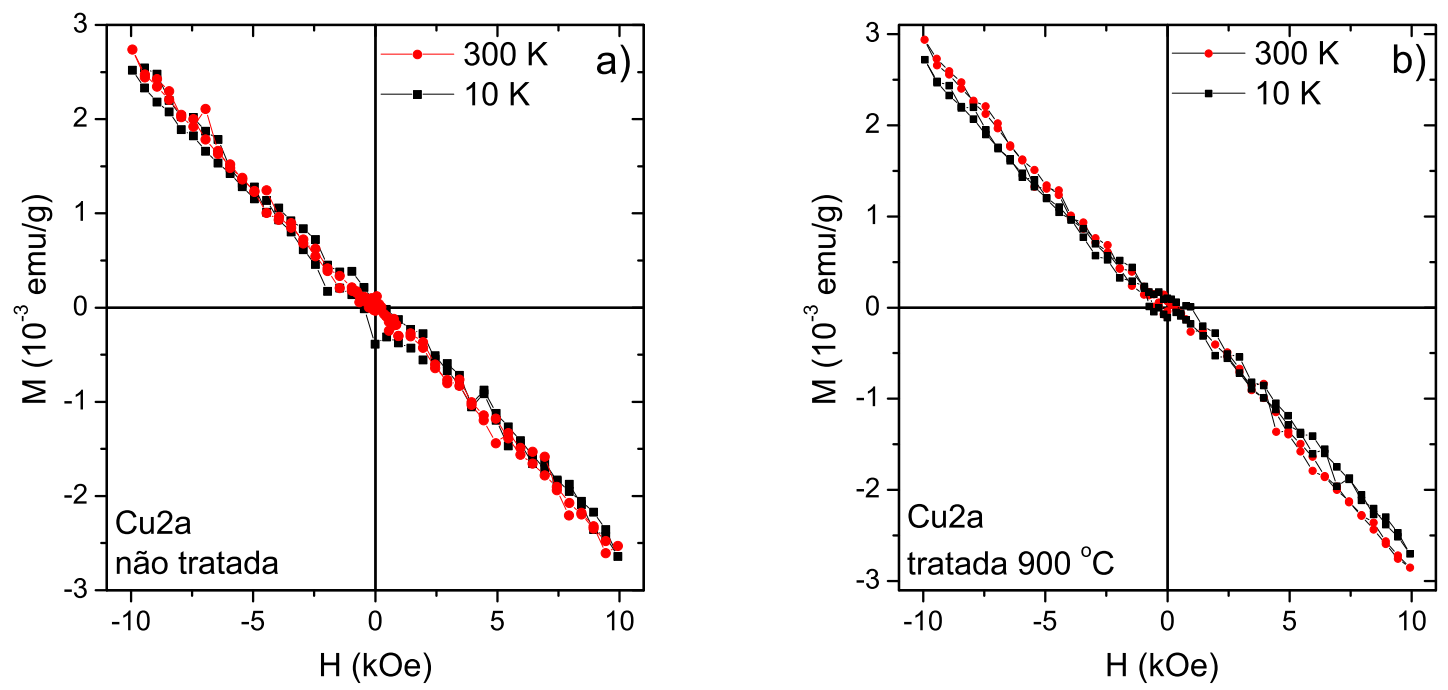

Figura 4.55: Medidas de magnetização por campo aplicado nas temperaturas de 10 e $300 \mathrm{~K}$ da amostra Cu2a não tratada (a) e tratada a $900{ }^{\circ} \mathrm{C}(\mathrm{b})$.

A amostra Cu2b não foi tratada termicamente, dessa maneira não foi possível estudar o efeito da temperatura de tratamento nas amostras dopadas com $\mathrm{Cu}$. Vemos na figura 4.56 as medidas de magnetização por campo aplicado nas temperaturas de 10 e $300 \mathrm{~K}$ da amostra Cu2b implantada com dose $2.4 \times 10^{16} \mathrm{~cm}^{-2}$.

Com a implantação iônica de $\mathrm{Cu}$ com alta dosagem nenhuma das amostras apresentou comportamento ferromagnético e apenas um fraco paramagnetismo pôde ser observado. O tratamento realizado a $900{ }^{\circ} \mathrm{C}$ na amostra $\mathrm{Cu} 2$ a não alterou significativamente o seu magnetismo. De maneira semelhante ao observado no estudo das amostras dopadas com $\mathrm{Fe}$, a variação da dose provocou um grande efeito no magnetismo nas amostras implantadas com $\mathrm{Cu}$, porém o efeito inverso foi observado, as amostras implantadas com alta dose não apresentaram ferromagnetismo. Sabendo-se da influência de vacâncias na formação do ferromagnetismo em amostras dopadas com $\mathrm{Cu}$, inferimos que a elevada amorfização provocada pela implantação em alta dosagem tenha reduzido a concentração deste tipo de defeito, coibindo o aparecimento de ferromagnetismo.

Nas tabelas 4.16 e 4.17 estão resumidos os valores de magnetização de saturação e susceptibilidade magnética total extraídos das medidas em função do campo.

\begin{tabular}{|c|c|c|c|c|}
\hline & \multicolumn{2}{|c|}{ Pré Tratamento } & \multicolumn{2}{c|}{ Pós Tratamento } \\
\hline Amostra & $\chi_{T}\left(10^{-7} \mathrm{emu} /\right.$ Oe.g $)$ & $M_{s}\left(10^{-4} \mathrm{emu} / \mathrm{g}\right)$ & $\chi_{T}\left(10^{-7} \mathrm{emu} /\right.$ Oe.g $)$ & $M_{s}\left(10^{-4} \mathrm{emu} / \mathrm{g}\right)$ \\
\hline Cu1 & -2.71 & 9.75 & -2.62 & 9.90 \\
Cu2a & -2.74 & 0 & -2.72 & 0 \\
Cu2b & -2.53 & 0 & - & - \\
\hline
\end{tabular}

Tabela 4.16: Valores de $\chi_{T}$ e momento de saturação pré e pós tratamento térmico das amostras implantadas com $\mathrm{Cu}$, extraídas das medidas de magnetização em função do campo na temperatura de $10 \mathrm{~K} . M_{s}=0$ indica que a amostra é para- e/ou diamagnética. 


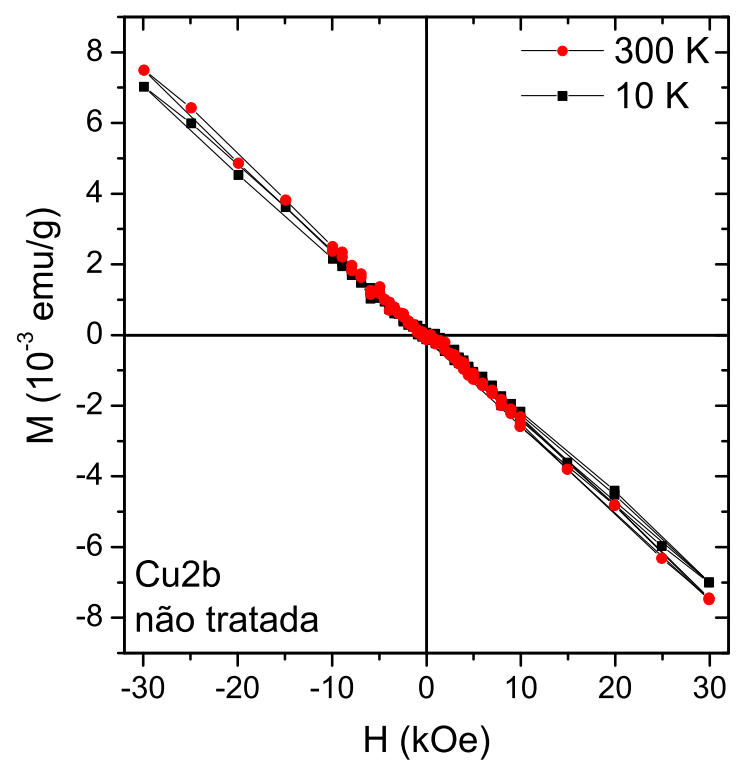

Figura 4.56: Medidas de magnetização por campo aplicado nas temperaturas de 10 e $300 \mathrm{~K}$ da amostra Cu2b não tratada.

\begin{tabular}{|c|c|c|c|c|}
\hline & \multicolumn{2}{|c|}{ Pré Tratamento } & \multicolumn{2}{c|}{ Pós Tratamento } \\
\hline Amostra & $\chi_{T}\left(10^{-7} \mathrm{emu} /\right.$ Oe.g $)$ & $M_{s}\left(10^{-4} \mathrm{emu} / \mathrm{g}\right)$ & $\chi_{T}\left(10^{-7} \mathrm{emu} /\right.$ Oe.g $)$ & $M_{s}\left(10^{-4} \mathrm{emu} / \mathrm{g}\right)$ \\
\hline Cu1 & -2.67 & 8.75 & -2.73 & 8.65 \\
$\mathrm{Cu} 2 \mathrm{a}$ & -2.78 & 0 & -2.84 & 0 \\
$\mathrm{Cu} 2 \mathrm{~b}$ & -2.62 & 0 & - & - \\
\hline
\end{tabular}

Tabela 4.17: Valores de $\chi_{T}$ e momento de saturação pré e pós tratamento térmico das amostras implantadas com $\mathrm{Cu}$, extraídas das medidas de magnetização em função do campo na temperatura de $300 \mathrm{~K} . M_{s}=0$ indica que a amostra é para- e/ou diamagnética.

Devido ao reduzido paramagnetismo presente nas amostras implantadas com $\mathrm{Cu}$, apenas a amostra Cu2a foi caracterizada por medidas em função da temperatura. Na figura 4.57 está apresentada a curva de susceptibilidade magnética corrigida em função da temperatura para a amostra Cu2a tratada termicamente, extraída de medidas de magnetização em função da temperatura nos campos de 10 e $15 \mathrm{kOe}$. Nota-se inicialmente uma grande incerteza nos dados obtidos, também reflexo do erro acumulado pelo tratamento dos dados de magnetização. Assim como observado nas medidas em função do campo e ao contrário do esperado da implantação de íons com momento magnético total nulo, uma variação da susceptibilidade entre as temperaturas de 10 e $100 \mathrm{~K}$ foi observada, indicando a presença de paramagnetismo na amostra. No entanto, sua intensidade foi bastante inferior à encontrada nas amostras implantadas com íons magnéticos (Fe e Mn). Os valores de susceptibilidade magnética obtidos através das medidas em função da temperatura para a amostra Cu2a são compatíveis com os valores encontrados nas tabelas 4.16 e 4.17.

Mesmo com momento magnético nulo em cada íon, a amostra implantada com baixa dosagem de $\mathrm{Cu}$ apresentou ferromagnetismo tanto após a implantação quanto após tratamento térmico, evidenciando a influência de defeitos da rede cristalina na geração de ferromagnetismo através de implantação iônica. As amostras implantadas com alta dosagem não apresentaram ferromagnetismo 


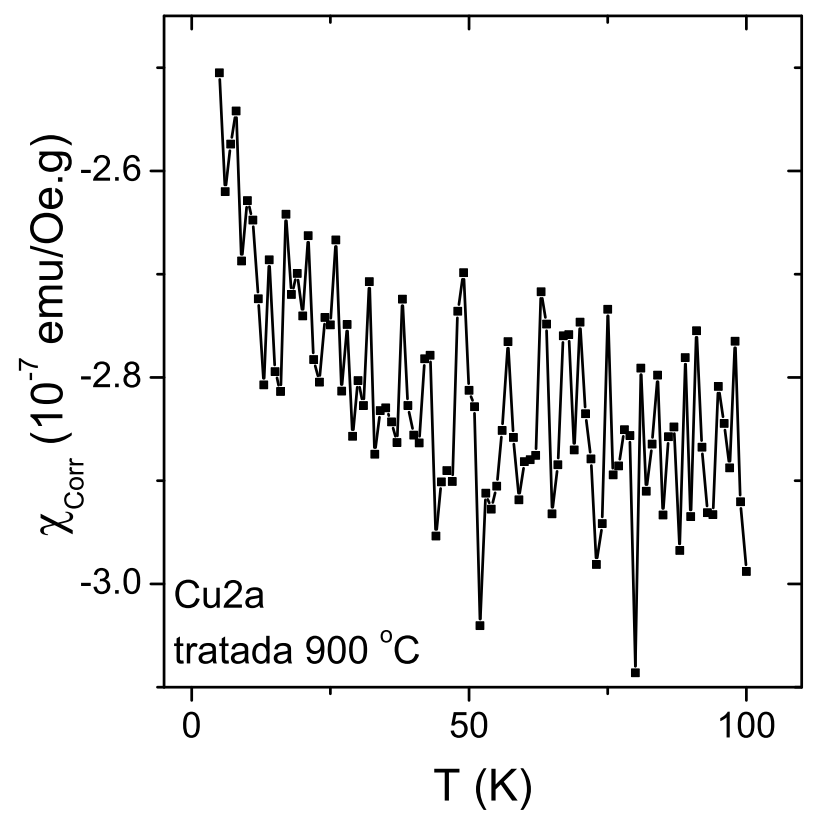

Figura 4.57: Curva de susceptibilidade corrigida em função da temperatura para a amostra Cu2a tratada termicamente a $900{ }^{\circ} \mathrm{C}$.

mesmo após tratamento térmico, fato que associamos à elevada amorfização da rede decorrente do processo de implantação iônica. 


\section{Capítulo 5}

\section{Conclusões}

O presente trabalho buscou caracterizar, estrutural e magneticamente, amostras de c-GaN/3C$\mathrm{SiC}$ implantadas com íons magnéticos e não magnéticos e tratadas termicamente. A correlação entre ambas as caracterizações foi almejada, porém nem sempre alcançada, tendo em vista a presença de análises conflitantes e também as limitações das diversas técnicas. O crescimento dos filmes de c-GaN por MBE resultou em amostras de boa qualidade cristalina. A estrutura cristalina cúbica do GaN tem natureza metaestável, dessa forma, algumas amostras apresentam incrustações de h-GaN, a estrutura cristalina mais estável para o GaN.

Com o intuito de compreender o processo de implantação iônica foram realizadas simulações computacionais baseadas em dois modelos distintos. O modelo mais simples se mostrou mais adequado para a descrição da implantação real, pois o software de simulação que levava em conta a rede cristalina superestimava os efeitos de canalização, distorcendo o perfil de implantação obtido. A implantação realizada com os diversos íons alterou significativamente as propriedades estruturais e magnéticas das amostras.

As técnicas estruturais de difratometria de raios-x, espectroscopias de fotoluminescência e Raman revelaram uma expansão da rede cristalina associada a um processo de amorfização, principalmente nas regiões superficiais em alta dose. A análise magnética das amostras recém-implantadas revelou, com exceção das amostras dopadas com baixa dose de $\mathrm{Fe}$ e $\mathrm{Cu}$, apenas comportamento diae paramagnético, não levando à formação de ferromagnetismo. Com o tratamento térmico algumas amostras mostraram recuperação das propriedades estruturais, enquanto outras apresentaram degradação, possivelmente associada à evaporação de $\mathrm{N}_{2}$. O magnetismo das amostras implantadas com $\mathrm{Fe}$ mudou radicalmente após o tratamento, com o desaparecimento do ferromagnetismo presente na amostra implantada com baixa dosagem e a forte geração de ferromagnetismo nas amostras implantadas com o dobro da dose. Analisando as medidas de magnetização em função da temperatura e também o comportamento magnético e estrutural da amostra Fe2b após retratamento térmico, associamos esse ferromagnetismo à formação de microcristalitos ferromagnéticos, provavelmente nitretos de Fe ou Fe metálico, não detectados pelas técnicas de caracterização estrutural. Em relação à temperatura de tratamento julgou-se que, para a formação de ferromagnetismo, o tratamento térmico realizado a $900{ }^{\circ} \mathrm{C}$ foi mais efetivo que o a $800{ }^{\circ} \mathrm{C}$ e também que o processo realizado em duas etapas não justificou a elevada degradação da rede provocada pelo aumento no tempo de tratamento. As amostras implantadas com Mn e tratadas termicamente também apresentaram ferromagnetismo até $300 \mathrm{~K}$, porém com intensidade menor em comparação com as implantadas com Fe. Julgamos que possivelmente o ferromagnetismo nestas amostras se deu pela interação entre os íons de Mn localizados na rede cristalina. Um resultado importante deste trabalho foi a obtenção de ferromagnetismo à temperatura ambiente em amostra implantada com $\mathrm{Cu}$, íon de tamanho atômico comparável ao $\mathrm{Fe}$ e ao Mn, mas não magnético. Este resultado evidenciou a influência e a importância de defeitos na formação de ferromagnetismo em amostras implantadas, 
essa formação se mostrou fortemente dependente da dose implantada e não foi alterada significativamente por tratamento térmico.

Uma perspectiva para o prosseguimento do presente trabalho seria a realização de tratamento térmico em baixa temperatura nas amostras implantadas com $\mathrm{Mn}$ e $\mathrm{Cu}$ do grupo $2 \mathrm{~b}$, o que permitiria uma melhor comparação do efeito do tratamento para estes íons. Já a prazo mais longo, seria interessante o estudo da influência de implantações em doses extremas (tanto altas quanto baixas) tanto no magnetismo quanto nas propriedades estruturais de filmes de c-GaN, já que resultados interessantes como segregação e propriedades magnéticas específicas de semicondutores magnéticos diluídos são encontrados na literatura do h-GaN para estes casos. 


\section{Capítulo 6}

\section{Bibliografia}

[1] H. Ohno, A. Shen, F. Matsukura, A. Oiwa, A. Endo, S. Katsumoto, and Y. Iye, "(Ga,Mn)As a new diluted magnetic semiconductor based on GaAs," Applied Physics Letters, vol. 69, pp. 363-365, July 1996.

[2] S. Strite and H. Morkoc, "GaN, AlN, and InN a review," Journal of Vacuum Science \& Technology B: Microelectronics and Nanometer Structures, vol. 10, no. 4, pp. 1237-1266, 1992.

[3] T. Dietl, H. Ohno, F. Matsukura, J. Cibert, and D. Ferrand, "Zener model description of ferromagnetism in zinc-blende magnetic semiconductors," Science, vol. 287, no. 5455, pp. 10191022,2000 .

[4] A. X. Gray, J. Minar, S. Ueda, P. R. Stone, Y. Yamashita, J. Fujii, J. Braun, L. Plucinski, C. M. Schneider, G. Panaccione, H. Ebert, O. D. Dubon, K. Kobayashi, and C. S. Fadley, "Bulk electronic structure of the dilute magnetic semiconductor $\mathrm{Ga}_{1-x} \mathrm{Mn}_{x} \mathrm{As}$ through hard X-ray angle-resolved photoemission," Nature Materials, vol. 11, no. 11, p. 9, 2012.

[5] W. C. Johnson, J. B. Parson, and M. C. Crew, "Nitrogen compounds of gallium. III," The Journal of Physical Chemistry, vol. 36, no. 10, pp. 2651-2654, 1931.

[6] R. Juza and H. Hahn, "Uber die kristallstrukturen von $\mathrm{Cu}_{3} \mathrm{~N}, \mathrm{GaN}$ und $\mathrm{InN}$ metallamide und metallnitride," Zeitschrift fur anorganische und allgemeine Chemie, vol. 239, no. 3, pp. 282287, 1938.

[7] H. P. Maruska and J. J. Tietjen, "The preparation and properties of vapor-deposited singlecrystal-line GaN," Applied Physics Letters, vol. 15, no. 10, pp. 327-329, 1969.

[8] T. Zhu and R. A. Oliver, "Unintentional doping in GaN," Physical Chemistry Chemical Physics, vol. 14, pp. 9558-9573, 2012.

[9] H. P. Maruska, D. A. Stevenson, and J. I. Pankove, "Violet luminescence of Mg doped GaN," Applied Physics Letters, vol. 22, no. 6, pp. 303-305, 1973.

[10] S. Nakamura, T. Mukai, and M. Senoh, "Candela-class high-brightness InGaN/AlGaN doubleheterostructure blue-light-emitting diodes," Applied Physics Letters, vol. 64, no. 13, pp. 16871689, 1994.

[11] S. Nakamura, S. Pearton, and G. Fasol, The Blue Laser Diode: The Complete Story. Springer, 2000 . 
[12] B. Lu, O. Saadat, and T. Palacios, "High-performance integrated dual-gate AlGaN/GaN enhancement-mode transistor," Electron Device Letters, IEEE, vol. 31, pp. 990 -992, sept. 2010 .

[13] M. Mizuta, S. Fujieda, Y. Matsumoto, and T. Kawamura, "Low temperature growth of GaN and AlN on GaAs utilizing metalorganics and hydrazine," Japanese Journal of Applied Physics, vol. 25, no. Part 2, No. 12, pp. L945-L948, 1986.

[14] M. J. Paisley, Z. Sitar, J. B. Posthill, and R. F. Davis, "Growth of cubic phase gallium nitride by modified molecular-beam epitaxy," Journal of Vacuum Science 83 Technology A: Vacuum, Surfaces, and Films, vol. 7, no. 3, pp. 701-705, 1989.

[15] J. G. Kim, A. C. Frenkel, H. Liu, and R. M. Park, "Growth by molecular beam epitaxy and electrical characterization of Si-doped zinc blende GaN films deposited on beta-SiC coated (001) Si substrates," Applied Physics Letters, vol. 65, no. 1, pp. 91-93, 1994.

[16] E. Martinez-Guerrero, B. Daudin, G. Feuillet, H. Mariette, Y. Genuist, S. Fanget, A. Philippe, C. Dubois, C. Bru-Chevallier, G. Guillot, P. Aboughe Nze, T. Chassagne, Y. Monteil, H. Gamez-Cuatzin, and J. Tardy, " $p$ and $n$ type doping of cubic GaN on SiC (001)," Materials Science and Engineering: B, vol. 82, no. 1, pp. 59-61, 2001.

[17] E. Tschumak, R. Granzner, J. K. N. Lindner, F. Schwierz, K. Lischka, H. Nagasawa, M. Abe, and D. J. As, "Nonpolar cubic AlGaN/GaN heterojunction field-effect transistor on Ar+ implanted 3C-SiC (001)," Applied Physics Letters, vol. 96, no. 25, pp. 253501-253501-3, 2010.

[18] R. Brazis and R. Raguotis, "Monte carlo modeling of phonon-assisted carrier transport in cubic and hexagonal gallium nitride," Optical and Quantum Electronics, vol. 38, no. 4-6, pp. 339-347, 2006 .

[19] W. Shockley, "Forming semiconductive devices by ionic bombardment," no. US 2787564, 1957.

[20] C. Kittel, Introduction to Solid State Physics. John Wiley \& Sons, Inc., 5a ed., 1976.

[21] M. E. Levinshtein, S. L. Rumyantsev, and M. Shur, Properties of advanced semiconductor materials: GaN, AlN, InN, BN, SiC, SiGe. Wiley, 2001.

[22] R. Cheung, Silicon Carbide Micro Electromechanical Systems for Harsh Environments. Imperial College Press, 2006.

[23] "Semiconductors on NSM." http://www.ioffe.ru/SVA/NSM/Semicond/. Acessado: $02 / 08 / 2013$.

[24] J. Schoermann, S. Potthast, D. J. As, and K. Lischka, "In situ growth regime characterization of cubic GaN using reflection high energy electron diffraction," Applied Physics Letters, vol. 90, no. 4, pp. 041918-041918-3, 2007.

[25] K. O'Donnell and V. Dierolf, Rare Earth Doped III-Nitrides for Optoelectronic and Spintronic Applications. Topics in applied physics, Springer, 2010.

[26] A. Burchard, E. Haller, A. Stoetzler, R. Weissenborn, and M. Deicher, "Annealing of ionimplanted GaN," Physica B: Condensed Matter, vol. 273-274, pp. 96-100, 1999.

[27] G. S. Aluri, M. Gowda, N. A. Mahadik, S. G. Sundaresan, M. V. Rao, J. A. Schreifels, J. A. Freitas, S. B. Qadri, and Y.-L. Tian, "Microwave annealing of Mg-implanted and in situ Bedoped GaN," Journal of Applied Physics, vol. 108, no. 8, pp. 083103-083103-7, 2010. 
[28] S. J. Pearton, J. C. Zolper, R. J. Shul, and F. Ren, "GaN: processing, defects, and devices," Journal of Applied Physics, vol. 86, no. 1, pp. 1-78, 1999.

[29] D. Harris and M. Bertolucci, Symmetry and Spectroscopy: An Introduction to Vibrational and Electronic Spectrosocpy. Dover Books on Chemistry Series, Dover, 1978.

[30] D. Olego and M. Cardona, "Raman scattering by coupled LO-phonon-plasmon modes and forbidden TO-phonon Raman scattering in heavily doped p-type GaAs," Phys. Rev. B, vol. 24, pp. 7217-7232, 1981.

[31] A. Tabata, R. Enderlein, J. R. Leite, S. W. da Silva, J. C. Galzerani, D. Schikora, M. Kloidt, and K. Lischka, "Comparative Raman studies of cubic and hexagonal GaN epitaxial layers," Journal of Applied Physics, vol. 79, no. 8, pp. 4137-4140, 1996.

[32] S. Blundell, Magnetism in Condensed Matter, vol. 71. Oxford University Press, 2001.

[33] B. The SQUID group, "SQUIDs: A technical report, http://rich.phekda.org/squid/technical/index.htm," tech. rep., 1998. Acessado em $22 / 04 / 2013$.

[34] A. Bonanni, M. Kiecana, C. Simbrunner, T. Li, M. Sawicki, M. Wegscheider, M. Quast, H. Przybyliska, A. Navarro-Quezada, A. Wolos, W. Jantsch, and T. Dietl, "Paramagnetic GaN:Fe and ferromagnetic (Ga,Fe)N the relationship between structural, electronic, and magnetic properties," Physical Review B, vol. 75, no. 12, p. 125210, 2007.

[35] J. Ziegler, J. Biersack, and M. Ziegler, SRIM - The Stopping and Range of Ions in Matter. Lulu Books, 2008.

[36] K. Nordlund, "Molecular dynamics simulation of ion ranges in the 1-100 keV energy range," Computational Materials Science, vol. 3, no. 4, pp. 448-456, 1995.

[37] N. Bohr Philosophical Magazine, vol. 25, p. 10, 1913.

[38] M. Nastasi and J. Mayer, Ion implantation and synthesis of materials. Springer Series in Materials Science, v.80, Springer-Verlag Berlin and Heidelberg GmbH \& Company KG, 2006.

[39] C. Ronning, E. Carlson, and R. Davis, "Ion implantation into gallium nitride," Physics Reports, vol. 351, no. 5, pp. 349-385, 2001.

[40] K. Lorenz and E. Wendler, Implantation Damage Formation in GaN and ZnO, Ion Implantation, Prof. Mark Goorsky (Ed.). InTech, 2012.

[41] C. Liu, B. Mensching, M. Zeitler, K. Volz, and B. Rauschenbach, "Ion implantation in GaN at liquid-nitrogen temperature: Structural characteristics and amorphization," Physical Review $B$, vol. 57, no. 4, pp. 2530-2535, 1998.

[42] A. Y. Azarov, A. Hallen, J. Jensen, T. Aggerstam, and S. Lourdudoss, "High dose Fe implantation of GaN, damage build-up and dopant redistribution," Journal of Physics: Conference Series, vol. 100, no. 4, p. 042036, 2008.

[43] J. Olivero and R. Longbothum, "Empirical fits to the voigt line width: A brief review," Journal of Quantitative Spectroscopy and Radiative Transfer, vol. 17, no. 2, pp. 233-236, 1977.

[44] Y. Shi, Y. Zhang, C. Jiang, D. Fu, and X. Fan, "The influence of implantation temperature on the magnetism and structure of Mn+ implanted p-GaN films," Physica B: Condensed Matter, vol. 388 , no. 1, pp. 82-86, 2007. 
[45] R. Groh, G. Gerey, L. Bartha, and J. I. Pankove, "On the thermal decomposition of GaN in vacuum," physica status solidi (a), vol. 26, no. 1, pp. 353-357, 1974.

[46] G. V. Hansson, H. H. Radamsson, and W.-X. Ni, "Strain and relaxation in Si-MBE structures studied by reciprocal space mapping using high resolution X-ray diffraction," Journal of Materials Science: Materials in Electronics, vol. 6, no. 5, pp. 292-297, 1995.

[47] E. Koppensteiner, P. Hamberger, G. Bauer, V. Holy, H. Kibbel, H. Presting, and E. Kasper, "Quantitative analysis of strain relaxation and mosaicity in short period SimGen superlattices using reciprocal space mapping by X-ray diffraction," Solid-State Electronics, vol. 37, no. 4, pp. 629-634, 1994.

[48] K. P. Lee, S. J. Pearton, M. E. Overberg, C. R. Abernathy, R. G. Wilson, S. N. G. Chu, N. Theodoropolou, A. F. Hebard, and J. M. Zavada, "Magnetic effects of direct ion implantation of Mn and Fe into p-GaN," Journal of Electronic Materials, vol. 31, no. 5, pp. 411-415, 2002 .

[49] G. Talut, H. Reuther, A. Mucklich, F. Eichhorn, and K. Potzger, "Nanocluster formation in Fe implanted GaN," Applied Physics Letters, vol. 89, no. 16, pp. 161909-161909-3, 2006.

[50] G. Talut, J. Grenzer, H. Reuther, A. Shalimov, C. Baehtz, D. Novikov, and B. Walz, "In situ observation of secondary phase formation in Fe implanted GaN annealed in low pressure $\mathrm{N}_{2}$ atmosphere," Applied Physics Letters, vol. 95, no. 23, pp. 232506-232506-3, 2009.

[51] B. Warren, X-ray Diffraction. Addison-Wesley series in metallurgy and materials, Dover, 1969.

[52] M. H. Kane, A. Asghar, A. M. Payne, C. R. Vestal, Z. J. Zhang, M. Strassburg, J. Senawirante, N. Dietz, C. J. Summers, and I. T. Ferguson, "Comparison of GaMnN epilayers prepared by ion implantation and metalorganic chemical vapor deposition," physica status solidi (c), vol. 2, no. 7, pp. 2441-2445, 2005.

[53] S. Dhar, O. Brandt, and K. H. Ploog, "Ferrimagnetic $\mathrm{Mn}_{4} \mathrm{~N}(111)$ layers grown on $6 \mathrm{H}-\mathrm{SiC}(0001)$ and GaN(0001) by reactive molecular-beam epitaxy," Applied Physics Letters, vol. 86, no. 11, pp. 112504-112504-3, 2005.

[54] J.-H. Lee, I.-H. Choi, S. Shin, S. Lee, J. Lee, C. Whang, S.-C. Lee, K.-R. Lee, J.-H. Baek, K. H. Chae, and J. Song, "Room-temperature ferromagnetism of Cu-implanted GaN," Applied Physics Letters, vol. 90, no. 3, pp. 032504-032504-3, 2007.

[55] M. Smith, J. Y. Lin, H. X. Jiang, and M. Asif Khan, "Room temperature intrinsic optical transition in GaN epilayers: The band-to-band versus excitonic transitions," Applied Physics Letters, vol. 71, no. 5, pp. 635-637, 1997.

[56] M. A. Reshchikov and H. Morkoc, "Luminescence properties of defects in GaN," Journal of Applied Physics, vol. 97, no. 6, pp. 061301-061301-95, 2005.

[57] D. K. Kim and C. B. Park, "Photoluminescence studies of GaN films on Si(111) substrate by using an AlN buffer control," Journal of the Korean Physical Society, vol. 47, no. 6, p. 1006, 2005 .

[58] J. Cao, D. Pavlidis, A. Eisenbach, A. Philippe, C. Bru-Chevallier, and G. Guillot, "Photoluminescence properties of GaN grown on compliant silicon-on-insulator substrates," Applied Physics Letters, vol. 71, no. 26, pp. 3880-3882, 1997. 
[59] M. A. Reshchikov, G.-C. Yi, and B. W. Wessels, "Defect luminescence in heavily Mg doped GaN," MRS Online Proceedings Library, vol. 537, 1998.

[60] T. Moustakas and J. Pankove, Gallium Nitride (GaN) I. Semiconductors and semimetals, Acad. Press, 1998.

[61] C. H. Hong, D. Pavlidis, S. W. Brown, and S. C. Rand, "Photoluminescence investigation of GaN films grown by metalorganic chemical vapor deposition on (100) GaAs," Journal of Applied Physics, vol. 77, no. 4, pp. 1705-1709, 1995.

[62] S. Kucheyev, J. Williams, and S. Pearton, "Ion implantation into GaN," Materials Science and Engineering: R: Reports, vol. 33, no. 2, pp. 51-108, 2001.

[63] D. J. As, U. Koehler, and K. Lischka, "Optical properties of carbon doped cubic GaN epilayers grown on GaAs (001) substrate by molecular beam epitaxy," MRS Proceedings, vol. 693, 02001.

[64] J. Fernandez, F. Cerdeira, E. Meneses, J. Soares, O. Noriega, J. Leite, D. As, U. Koehler, D. Salazar, D. Schikora, and K. Lischka, "Near band-edge optical properties of cubic GaN with and without carbon doping," Microelectronics Journal, vol. 35, no. 1, pp. 73-77, 2004.

[65] E. M. Goldys, M. Godlewski, K. Drozdowicz-Tomsia, R. Langer, and A. Baraki, "Optical emission bands in cubic GaN grown by MBE," in 1998 Conference on Optoelectronic and Microelectronic Materials Devices, 1998. Proceedings, pp. 202-205, 1998.

[66] J. I. Pankove and J. A. Hutchby, "Photoluminescence of ion-implanted GaN," Journal of Applied Physics, vol. 47, no. 12, pp. 5387-5390, 1976.

[67] T. Ogino and M. Aoki, "Mechanism of yellow luminescence in GaN," Japanese Journal of Applied Physics, vol. 19, no. 12, pp. 2395-2405, 1980.

[68] G. Ramirez-Flores, H. Navarro-Contreras, A. Lastras-Martinez, R. C. Powell, and J. E. Greene, "Temperature-dependent optical band gap of the metastable zinc-blende structure $\beta$-GaN," Physical Review B, vol. 50, no. 12, pp. 8433-8438, 1994.

[69] H. Yaguchi, J. Wu, B. Zhang, Y. Segawa, H. Nagasawa, K. Onabe, and Y. Shiraki, "Micro Raman and micro photoluminescence study of cubic GaN grown on 3C-SiC substrates by metalorganic vapor phase epitaxy," Journal of Crystal Growth, vol. 195, no. 1, pp. 323-327, 1998.

[70] P. Perlin, C. Jauberthie-Carillon, J. P. Itie, A. San Miguel, I. Grzegory, and A. Polian, "Raman scattering and x-ray-absorption spectroscopy in gallium nitride under high pressure," Physical Review B, vol. 45, no. 1, pp. 83-89, 1992.

[71] C. Liu, A. Wenzel, J. Gerlach, X. Fan, and B. Rauschenbach, "Annealing study of ion implanted GaN," Surface and Coatings Technology, vol. 128 / 129, pp. 455-460, 2000.

[72] O. Madelung, U. Roessler, and M. Schulz, eds., Silicon carbide (SiC), magnetic properties, vol. 41A1b of Landolt-Boernstein - Group III Condensed Matter. Springer Berlin Heidelberg, 2002.

[73] U. Wahl, A. Vantomme, G. Langouche, J. G. Correia, and L. Peralta, "Direct evidence for implanted Fe on substitutional Ga sites in GaN," Applied Physics Letters, vol. 78, no. 21, pp. 3217-3219, 2001. 
[74] S. Pearton, C. Abernathy, D. Norton, A. Hebard, Y. Park, L. Boatner, and J. Budai, "Advances in wide bandgap materials for semiconductor spintronics," Materials Science and Engineering: R: Reports, vol. 40, no. 4, pp. 137-168, 2003.

[75] F. Filippone, G. Mattioli, P. Alippi, and A. A. Bonapasta, "Clusters and magnetic anchoring points in $(\mathrm{Ga}, \mathrm{Fe}) \mathrm{N}$ condensed magnetic semiconductors," Physical Review Letters, vol. 107, no. 19, p. 196401, 2011.

[76] I. A. Kowalik, A. Persson, M. . Nino, A. Navarro-Quezada, B. Faina, A. Bonanni, T. Dietl, and D. Arvanitis, "Element-specific characterization of heterogeneous magnetism in $(\mathrm{Ga}, \mathrm{Fe}) \mathrm{N}$ films," Physical Review B, vol. 85, no. 18, p. 184411, 2012.

[77] N. Gonzalez Szwacki, J. A. Majewski, and T. Dietl, "Aggregation and magnetism of Cr, Mn, and Fe cations in GaN," Physical Review B, vol. 83, no. 18, p. 184417, 2011.

[78] G. M. Dalpian, J. L. F. Da Silva, and S.-H. Wei, "Ferrimagnetic Fe-doped GaN: An unusual magnetic phase in dilute magnetic semiconductors," Physical Review B, vol. 79, no. 24, p. 241201, 2009.

[79] J. M. Baik, H. S. Kim, C. G. Park, and J.-L. Lee, "Effect of microstructural evolution on magnetic property of Mn-implanted p-type GaN," Applied Physics Letters, vol. 83, no. 13, pp. 2632-2634, 2003.

[80] W. Kim, H. J. Kang, S. K. Noh, J. Song, and C. S. Kim, "Magnetic and structural properties of Fe ion-implanted GaN," Journal of Magnetism and Magnetic Materials, vol. 316, no. 2, pp. e199-e202, 2007.

[81] G. Talut, H. Reuther, S. Zhou, K. Potzger, F. Eichhorn, and F. Stromberg, "Ferromagnetism in GaN induced by Fe ion implantation," Journal of Applied Physics, vol. 102, no. 8, pp. 083909 083909-7, 2007.

[82] A. Bonanni, C. Simbrunner, M. Wegscheider, H. Przybylinska, A. Wolos, H. Sitter, and W. Jantsch, "Doping of GaN with Fe and Mg for spintronics applications," physica status solidi (b), vol. 243, no. 7, p. 1701, 2006.

[83] C. Liu, E. Alves, A. D. Sequeira, N. Franco, M. F. da Silva, and J. C. Soares, "Fe ion implantation in GaN damage, annealing, and lattice site location," Journal of Applied Physics, vol. 90, no. 1, pp. 81-86, 2001.

[84] C. Timm, "Disorder effects in diluted magnetic semiconductors," Journal of Physics: Condensed Matter, vol. 15, no. 50, p. R1865, 2003.

[85] P. A. Joy, P. S. A. Kumar, and S. K. Date, "The relationship between field-cooled and zerofield-cooled susceptibilities of some ordered magnetic systems," Journal of Physics: Condensed Matter, vol. 10, no. 48, p. 11049, 1998.

[86] N. Theodoropoulou, A. F. Hebard, M. E. Overberg, C. R. Abernathy, S. J. Pearton, S. N. G. $\mathrm{Chu}$, and R. G. Wilson, "Magnetic and structural properties of mn-implanted GaN," Applied Physics Letters, vol. 78, no. 22, pp. 3475-3477, 2001.

[87] N. S. Gajbhiye and S. Bhattacharyya, "Magnetic interactions in epsilon-Fe3N-GaN nanocomposites," Journal of Applied Physics, vol. 101, no. 11, pp. 113902-113902-4, 2007. 
[88] K. H. Ploog, S. Dhar, and A. Trampert, "Structural and magnetic properties of (Ga,Mn)N layers grown on $\mathrm{SiC}$ by reactive molecular beam epitaxy," in Papers from the 30th Conference on the Physics and Chemistry of Semiconductor Interfaces, vol. 21, (Salt Lake City, Utah (USA)), pp. 1756-1759, AVS, 2003.

[89] S. R. Shinde, S. B. Ogale, J. S. Higgins, H. Zheng, A. J. Millis, V. N. Kulkarni, R. Ramesh, R. L. Greene, and T. Venkatesan, "Co-occurrence of superparamagnetism and anomalous Hall effect in highly reduced cobalt-doped rutile $\mathrm{TiO}_{2}$ films," Physical Review Letters, vol. 92, no. 16, p. 166601, 2004.

[90] G. T. Thaler, M. E. Overberg, B. Gila, R. Frazier, C. R. Abernathy, S. J. Pearton, J. S. Lee, S. Y. Lee, Y. D. Park, Z. G. Khim, J. Kim, and F. Ren, "Magnetic properties of n-GaMnN thin films," Applied Physics Letters, vol. 80, no. 21, pp. 3964-3966, 2002.

[91] X. G. Cui, Z. K. Tao, R. Zhang, X. Li, X. Q. Xiu, Z. L. Xie, S. L. Gu, P. Han, Y. Shi, and Y. D. Zheng, "Structural and magnetic properties in Mn-doped GaN grown by metal organic chemical vapor deposition," Applied Physics Letters, vol. 92, no. 15, pp. 152116-152116-3, 2008.

[92] V. A. Chitta, J. A. H. Coaquira, J. R. L. Fernandez, C. A. Duarte, J. R. Leite, D. Schikora, D. J. As, K. Lischka, and E. Abramof, "Room temperature ferromagnetism in cubic GaN epilayers implanted with $\mathrm{Mn}^{+}$ions," Applied Physics Letters, vol. 85, no. 17, pp. 3777-3779, 2004.

[93] B. Zhang, C. Chen, C. Yang, J. Wang, L. Shi, H. Cheng, and D. Zhao, "Ferromagnetic modification of GaN film by $\mathrm{Cu}^{+}$ions implantation," Nuclear Instruments and Methods in Physics Research Section B: Beam Interactions with Materials and Atoms, vol. 268, no. 2, pp. 123-126, 2010.

[94] P. Ganz, G. Fischer, C. Suergers, and D. Schaadt, "Cu-doped nitrides: Promising candidates for a nitride based spin-aligner," Journal of Crystal Growth, vol. 323, no. 1, pp. 355-358, 2011.

[95] H.-K. Seong, J.-Y. Kim, J.-J. Kim, S.-C. Lee, S.-R. Kim, U. Kim, T.-E. Park, and H.-J. Choi, "Room-temperature ferromagnetism in $\mathrm{Cu}$ doped GaN nanowires," Nano Letters, vol. 7 , no. 11 , pp. $3366-3371,2007$.

[96] X. L. Yang, Z. T. Chen, C. D. Wang, Y. Zhang, X. D. Pei, Z. J. Yang, G. Y. Zhang, Z. B. Ding, K. Wang, and S. D. Yao, "Structural, optical, and magnetic properties of Cu-implanted GaN films," Journal of Applied Physics, vol. 105, no. 5, pp. 053910-053910-4, 2009. 